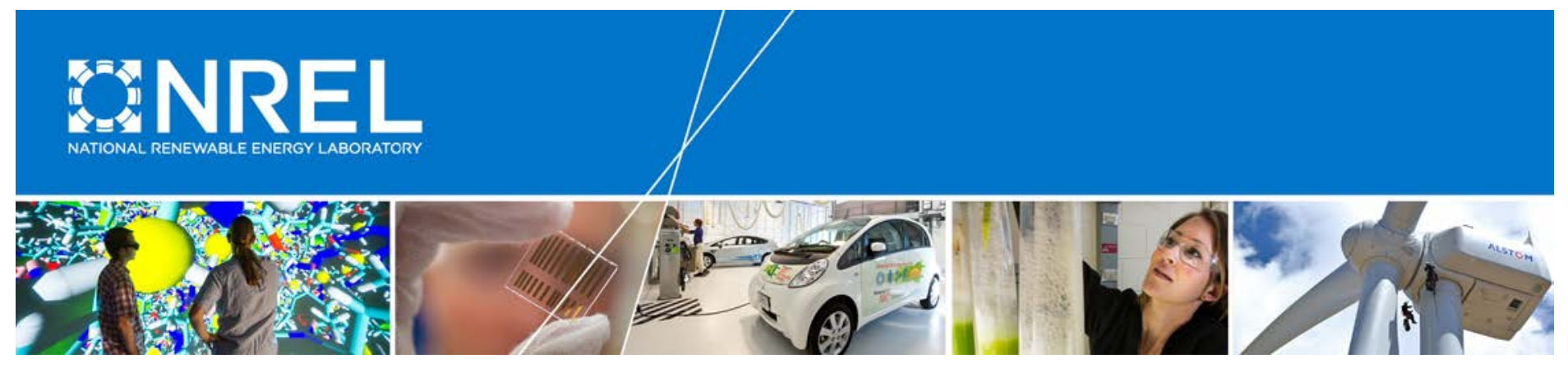

\title{
Regional Energy Deployment System (ReEDS) Model Documentation: Version 2016
}

Kelly Eurek, Wesley Cole, David Bielen, Nate Blair, Stuart Cohen, Bethany Frew, Jonathan Ho, Venkat Krishnan, Trieu Mai, Benjamin Sigrin, and Daniel Steinberg National Renewable Energy Laboratory

NREL is a national laboratory of the U.S. Department of Energy Office of Energy Efficiency \& Renewable Energy Operated by the Alliance for Sustainable Energy, LLC

This report is available at no cost from the National Renewable Energy Laboratory (NREL) at www.nrel.gov/publications.

Technical Report

NREL/TP-6A20-67067

November 2016 


\section{Regional Energy Deployment System (ReEDS) Model Documentation: Version 2016}

Kelly Eurek, Wesley Cole, David Bielen, Nate Blair, Stuart Cohen, Bethany Frew, Jonathan Ho, Venkat Krishnan, Trieu Mai, Benjamin Sigrin, and Daniel Steinberg National Renewable Energy Laboratory

Prepared under Task No. SA15.1012

NREL is a national laboratory of the U.S. Department of Energy Office of Energy Efficiency \& Renewable Energy Operated by the Alliance for Sustainable Energy, LLC

This report is available at no cost from the National Renewable Energy Laboratory (NREL) at www.nrel.gov/publications.

National Renewable Energy Laboratory 15013 Denver West Parkway Golden, CO 80401

303-275-3000 • www.nrel.gov

\section{Technical Report}

NREL/TP-6A20-67067

November 2016

Contract No. DE-AC36-08GO28308 


\section{NOTICE}

This report was prepared as an account of work sponsored by an agency of the United States government. Neither the United States government nor any agency thereof, nor any of their employees, makes any warranty, express or implied, or assumes any legal liability or responsibility for the accuracy, completeness, or usefulness of any information, apparatus, product, or process disclosed, or represents that its use would not infringe privately owned rights. Reference herein to any specific commercial product, process, or service by trade name, trademark, manufacturer, or otherwise does not necessarily constitute or imply its endorsement, recommendation, or favoring by the United States government or any agency thereof. The views and opinions of authors expressed herein do not necessarily state or reflect those of the United States government or any agency thereof.

This report is available at no cost from the National Renewable Energy Laboratory (NREL) at www.nrel.gov/publications.

Available electronically at SciTech Connect http:/www.osti.gov/scitech

Available for a processing fee to U.S. Department of Energy and its contractors, in paper, from:

U.S. Department of Energy

Office of Scientific and Technical Information

P.O. Box 62

Oak Ridge, TN 37831-0062

OSTI http://www.osti.gov

Phone: 865.576.8401

Fax: 865.576.5728

Email: reports@osti.gov

Available for sale to the public, in paper, from:

U.S. Department of Commerce

National Technical Information Service

5301 Shawnee Road

Alexandria, VA 22312

NTIS http://www.ntis.gov

Phone: 800.553 .6847 or 703.605 .6000

Fax: 703.605.6900

Email: orders@ntis.gov 


\section{Acknowledgments}

We gratefully acknowledge the many people whose efforts contributed to this report. The ReEDS modeling and analysis team at the National Renewable Energy Laboratory (NREL) was active in developing and testing the ReEDS model v.2016. Additional ReEDS team members who have contributed to this work include Paul Denholm, Donna Heimiller, Eduardo Ibanez, Anthony Lopez, Andrew Martinez, Matthew Mowers, David Mulcahy, Patrick Sullivan, Caroline Uriate, and Owen Zinaman. We are especially grateful to Walter Short who first envisioned and developed the WinDS and ReEDS models. We also thank the NREL analysts who provided input on the technology costs, assumptions, and methodologies in ReEDS, including Chad Augustine, Maureen Hand, David Feldman, Jenny Heeter, Eric Lantz, Robert Margolis, Mark Mehos, Craig Turchi, and many others over the years. We thank Walter Short, Ella Zhou, and Owen Zinaman, Laura Vimmerstedt, and Jeffrey Logan for their comments on this report. Finally, we are grateful to all those who helped sponsor ReEDS model development and analysis, particularly supporters from the U.S. Department of Energy (DOE) but also others who have funded our work over the years. This report was funded by the DOE Office of Energy Efficiency and Renewable Energy under contract number DE-AC36-08GO28308. Any errors or omissions are the sole responsibility of the authors. 


\section{Table of Contents}

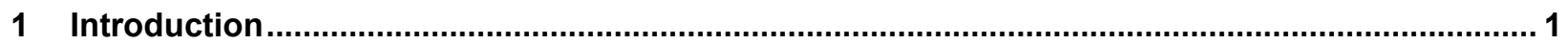

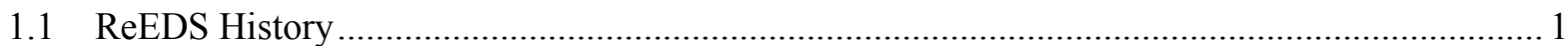

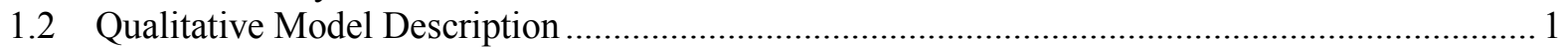

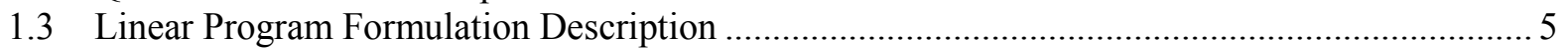

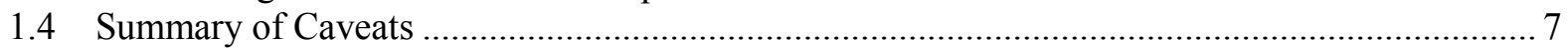

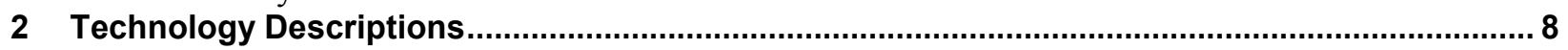

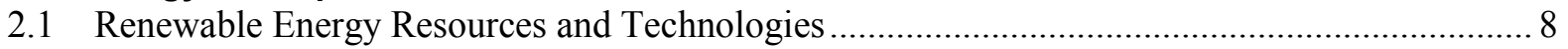

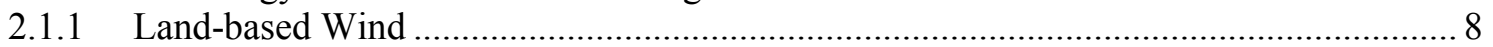

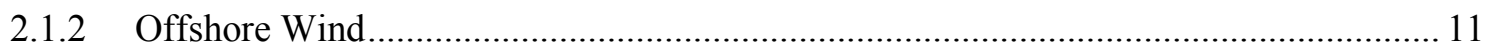

2.1.3 Solar Photovoltaics.......................................................................... 13

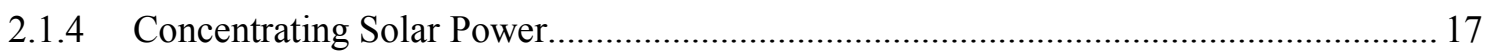

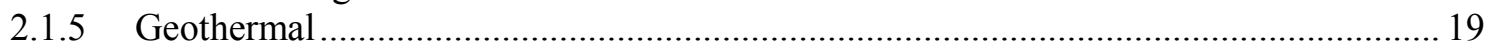

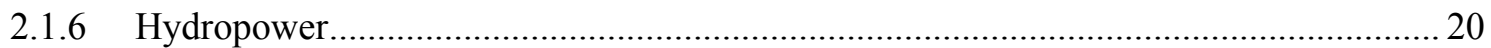

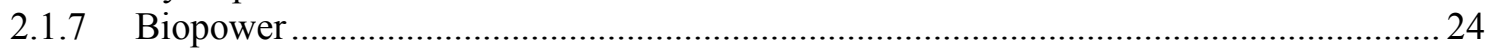

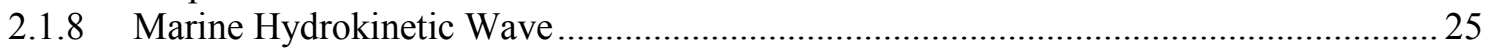

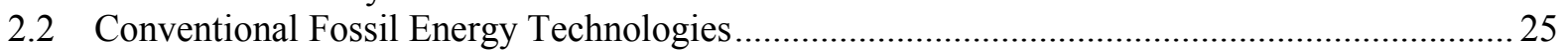

2.2.1 Conventional Technology Performance Considerations ...........................................26

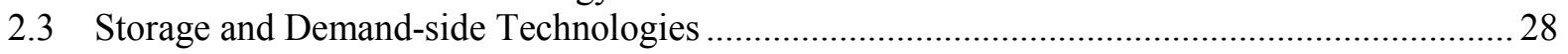

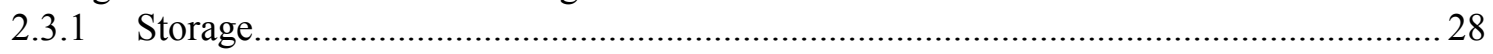

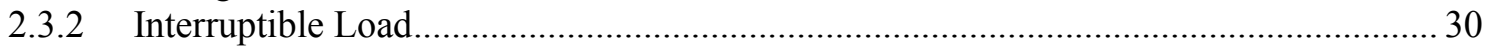

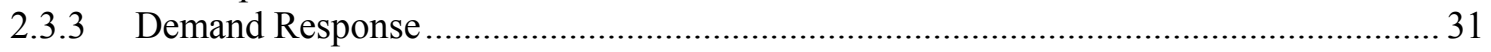

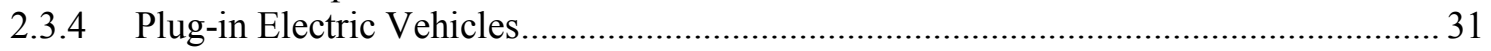

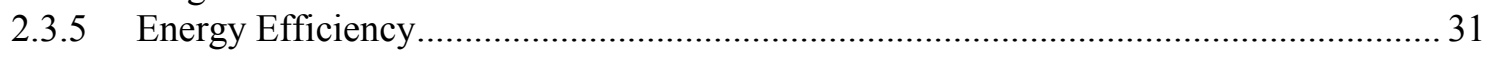

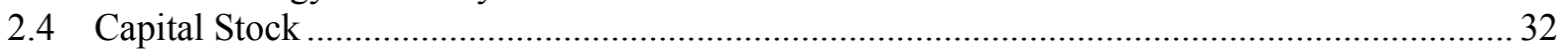

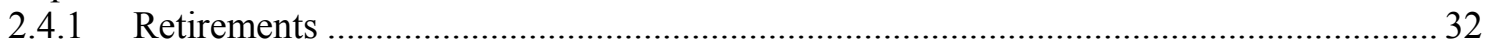

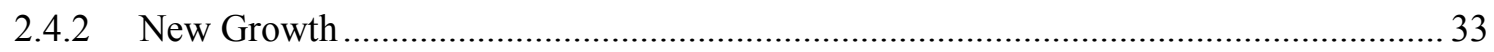

2.5 Regional Parameter Variations and Adjustments............................................................... 34

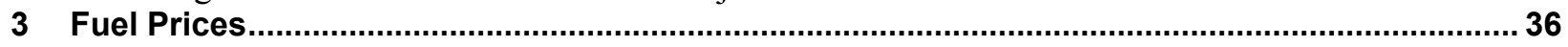

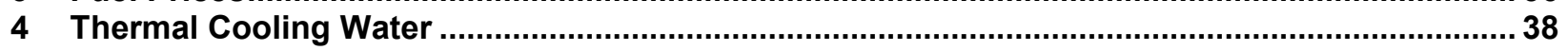

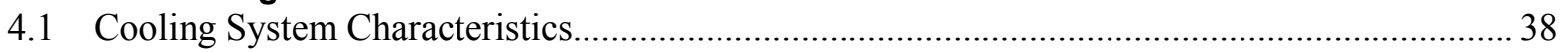

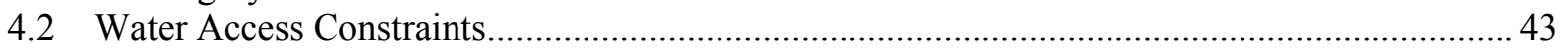

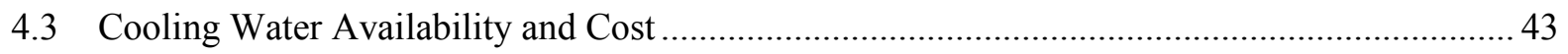

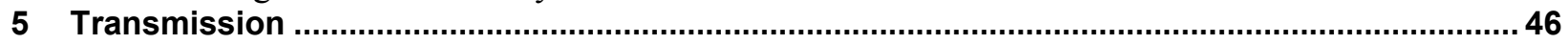

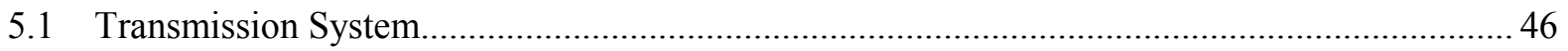

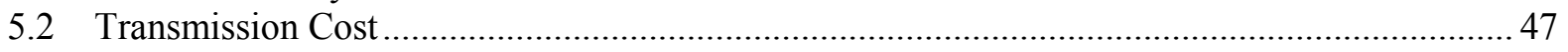

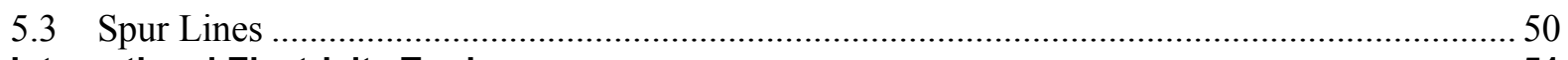

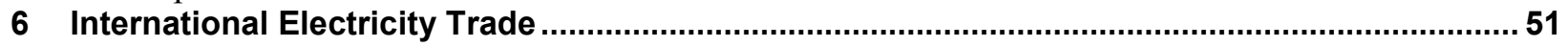

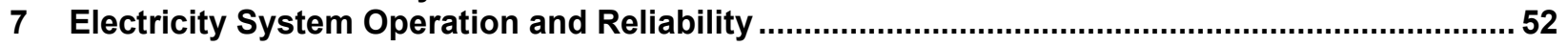

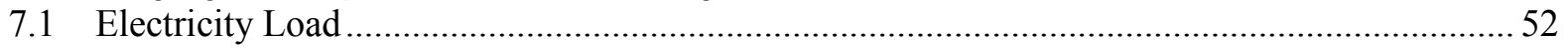

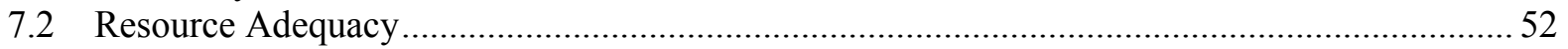

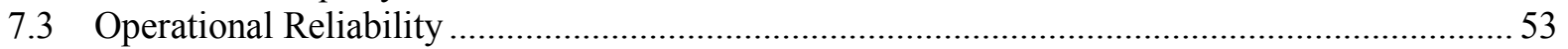

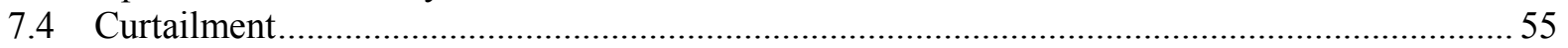

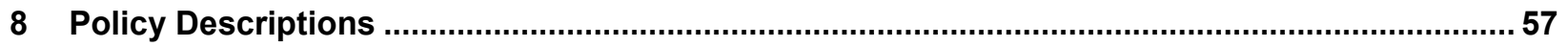

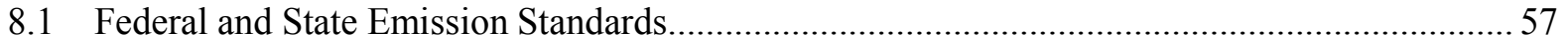

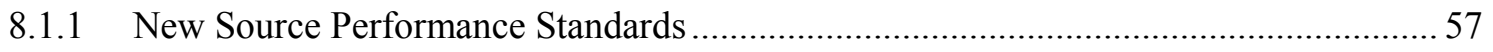

8.1.2 Existing Source Performance Standard: Clean Power Plan ......................................... 57

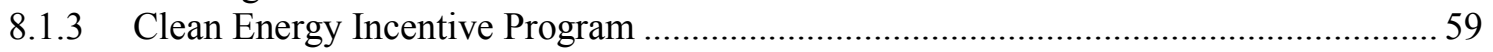

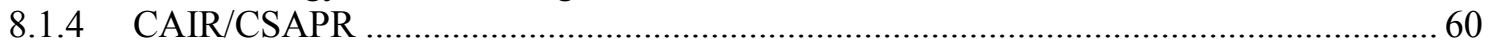

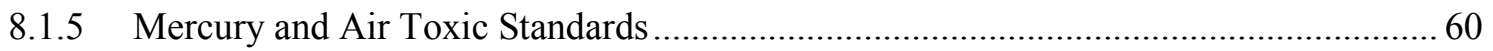

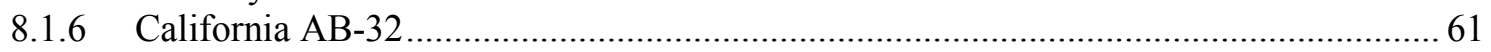




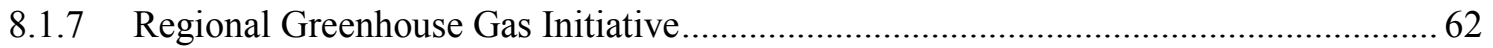

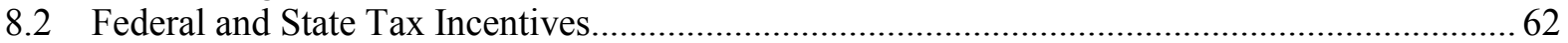

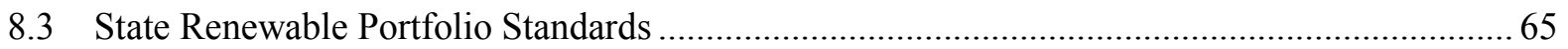

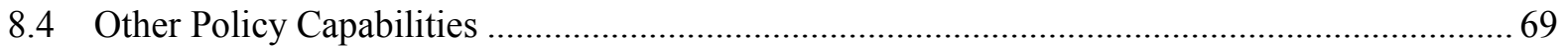

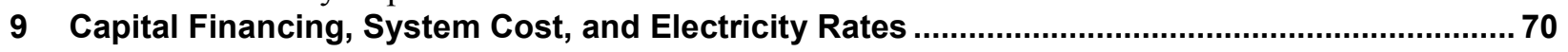

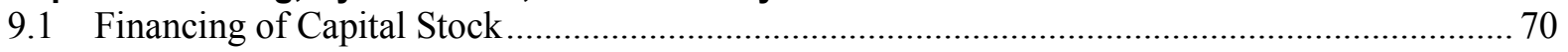

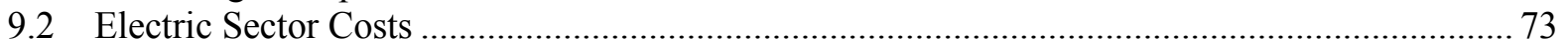

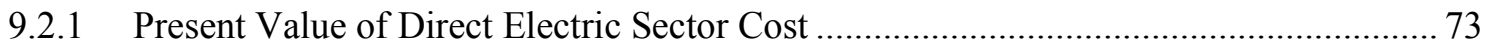

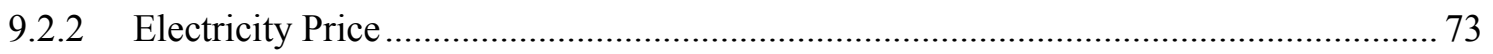

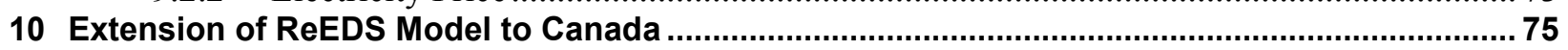

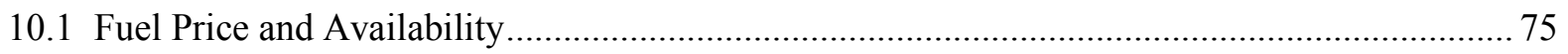

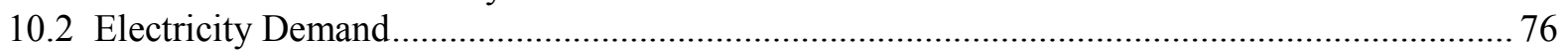

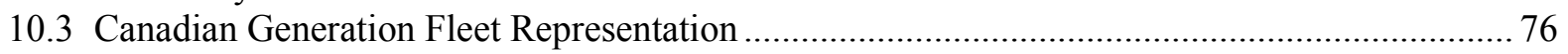

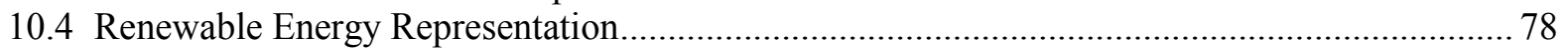

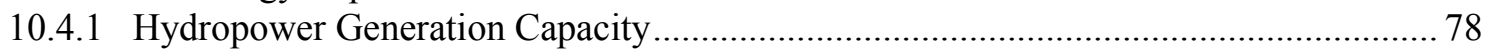

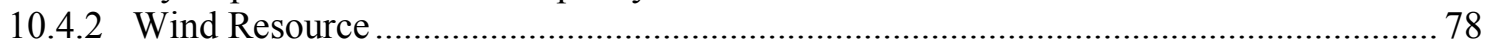

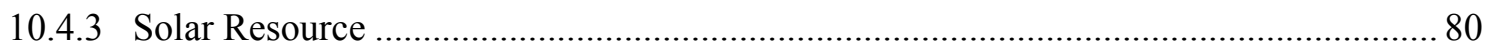

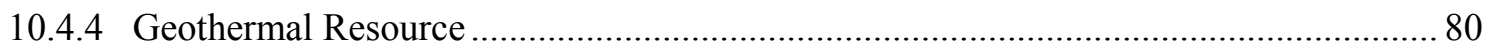

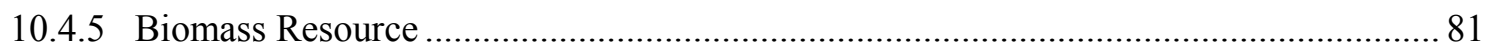

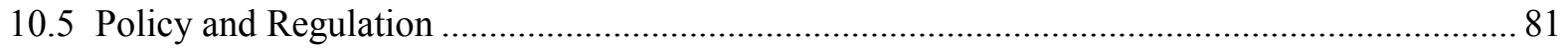

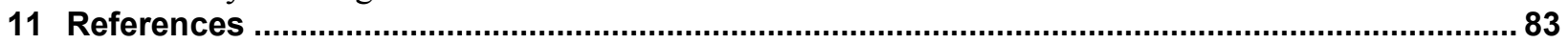

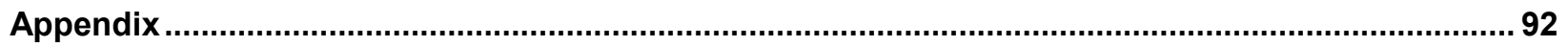

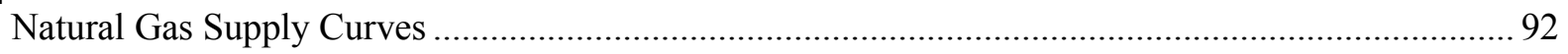

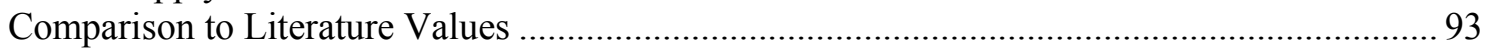

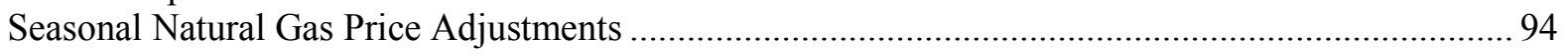

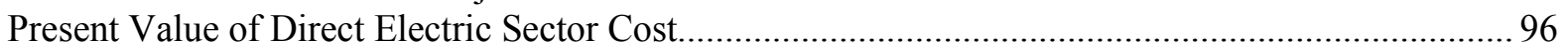

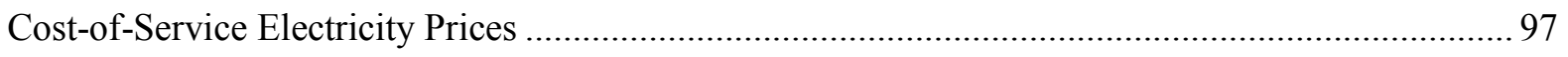

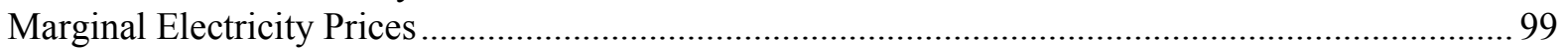




\section{List of Figures}

Figure 1. Map showing the ReEDS regional structure ................................................................. 2

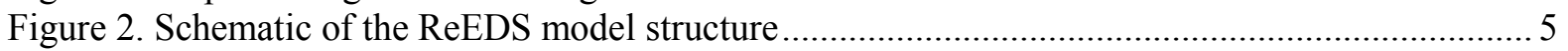

Figure 3. Land-based wind resource map for the contiguous United States ..................................... 10

Figure 4. Estimated wind supply curves of all wind resource modeled in ReEDS ........................... 11

Figure 5. Offshore wind resource map for the contiguous United States.......................................... 12

Figure 6. UPV resource availability by ReEDS BA region and resource class................................... 14

Figure 7. DUPV resource availability in each ReEDS region by resource class ................................ 15

Figure 8. Prescribed distributed PV deployment used in the ReEDS as determined by dGen, with

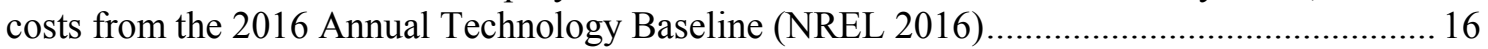

Figure 9. ReEDS constraints and corresponding feasible space (hashed line) for CSP with storage .. 18

Figure 10. Capacity factor trends versus solar multiple ................................................................ 19

Figure 11. National capital cost supply curves for new identified hydrothermal and near-field EGS

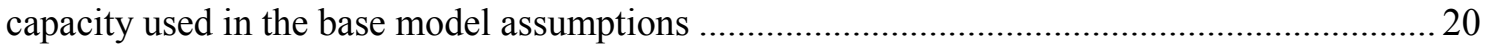

Figure 12. Modeled hydropower upgrade resource potential (DOE 2016b) ..................................... 21

Figure 13. Modeled non-powered dam resource potential (DOE 2016b) ........................................ 22

Figure 14. Modeled new stream-reach development resource potential (DOE 2016b)..................... 23

Figure 15. National hydropower supply curve of capital cost versus cumulative capacity potential... 23

Figure 16. Modeled new PHS resource potential (DOE 2016b) ..................................................... 29

Figure 17. National PHS supply curve of capital cost versus cumulative capacity potential.............. 30

Figure 18. National and regional growth penalty cost curve ............................................................ 33

Figure 19. Maps of regional capital cost multipliers for the various technology types....................... 35

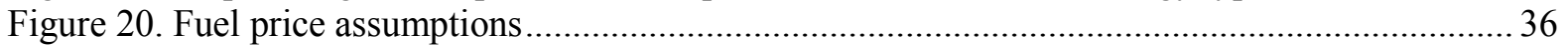

Figure 21. Water availability and cost for each water type (AFY = acre-feet per year) (Tidwell,

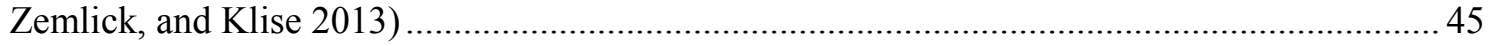

Figure 22. Existing long-distance transmission infrastructure as represented in ReEDS .................. 46

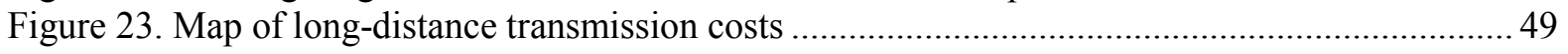

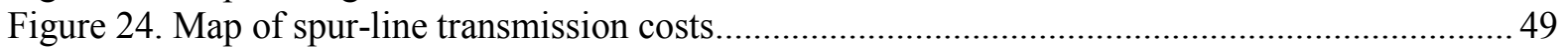

Figure 25. Net exports from Canada to the United States .......................................................... 51

Figure 26. Example of storage effectiveness as a function of load and renewable energy generation

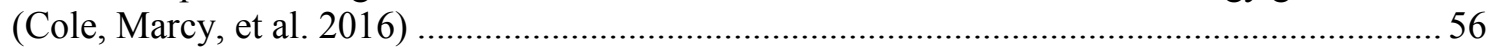

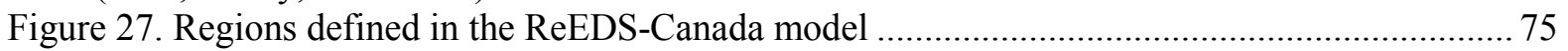

Figure 28. Map of EIA Census Division boundaries extended to Canadian provinces......................... 76

Figure 29. Capacity factor versus average wind speed in the western United States......................... 78

Figure 30. Capacity factor versus average wind speed in the U.S. Great Lakes ................................ 79

Figure 31. Capacity factor versus average wind speed in the northeast United States........................ 79

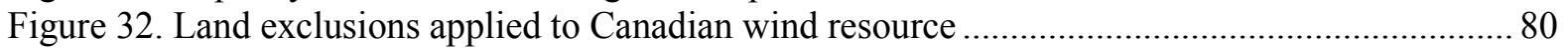

Figure 33. The nine census divisions defined by EIA (EIA 2014a) ............................................. 92

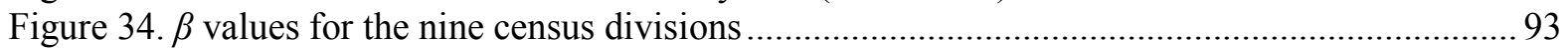

Figure 35. Natural gas futures prices from the New York Mercantile Exchange for July 10, 2014 .... 94

Figure 36. Natural gas futures prices from Figure 35 separated by season ....................................... 95 


\section{List of Tables}

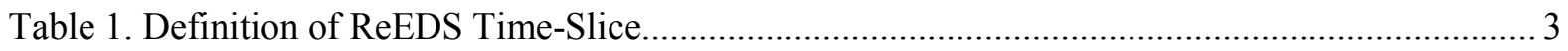

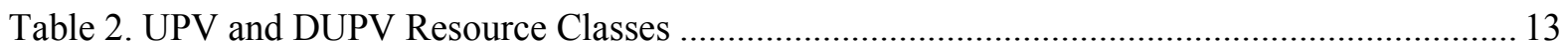

Table 3. Characteristics of CSP Technology Storage Options ......................................................... 17

Table 4. Capacity Factor Groups for Concentrating Solar Power plants using a solar multiple of 1.4

Table 5. Multipliers Applied to Full-Load Heat Rates to Approximate Heat Rates for PartLoad Operation.

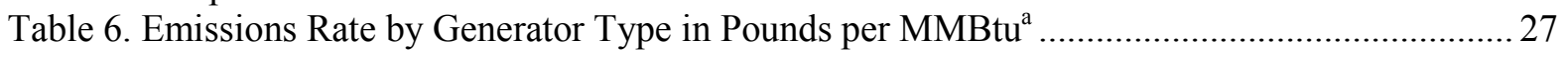

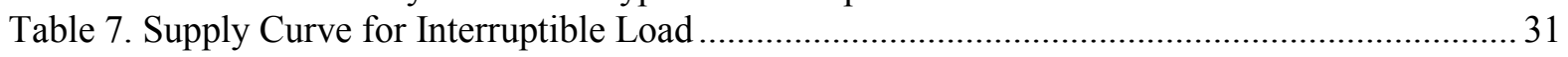

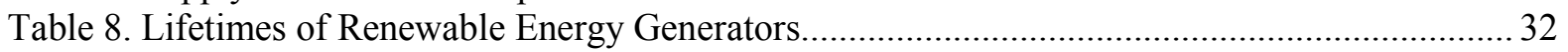

Table 9. Minimum Base Values for Assessing Excessive Growth ................................................. 34

Table 10. Allowed Power and Cooling Technology Combinations in ReEDS ................................. 39

Table 11. Capital Cost Multipliers for Power-Cooling Technology Combinations ............................. 40

Table 12. Operations and Maintenance Cost Multipliers for Power-Cooling

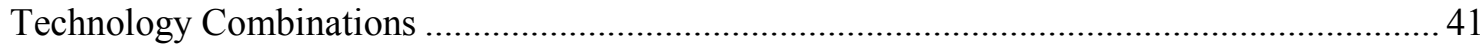

Table 13. Heat Rate Multipliers for Power-Cooling Technology Combinations ................................ 41

Table 14. Water Withdrawal Rates for Power-Cooling Technology Combinations (gal/MWh) ......... 42

Table 15. Water Consumption Rates for Power-Cooling Technology Combinations (gal/MWh)...... 42

Table 16. Flexibility parameters of the ReEDS generation technologies.......................................... 54

Table 17. Actual and Modeled Schedule of Wind and Solar Tax Credits from the Consolidated

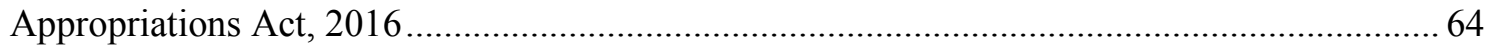

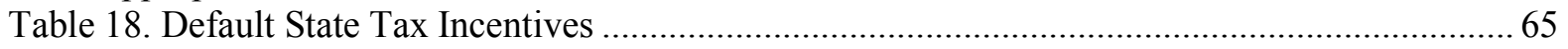

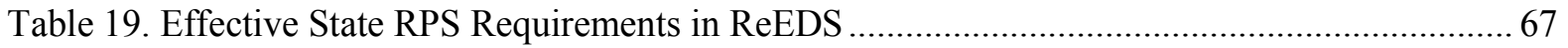

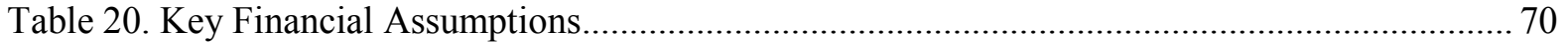

Table 21. Summary of Debt Fractions Found in the Literature....................................................... 72

Table 22. Pending Cross-Border Transmission Lines as of January 2016 (DOE 2016a) ................... 77

Table 23. International REC Trading Rules Implemented in ReEDS ............................................ 82 


\section{Introduction}

The Regional Energy Deployment System (ReEDS) model is a capacity expansion and dispatch model for the contiguous United States electric power sector that relies on system-wide least cost optimization to estimate the type and location of future generation and transmission capacity. ${ }^{1}$

\subsection{ReEDS History}

The ReEDS model heritage traces back to National Renewable Energy Laboratory's (NREL's) seminal electric sector capacity expansion model called the Wind Deployment System (WinDS) model. The WinDS model was developed in 2003 to examine long-term market penetration of wind in the electric power sector (Short et al. 2003). From 2003 to 2008, WinDS was used in a variety of wind-related analyses, including the production of hydrogen from wind power, the impacts of state-level policies on wind deployment, the role plug-in hybrid electric vehicles in wind markets, the impacts of high wind penetration on U.S wind manufacturing, the potential for offshore wind, the benefits of storage to wind power, and the feasibility of producing $20 \%$ of electricity from wind power by 2030 (DOE 2008). In 2006, a variation of WinDS was developed to analyze concentrating solar power (CSP) potential and its response to state and federal incentives. By 2009, WinDS was recast as ReEDS - a general tool for examining the long-term deployment interactions of multiple technologies in the power sector (Short et al. 2009).

Since 2009, ReEDS has been the primary analytical tool in several studies, including Hydropower Vision (DOE 2016b), Wind Vision (DOE 2015), SunShot Vision (DOE 2012), and Renewable Electricity Futures (NREL 2012). It has also been used to examine impacts of a range of existing and proposed energy policies (Lantz et al. 2014; Mai et al. 2015; Mai et al. 2015). Other recent studies use ReEDS to examine the role of natural gas, high renewable scenarios, and other important issues for the U.S. electricity sector (Mignone et al. 2012; Logan et al. 2013; Clemmer et al. 2013; Mai et al. 2014; Sullivan et al. 2015; Cole et al. 2015; Cole, Lewis, et al. 2016). The ReEDS website ${ }^{2}$ includes an up-to-date list of publications that use ReEDS.

\subsection{Qualitative Model Description}

To represent the competition between the many electricity generation, storage, and transmission options throughout the contiguous United States, ReEDS identifies the cost-optimal mix of technologies that meet regional electric power demand requirements, based on grid reliability (reserve) requirements, technology resource constraints, and policy constraints. This cost minimization routine is performed for each of 21 two-year periods from 2010 to 2050 . Some of the major outputs of ReEDS include the amount and location of generator capacity and annual generation from each technology, storage capacity expansion, transmission capacity expansion, total electric sector costs, electricity price, fuel demand and prices, and carbon dioxide $\left(\mathrm{CO}_{2}\right)$ emissions.

Within ReEDS, load is served and power plants are constructed in 134 model balancing areas (BAs) that overlay the contiguous United States, shown in Figure 1. The model BAs are not designed to represent or align perfectly with real balancing authority areas, but they instead

\footnotetext{
${ }^{1}$ http://www.nrel.gov/analysis/ReEDS

2 http://www.nrel.gov/analysis/reeds/related_pubs.html
} 
represent model nodes where electricity supply and demand is balanced. The model's transmission network connects those BAs and comprises roughly 300 representative lines across the three asynchronous interconnections: the Western Interconnection, the Eastern Interconnection, and Electric Reliability Council of Texas (ERCOT). The BAs also respect state boundaries, allowing the model to represent individual state regulations and incentives. The BAs are subdivided into 356 resource regions that describe wind and solar resource supply and quantity in order to have more spatial granularity in represent these resources. Additional geographical layers include 3 electricity interconnects, 18 model regional transmission operators designed after existing regional transmission operators, 19 North American Electric Reliability Corporation (NERC) reliability subregions, and 9 census divisions as defined by the U.S. Census Bureau. ${ }^{3}$

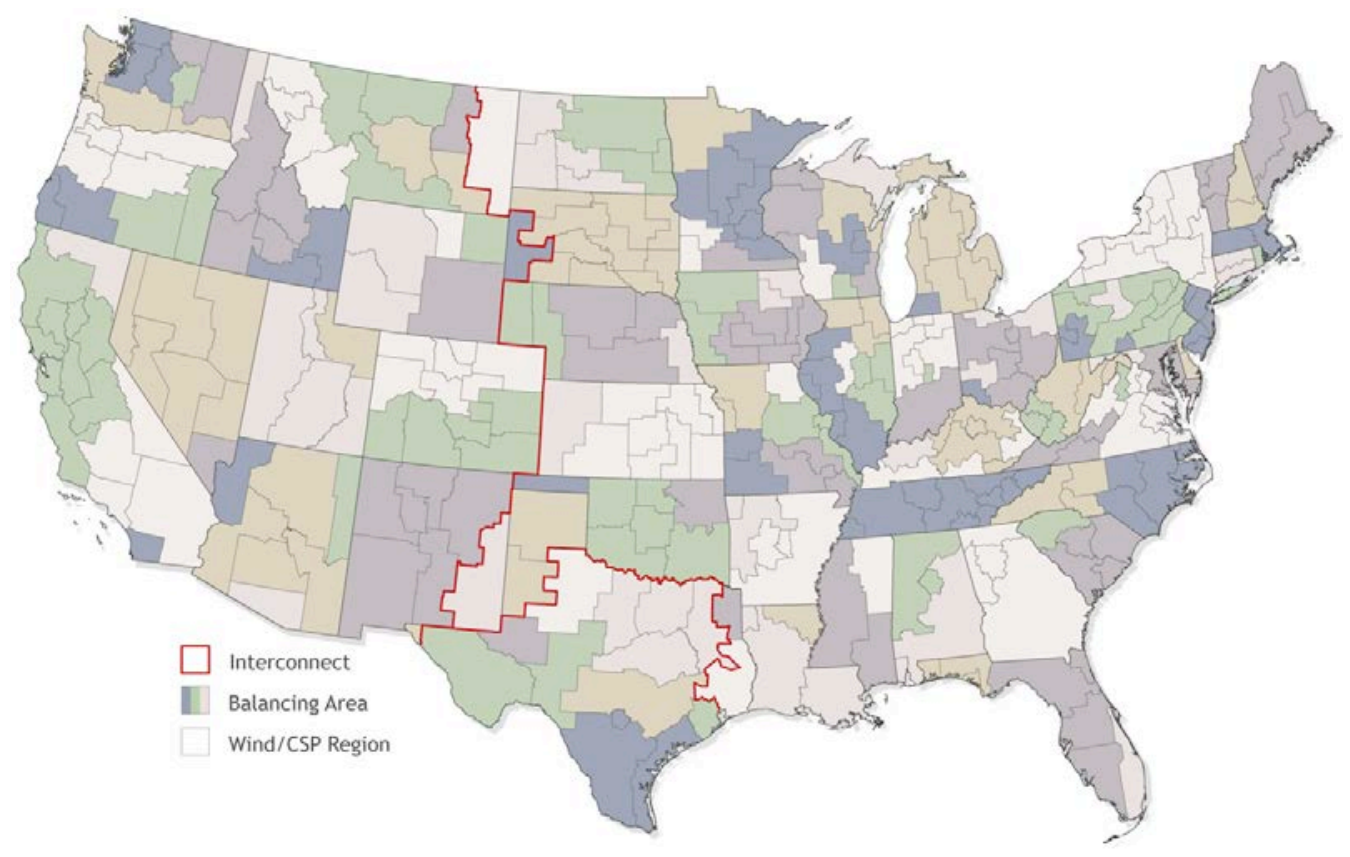

Figure 1. Map showing the ReEDS regional structure

ReEDS includes 3 interconnections, 134 model BAs, and 356 wind and CSP resource regions.

\footnotetext{
${ }^{3}$ These additional geographical layers defined in ReEDS do not align perfectly with the actual regions.
} 
Table 1. Definition of ReEDS Time-Slice

\begin{tabular}{lllll}
\hline Time-Slice & $\begin{array}{l}\text { Number of } \\
\text { Hours per Year }\end{array}$ & Season & Time of Day & Period \\
\hline H1 & 736 & Summer & Overnight & 10 p.m. to 6 a.m. \\
H2 & 644 & Summer & Morning & 6 a.m. to 1 p.m. \\
H3 & 328 & Summer & Afternoon & 1 p.m. to 5 p.m. \\
H4 & 460 & Summer & Evening & 5 p.m. to 10 p.m. \\
H5 & 488 & Fall & Overnight & 10 p.m. to 6 a.m. \\
H6 & 427 & Fall & Morning & 6 a.m. to 1 p.m. \\
H7 & 244 & Fall & Afternoon & 1 p.m. to 5 p.m. \\
H8 & 305 & Fall & Evening & 5 p.m. to 10 p.m. \\
H9 & 960 & Winter & Overnight & 10 p.m. to 6 a.m. \\
H10 & 840 & Winter & Morning & 6 a.m. to 1 p.m. \\
H11 & 480 & Winter & Afternoon & 1 p.m. to 5 p.m. \\
H12 & 600 & Winter & Evening & 5 p.m. to 10 p.m. \\
H13 & 736 & Spring & Overnight & 10 p.m. to 6 a.m. \\
H14 & 644 & Spring & Morning & 6 a.m. to 1 p.m. \\
H15 & 368 & Spring & Afternoon & 1 p.m. to 5 p.m. \\
H16 & 460 & Spring & Evening & 5 p.m. to 10 p.m. \\
H17 & 40 & Summer & Peak & 40 highest demand \\
& & & & hours of H3 \\
\hline
\end{tabular}

ReEDS serves load and maintains operational reliability over 17 time-slices in each model year, as defined in Table 1. Each of the four seasons is modeled as a representative day of four timeslices: overnight, morning, afternoon, and evening. ${ }^{4}$ The $17^{\text {th }}$ time-slice is a summer "superpeak" representing the top 40 hours of summer load. While this schedule does allow the model to capture seasonal and diurnal variations in demand, wind, and solar profiles, it is insufficient to address some of the shorter timescale challenges associated with unit commitment and economic dispatch especially under scenarios with high penetration of variable generation (e.g. wind and solar). To more accurately represent how renewable grid integration might affect investment and dispatch decisions, the ReEDS model includes statistical parameters designed to address intratime-slice variability and uncertainty of wind and certain other renewable resources. These parameters, including capacity value for system adequacy, forecast error reserve requirements, and curtailment estimates, are each discussed in detail in Section 7.

The major conventional thermal generating technologies represented in ReEDS include simple and combined cycle natural gas, several varieties of coal, oil/gas steam, and nuclear. In addition to representing these technologies, ReEDS includes many renewable technologies using several

\footnotetext{
${ }^{4}$ The modeled load is an average of all hours represented by each time-slice. Therefore, the representative days are non-chronological.
} 
kinds of resources, including geothermal, hydropower, biopower, wind, and solar. Electricity storage technologies include pumped-hydropower storage (PHS), compressed-air energy storage (CAES), batteries, and CSP with thermal storage. Modeled solar technologies, including the parameters by which they are characterized and the sources of those parameters, are discussed in Sections 2.1.3 and 2.1.4.

With a system-wide central-planner perspective, ReEDS is not designed to evaluate distributed generation adoption decisions. For this reason, the ReEDS analysis is supported by the dGen model (Sigrin et al. 2016) - an adoption model well suited to producing scenarios of market uptake of distributed rooftop photovoltaics (PV). ReEDS uses dGen ${ }^{5}$ adoption scenarios to exogenously specify the amount and location of new rooftop PV. ${ }^{6}$

ReEDS is structured as a sequence of 21 individual, but interacting, ${ }^{7}$ optimization problems, each representing a two-year period from 2010 to 2050. Each ReEDS scenario launches with an infrastructure base representing installed generation and transmission capacity as of December 31,2010 . New infrastructure that came online from 2011 through the present is prescribed into the ReEDS system in the proper model year, and recently decommissioned units are removed in the same way. Similarly, high-likelihood, pending generators are included as prescribed builds in near-term future years, and scheduled retirements are set to be removed from the fleet as appropriate. Additionally, ReEDS inputs include an equipment lifetime for each technology that is used to retire capacity as it ages. In certain types of scenarios, some existing stock can be underutilized due to, for example, high fuel prices or emissions standards. ReEDS facilitates "economic" retirements of underutilized coal capacity if usage (i.e., capacity factor) falls below a certain threshold. Economic coal retirement in ReEDS is applied starting in 2022 with an increasingly stringent threshold of underutilization through $2040 .^{8}$

ReEDS tracks emissions of $\mathrm{CO}_{2}$, sulfur dioxide $\left(\mathrm{SO}_{2}\right)$, nitrogen oxides $\left(\mathrm{NO}_{\mathrm{x}}\right)$, and mercury from both generators and storage technologies. Caps can be imposed at the national level on any of these emissions, and constraints can be applied to impose caps at state or regional levels. Applying a carbon tax instead of a cap is another option; the tax level and ramp-in pattern can be defined exogenously.

Annual electric loads and fuel price supply curves are exogenously specified to define the system boundaries for each period of the optimization. The source for most load and fuel inputs is the most recent Annual Energy Outlook (AEO) from the U.S. Energy Information Administration (EIA) ${ }^{9}$ Coal and uranium fuels are assumed to be price-inelastic; ReEDS can demand as much

\footnotetext{
${ }^{5}$ For documentation of the dGen model, see Sigrin et al. (2016).

${ }^{6}$ ReEDS and dGen do have the capability to interact dynamically, though that capability is not typically used. See Cole, Lewis, et al. (2016) for more information.

${ }^{7}$ Because ReEDS is a sequential model, it is path dependent, so that solutions in a given solve period inform the starting point of the next optimization year.

${ }^{8}$ The minimum capacity factor threshold is $6 \%$ in 2022 , increases linearly to $50 \%$ by 2040 , and remains flat thereafter.

${ }^{9}$ Any inputs to ReEDS v.2016 from AEO are sourced from the 2016 edition of the AEO (EIA 2016) or its assumptions (EIA 2014a) unless otherwise specified.
} 
of those fuels as it likes at the AEO-specified price. However, natural gas prices are defined by regional supply curves so that the prices respond to changes in electric sector demand for gas.

\subsection{Linear Program Formulation Description}

This section qualitatively describes the basic linear program formulation of ReEDS. The model is recursive-dynamic in that it solves a linear program for each of the 21 two-year periods as it moves successively from 2010 to 2050 .

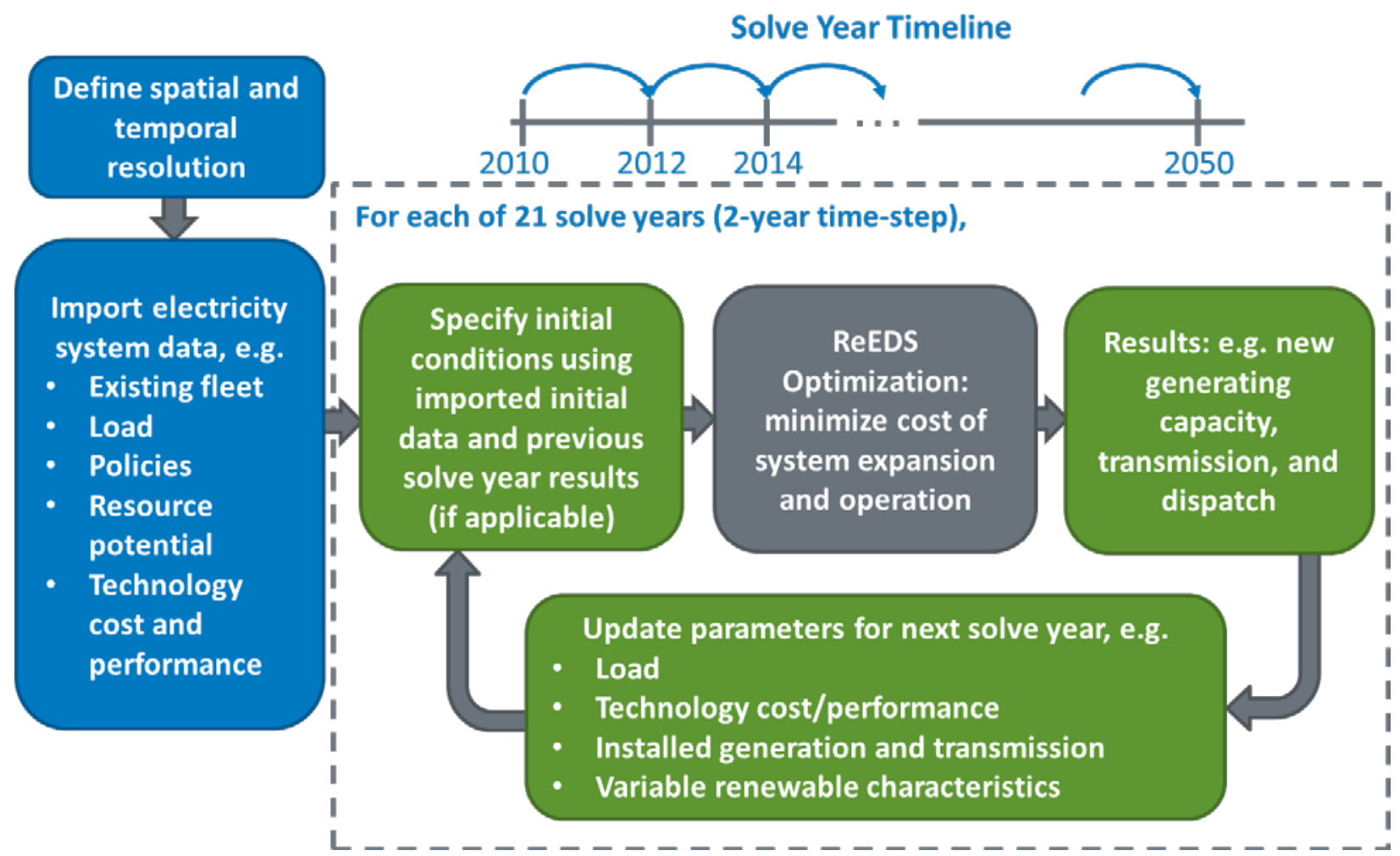

Figure 2. Schematic of the ReEDS model structure

The objective function in the ReEDS linear program is a minimization of both capital and operating costs for the U.S. electric sector including:

- The net present value of the cost of adding new generation, storage, and transmission capacity

- The present value of 20 years of operating expenses (e.g., expenditures for fuel and operation and maintenance $[\mathrm{O} \& \mathrm{M}])$ for all installed capacity

- The cost of several categories of ancillary services and storage.

By minimizing these costs and meeting the system constraints (discussed below), the linear program determines the types of new capacity that are the most economical to add in each region during each period. Simultaneously, the linear program determines how generation and storage capacity should be dispatched to provide the necessary energy in each of the 17 time-slices at least cost to the system. The capacity factor for each dispatchable technology in each region therefore is an output of the model and not an input. 
The constraints that govern how ReEDS builds and operates capacity fall into several main categories, including:

- Load constraints: Sufficient power must be generated in or imported to each of the 134 BAs in each of the 17 time-slices to meet the projected load. The annual demand and the time-slice-specific electricity demand in future years are based on projections for each NERC subregions. Within each NERC subregions, the load distribution between BAs and the load shape in each BA is retained for all years.

- Planning reserve constraints: There must be sufficient firm-generating capacity available in each region to meet the forecasted peak demand plus an additional reserve (safety) margin (NERC 2010). For variable renewable energy (VRE) technologies, ReEDS uses a statistical method to estimate the effective load-carrying capacity of both existing capacity and potential capacity additions to determine their contribution to meeting the reserve margin. Firm capacity can be contracted from one region to another as long as transmission is available.

- Operating reserve constraints: This constraint ensures there is enough quick-start capacity, spinning capacity, and/or interruptible load to meet unexpected changes in generation and load in each reserve-sharing group (see Section 7.3) and time-slice. ReEDS accounts for the following operating reserve requirements: contingency reserve, frequency regulation, and VRE forecast error reserve.

- Transmission constraints: Power transfers among regions are constrained by the nominal carrying capacity of transmission lines that connect the regions. Firm power contracts for planning reserves are also subject to transmission limits. A detailed description of the transmission constraint can be found in Section 5.

- Resource constraints: Many renewable technologies, including wind, solar, geothermal, biopower, and hydropower, are constrained by location and quantity at each location. Several of the technologies include cost- and resource-quality considerations in resource supply curves to account for depletion, transmission, and competition effects. The resource assessments that seed the supply curves are from various sources and are discussed in detail below, where characteristics about the technologies are also provided.

- Emissions constraints: ReEDS has the ability to limit or cap the emissions from fossilfueled generators for $\mathrm{SO}_{2}, \mathrm{NO}_{\mathrm{x}}$, mercury, and $\mathrm{CO}_{2}$. The emission limit and the emission per megawatt-hour by fuel and plant type are inputs to the model. In carbon-constrained scenarios, $\mathrm{CO}_{2}$ can be either capped or taxed, and either a cap or tax can be finely adjusted to match proposed legislation. Alternatively, emissions intensities can also be limited to certain bounds in ReEDS.

- Renewable portfolio standards or clean electricity standards: ReEDS allows users to input renewable portfolio standards (RPSs) or clean electricity standards constraints at the national and state levels. All renewable generation is considered eligible under a national RPS requirement. The renewable generation sources include hydropower, wind, CSP, geothermal, PV, and biopower (including the biomass fraction of co-firing plants). The eligibility of technologies for state RPSs depends on the state's specific requirements and thus varies by state. The RPS targets over time are based on an externally defined profile. Penalties for non-compliance can be imposed for each megawatt-hour shortfall 
occurring in the nation or a given state. In the same way, a clean energy standard constraint can be implemented to account for the crediting of clean energy resources, such as nuclear, carbon capture and sequestration (CCS), or natural gas.

\subsection{Summary of Caveats}

While ReEDS represents many aspects of the U.S. electricity system, it necessitates simplifications as all models do. We offer a list of some key limitations and caveats that result from these simplifications.

- System-wide optimization: ReEDS takes a system-wide, least-cost perspective that does not necessarily reflect the perspective of individual decision makers, including specific investors, regional market participants, or corporate or individual consumer choice; nor does it model contractual obligations or non-economic decisions. In addition, like other optimization models, ReEDS finds the absolute least-cost solution that does not fully reflect real distributions or uncertainties in the parameters; however, the heterogeneity resulting from the high spatial resolution of ReEDS mitigates this effect to some degree.

- Foresight and behavior: Except for limited foresight of future natural gas prices, model decision-making does not account for anticipated changes to markets and policies. The model is not inter-temporally optimized and for example, it does not endogenously model banking and borrowing of credits for carbon, renewable, or clean energy policy between solve periods.

- Project pipeline: The model incorporates data of planned or under-construction projects, but these data likely do not include all projects in progress.

- Manufacturing, supply chain, and siting: The model does not explicitly simulate manufacturing, supply chain, or siting and permitting processes. Potential bottlenecks or delays in project development stages for new generation or transmission would not be fully reflected in the results. All technologies are assumed to be available at their defined capital cost in any quantity up to their technical resource potential. Penalties for rapid growth are applied in ReEDS; however, these do not fully consider all potential manufacturing or deployment limits. Dates used for the cost inputs in the model reflect project costs for the commercial operation dates but not when equipment is ordered.

- Financing interactions: Financial parameters used in the model reflect long-term historical averages as opposed to current or near-term market conditions.

- Technology learning: Future technology improvements are considered exogenously.

- Power sector: ReEDS models the power system of the contiguous United States, and it does not represent the broader U.S. or global energy economy. For example, competing uses of resources across sectors (e.g., natural gas) are not dynamically represented in ReEDS, and end-use electricity demand is exogenously input into ReEDS.

Notwithstanding these limitations - many of which exist in other similar tools - the modeling approach considers complex interactions among numerous different policies and technologies while ensuring electric system reliability requirements are maintained within the resolution and scope of the model. In doing so, we can comprehensively estimate the cost and value of a wide range of technology options to the system given a set of assumptions, and we can use the model to generate self-consistent future deployment portfolios. 


\section{Technology Descriptions}

This section describes the electricity generating technologies included in ReEDS. Cost and performance assumptions for these technologies are not included in this report but are incorporated directly in the model using the values from the 2016 Annual Technology Baseline (NREL 2016).

\subsection{Renewable Energy Resources and Technologies}

Because renewable energy technologies are a primary focus areas of the ReEDS model, they are characterized in detail in the model. Their characterization encompasses resource assessments, projected technology improvement, interconnection costs, and operational implications of integration. Renewable energy technologies modeled include land-based and offshore wind power, solar PV (both distributed and utility), CSP, ${ }^{10}$ hydrothermal geothermal, near-field enhanced geothermal systems (EGS), deep EGS, run-of-the-river and traditional hydropower (including upgrades and non-powered dams), dedicated biomass, co-fired biomass, land-fill gas, and marine hydrokinetic wave technologies. The input assumptions, sources, and treatments are discussed in the following sections. Transmission considerations for renewable energy technologies are discussed in Section 5.3.

Where given in the sections below, renewable energy resource potential values refer to the resource potential represented in ReEDS and not the total technical resource potential. The renewable potential capacity modeled in ReEDS includes cutoffs in the pre-processing steps for the model, such as site exclusions, assumed transmission access limits, or a narrower set of technologies considered. ${ }^{11}$

\subsubsection{Land-based Wind}

Wind technologies are modeled using representative turbine technologies by region depending on wind resource quality. Details of the wind resource data and technology representation can be found in Appendix H of the Wind Vision study (DOE 2015). In the current version of ReEDS, we have relied on the same data sources and approach; however, we extend the wind resource data to lower quality wind sites. The following summarizes the technology and resource representation in the current version of the model.

Wind turbine models can be classified into three different International Electrotechnical Commission turbine ratings (I-III), which are designed for a range of annual average wind speeds. ${ }^{12}$ The Class I turbines have smaller rotors relative to the size of the generator, or a higher specific power (watts per meter squared, or $\mathrm{W} / \mathrm{m}^{2}$ ), and they are therefore rated to withstand higher winds. In the lowest wind resources, Class III turbines are primarily used to gain the highest capacity factor possible in lower wind speeds. Interpolating cost and performance across the three International Electrotechnical Commission classes allows monotonic functions of cost

\footnotetext{
${ }^{10} \mathrm{CSP}$ refers to solar thermal power and not concentrating PV.

${ }^{11}$ Lopez et al. (2012) present renewable technical potential for the United States.

${ }^{12}$ International Electrotechnical Commission Class I turbines are used with an annual average wind speeds of 10 meters/second (m/s) and higher; Class III are used with an annual average wind speed of $7.5 \mathrm{~m} / \mathrm{s}$ and lower. A blend of Class II and Class III turbines is used at annual average wind speeds of 7.5-8.5 m/s; while a blend of Class II and Class I turbines is used at annual average wind speeds of $8.5-10 \mathrm{~m} / \mathrm{s}$.
} 
and performance by annual average wind speed. Cost and performance assumptions for landbased wind plants are based on expected cost and performance for a turbine (representative or interpolated) appropriate for the average annual wind speed at the site.

The resource assessment for land-based wind starts with a resource map of hourly wind speeds for the United States and offshore areas (for offshore wind, see Section 2.1.2). Land area is filtered to exclude a standard set of areas considered unlikely to be developed for environmental or technical reasons: federal and state protected areas (e.g., parks, wilderness areas, and wildlife sanctuaries), areas covered by water, urban areas, wetlands, airports, and rough terrain. Areas classified as non-ridge-crest forest, non-ridge-crest U.S. Forest Service and U.S. Department of Defense lands, and state forests (where available in geographic information systems [GIS]) are $50 \%$ excluded. The remaining resource totals more than 10,640 gigawatts $(\mathrm{GW})$.

Wind sites are grouped into ten resource classes (a.k.a., techno-resource groups or TRGs) for ReEDS, based on estimated levelized cost of energy for present-day technology. ${ }^{13}$ Each class includes representative costs (capital and O\&M) and expected output (capacity factor) along with cost and performance improvements over time. Figure 3 shows the land-based wind resource data modeled in ReEDS for all 10 TRGs, where the highest quality wind resources belong to TRG 1 and the lowest in TRG 10. Costs for new wind capacity include grid interconnection costs estimated using supply curves for each region and TRG. See Section 5.3 for a discussion of supply curves for accessing the wind resource. Figure 4 shows estimated 2014 supply curves (levelized cost of energy versus resource) of all wind resources modeled in ReEDS, including land-based and offshore wind.

\footnotetext{
${ }^{13}$ The wind resource is not evenly binned into the 10 TRGs. The best resource sites (TRGs 1-4) are grouped into smaller bins to better represent the sites that are likely to be most economical.
} 
TRG 1

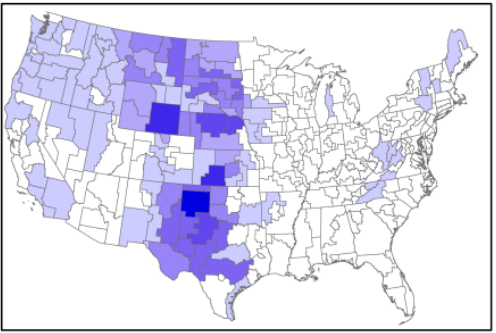

TRG 2

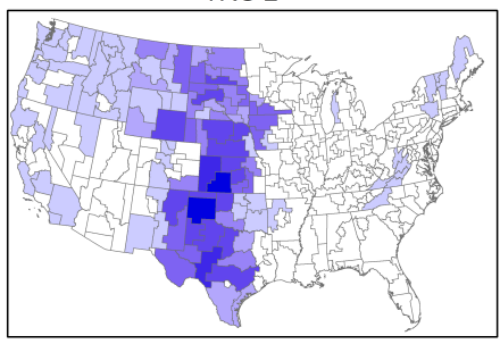

TRG 3

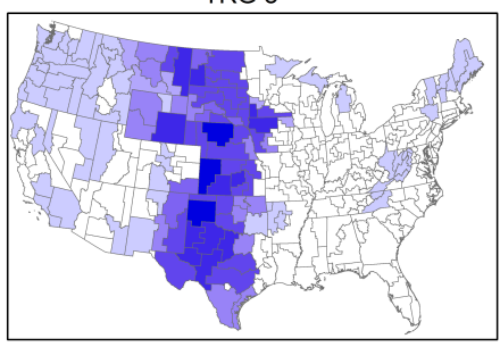

TRG 4

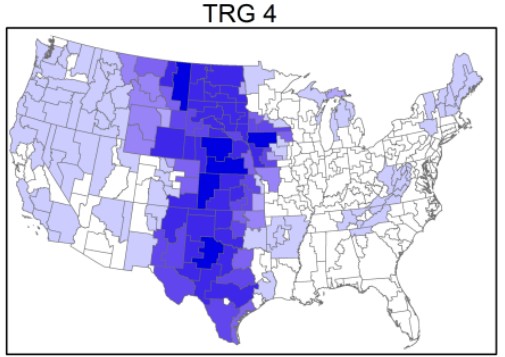

TRG 5

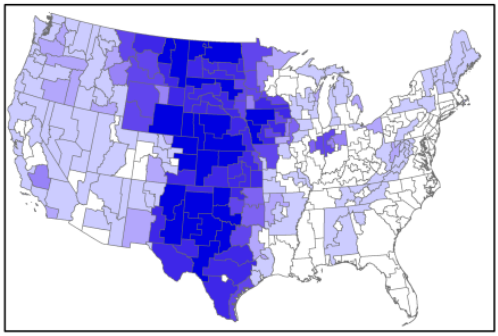

TRG 6

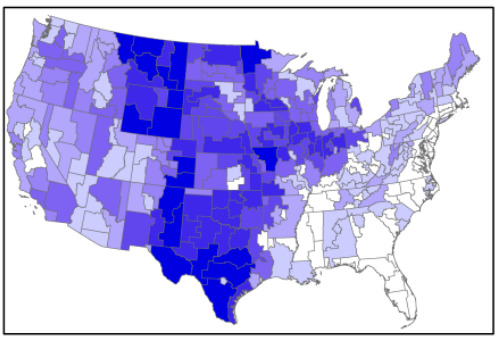

TRG 7

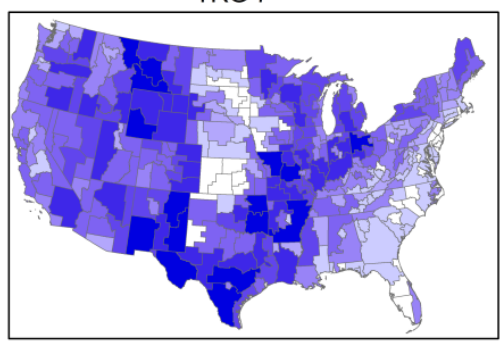

TRG 8

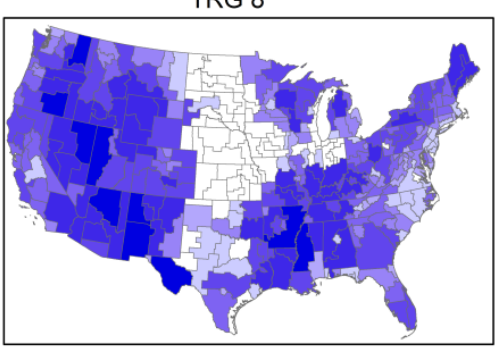

TRG 9

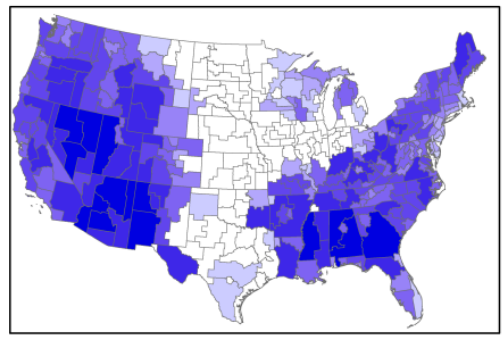

TRG 10

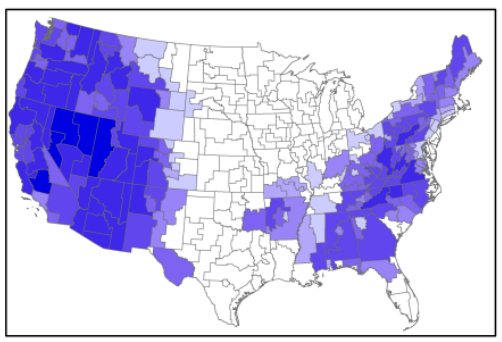

Land Based Wind Capacity (MW)

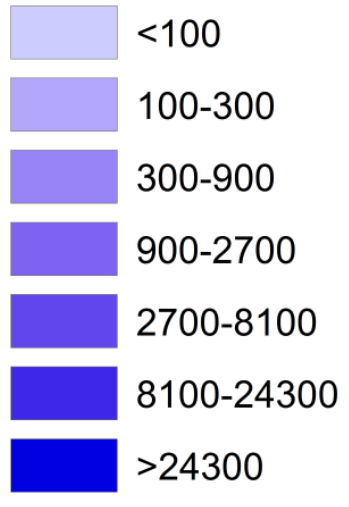

Figure 3. Land-based wind resource map for the contiguous United States 


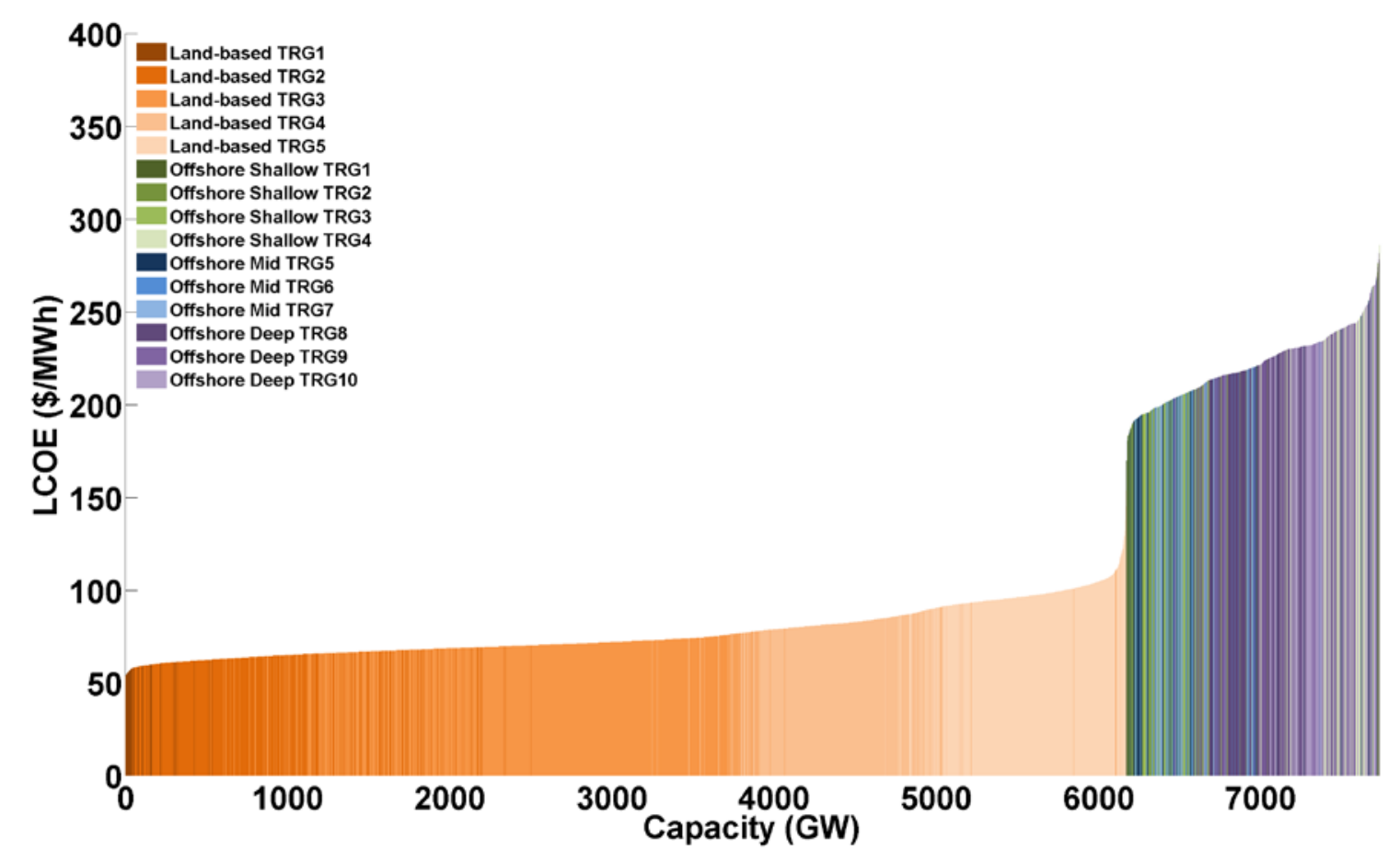

Figure 4. Estimated wind supply curves of all wind resource modeled in ReEDS

Distinct wind production profiles are also modeled for each TRG and wind resource region. In addition, to inform the statistical parameterizations for capacity value and curtailment, we use hourly data and correlations between regions and TRGs.

\subsubsection{Offshore Wind}

There is substantial diversity in offshore wind generators, in terms of distance from shore, water depth, and resource quality. ReEDS subdivides offshore wind potential into ten resource classes: four for shallow resource and three each for mid-depth and deep-water resource. The depth categories correspond to turbine mounting and anchoring technologies. The shallow resource $(0$ 30 meters $[\mathrm{m}])$ is accessible via current monopile foundations; the mid-depth resource $(30-60 \mathrm{~m})$ is expected to be accessible to jacket (truss-style) foundations, and deep-water resource (60-700 m) sites are expected to be feasible only for floating anchorage. Within each depth category, the classes are distinguished by resource quality, and then cost supply curves differentiate resource by cost of accessing transmission.

Eligible offshore area for wind development includes open water within the U.S.-exclusive economic zone with water depth less than $700 \mathrm{~m}$, including the Great Lakes. As with land-based resource, offshore zones are filtered to remove areas considered unsuitable for development, including national marine sanctuaries, marine protected areas, wildlife refuges, shipping and towing lanes, offshore platforms, and ocean pipelines. More than 1,500 GW of technical offshore wind potential remain after applying the exclusions.

Starting-point cost data are derived from the published data of the global offshore wind industry as well as estimates from recent development activity on the Atlantic Coast of the United States (Tegen et al. 2012). These data are coupled with engineering assessments and distance-based 
cost functions (specific to the offshore export cable and incremental construction cost associated with moving farther from shore) to determine expected site-specific costs for technology across a broad range of water depths and distances from shore.

Other aspects of our model representations for offshore wind follow the same methods as those for land-based wind (see Appendix H of the Wind Vision study [DOE 2015]). Figure 5 shows the offshore wind resource potential modeled in ReEDS using the 10 TRGs with TRG 1 representing the lowest-cost resource (shallow, fixed-bottom) and TRG 10 representing the highest-cost one (deep-water, floating).
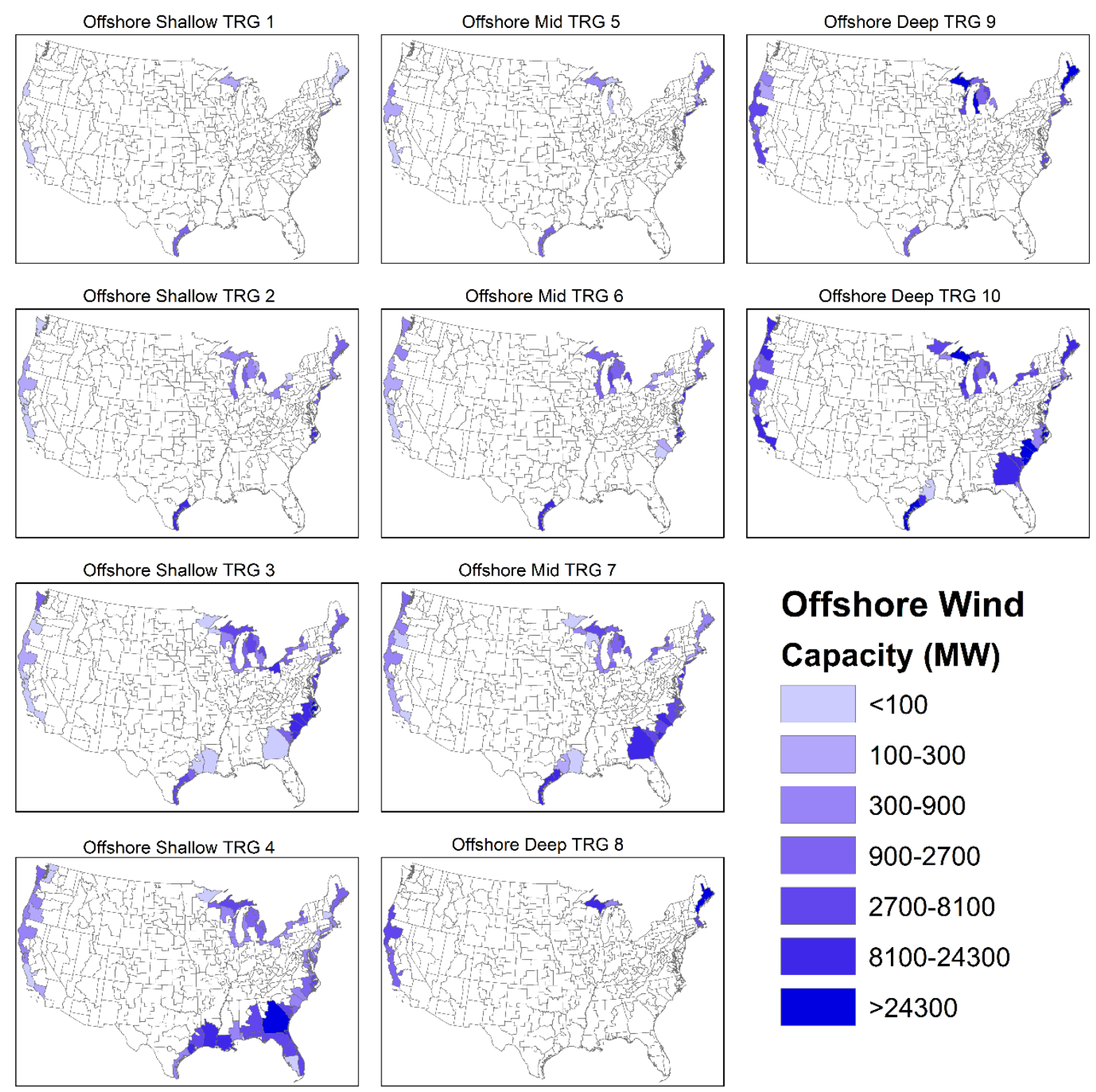

Figure 5. Offshore wind resource map for the contiguous United States 


\subsubsection{Solar Photovoltaics}

ReEDS classifies three solar photovoltaic technologies: large-scale utility PV (UPV), distribution-side utility PV (DUPV), and rooftop PV. Investments in UPV and DUPV are evaluated directly in ReEDS, while rooftop PV deployment and performance are exogenously input into ReEDS from the dGen model.

UPV in ReEDS represents utility-scale single-axis-tracking PV systems with a representative size of 100 megawatts (MW) and an array density of $39 \mathrm{MW}$ per square kilometer $\left(\mathrm{km}^{2}\right)$. Resource potential is assumed to be large parcels outside urban boundaries, excluding federally protected lands, inventoried "roadless" areas, areas of critical environmental concern, and areas with slope greater than $5 \%$. Each eligible UPV site is characterized by a raw hourly $(8,760)$ irradiance profile that is representative of the solar resource within a $10-\mathrm{km}^{2}$ contiguous area. Each of these UPV sites are compiled into supply curves by the 134 ReEDS BA regions and $9 \mathrm{PV}$ resource classes, differentiated by cost to connect to the transmission network (process described in Section 5.3). The nine resource classes reflect different resource qualities based on the annual average irradiance, assuming a tilt angle equal to the latitude (Table 2). The UPV supply curves input into ReEDS include nearly 157 terawatts (TW) of directly connected potential, which is shown by resource class in Figure 6.

Table 2. UPV and DUPV Resource Classes

\begin{tabular}{cl}
\hline Class & $\mathbf{k W h} / \mathbf{m}^{2} /$ day \\
\hline 1 & $3.0-3.5$ \\
2 & $3.5-4.0$ \\
3 & $4.0-4.5$ \\
4 & $4.5-5.0$ \\
5 & $5.0-5.5$ \\
6 & $5.5-6.0$ \\
7 & $6.0-6.5$ \\
8 & $6.5-7.0$ \\
9 & $7.0-7.5$ \\
\hline
\end{tabular}




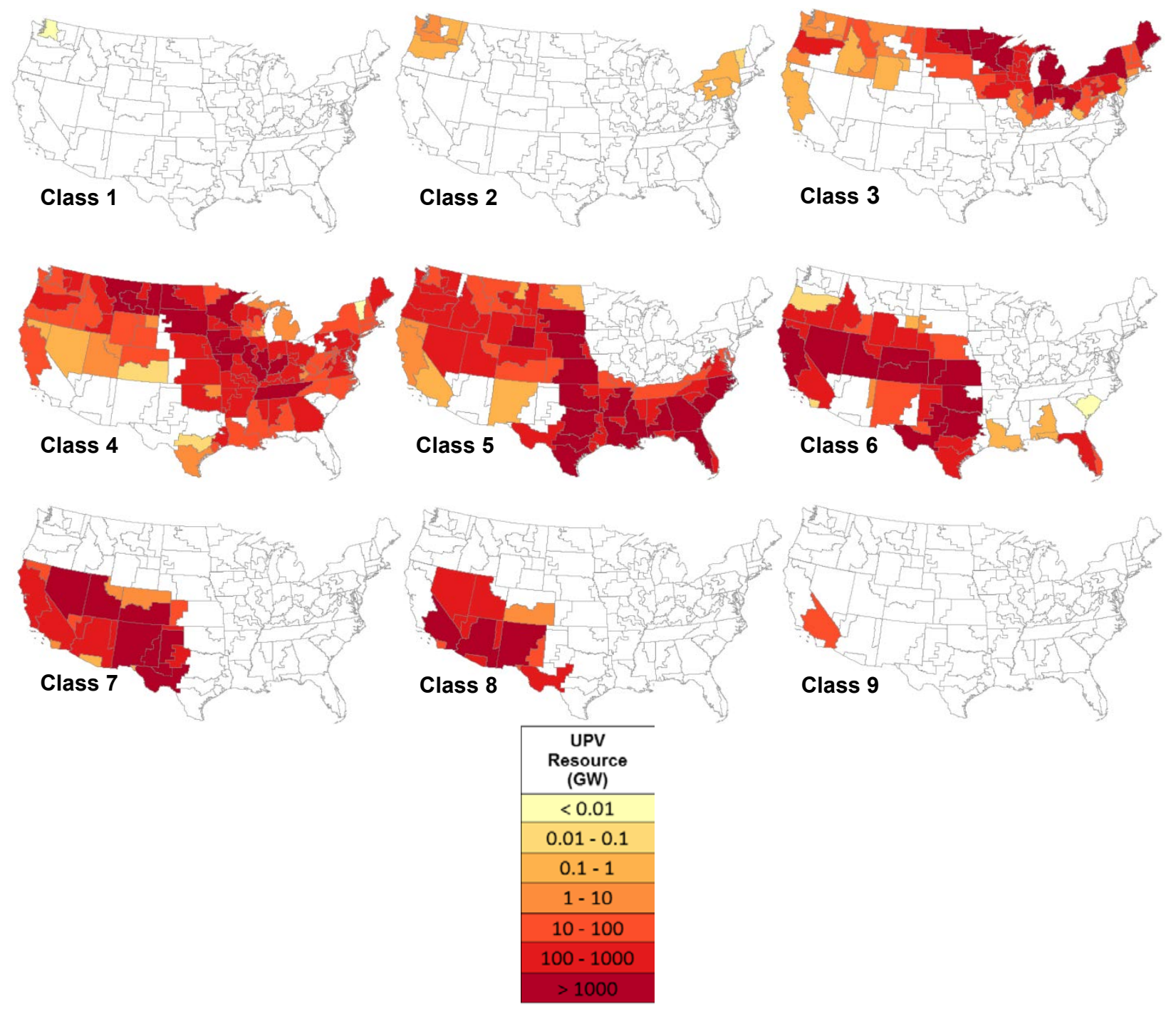

Figure 6. UPV resource availability by ReEDS BA region and resource class

Distributed utility-scale PV (DUPV) in ReEDS represents utility-scale single-axis-tracking systems with a representative size of $1 \mathrm{MW}$ and an array density of $39 \mathrm{MW} / \mathrm{km}^{2}$. These systems are located within or are directly connected to distribution networks in urban areas. Resource potential estimates for DUPV are made by defining the eligible area as open space within urban areas and near existing distribution substations. Parking lots, roads, and urbanized areas are excluded by identifying areas with imperviousness greater than or equal to 1\% (Fry et al. 2011). Additional exclusions for landmarks, parks, and water further exclude areas deemed unlikely for development. Each DUPV site within the resulting eligible rural land areas is characterized by a raw hourly $(8,760)$ irradiance profile that is representative of the solar resource within a $10-\mathrm{km}^{2}$ contiguous area. This process returns an urban DUPV potential of nearly $1.15 \mathrm{TW}$ across the contiguous United States (see Figure 7), with resource potential generally correlated with region size and population, and with higher-quality potential in the Southwest. Similar to UPV, these values are input into ReEDS as supply curves by BA region and the nine PV resource classes from Table 2 . 


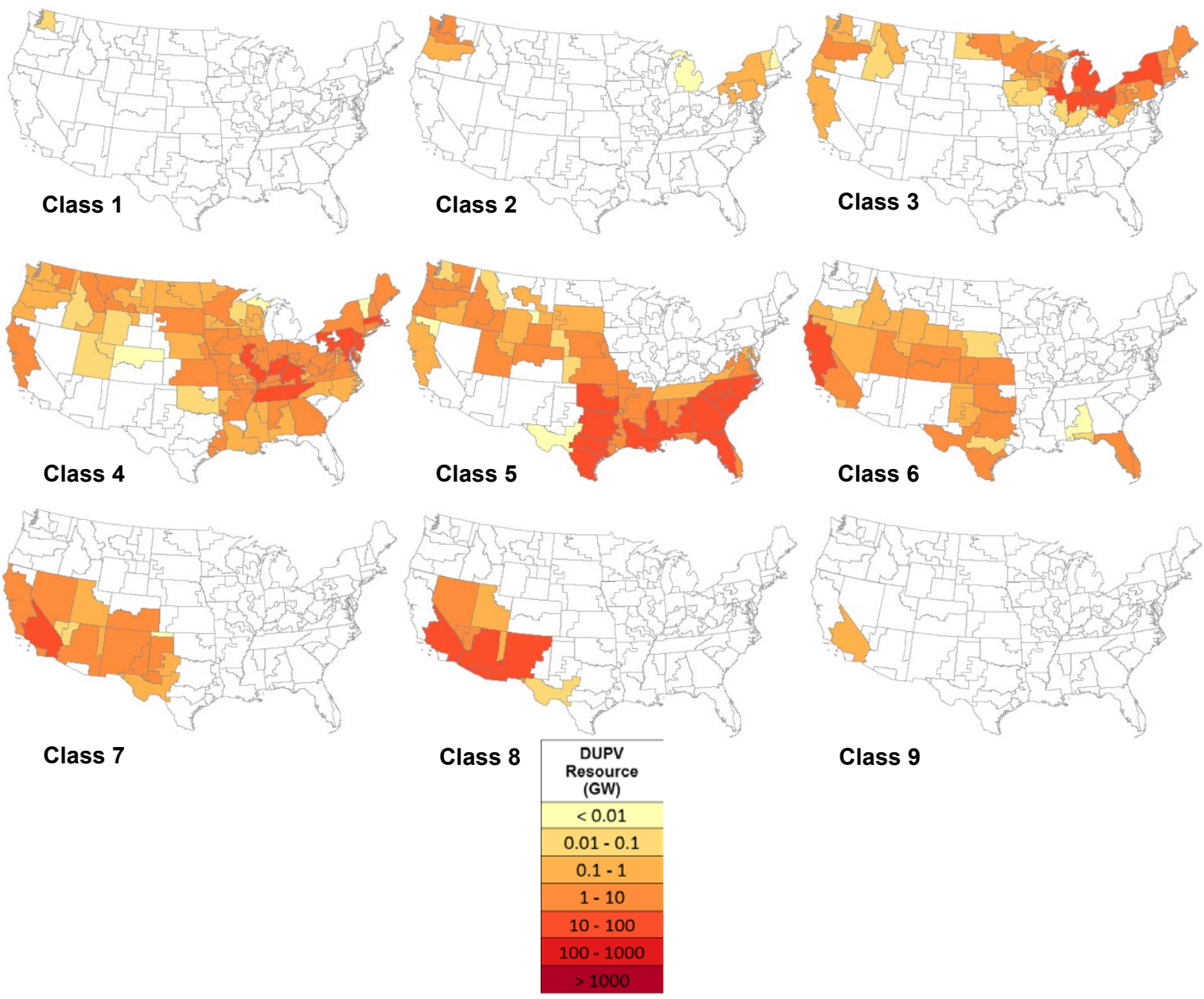

Figure 7. DUPV resource availability in each ReEDS region by resource class

Compared to large-scale rural UPV systems, DUPV systems have lower infrastructure requirements; we assume they connect to existing nearby distribution substations at about 13 kilovolts $(\mathrm{kV})$, whereas the representative UPV system connects to a high-voltage bus at $230 \mathrm{kV}$ and may require a spur line several miles long to reach that connection point. The cost of the spur line is handled separately in the accessibility supply curve (Section 5.3), but the additional transformers and power electronics associated with the larger systems and higher-voltage interconnections add cost and losses to the UPV systems. On the other hand, the larger UPV systems benefit from economies of scale. On balance, we assume a per-kW capital cost penalty of $8.7 \%{ }^{14}$ and $3.5 \%$ higher delivered energy (i.e., reduced losses) for DUPV relative to UPV.

Performance characteristics for UPV and DUPV were developed using NREL's PVWatts (Version 5) accessed through the System Advisor Model (SAM) ${ }^{15}$ using annual hourly weather

\footnotetext{
${ }^{14}$ Represents the average of union and non-union total system cost without transmission between a 10MW (proxy for DUPV) and 100MW (UPV) system (Fu et al. 2015).

${ }^{15} \mathrm{https://sam.nrel.gov/}$
} 
files from the National Solar Radiation Database ${ }^{16}$ for 1,454 sites throughout the contiguous United States from 1998 to 2009. No changes or improvements in capacity factor are assumed for PV technologies. For each ReEDS BA region, resource quality classifications were made by averaging across the 12-year period for all available parcels. Hourly generation profiles were taken from 2006. The generation profiles from all the regions in a BA for each resource class were averaged to provide ReEDS with average capacity factors by time-slice and resource class.

ReEDS assumes all power generated by both DUPV and rooftop PV systems is permitted to be exported to neighboring BAs only when total generation in the source region exceeds the load for a given time-slice. UPV-generated electricity, in contrast, is allowed to be exported in all time-slices and regions.

Degradation of the efficiency of solar PV capacity over time is also modeled at $0.5 \%$ /year (Jordan and Kurtz 2013). This degradation is modeled by reducing the capacity of PV that generates energy by $0.5 \%$ year.

Rooftop PV includes commercial, industrial, and residential systems. dGen, a capacity expansion model for the contiguous U.S. rooftop market, is used to develop a future scenarios for rooftop PV capacity (Sigrin et al. 2016). The default dGen trajectories used in this version of ReEDS are based on the residential and commercial PV cost trajectories as described in the 2016 Annual Technology Baseline (NREL 2016). Figure 8 shows capacity deployment for rooftop PV from $\mathrm{dGen}$ for the low, mid, and high cost trajectories from the Annual Technology Baseline. The trajectories incorporate existing net metering policy as of April 1, 2016, and they include the ITC as discussed in Section 8.2.

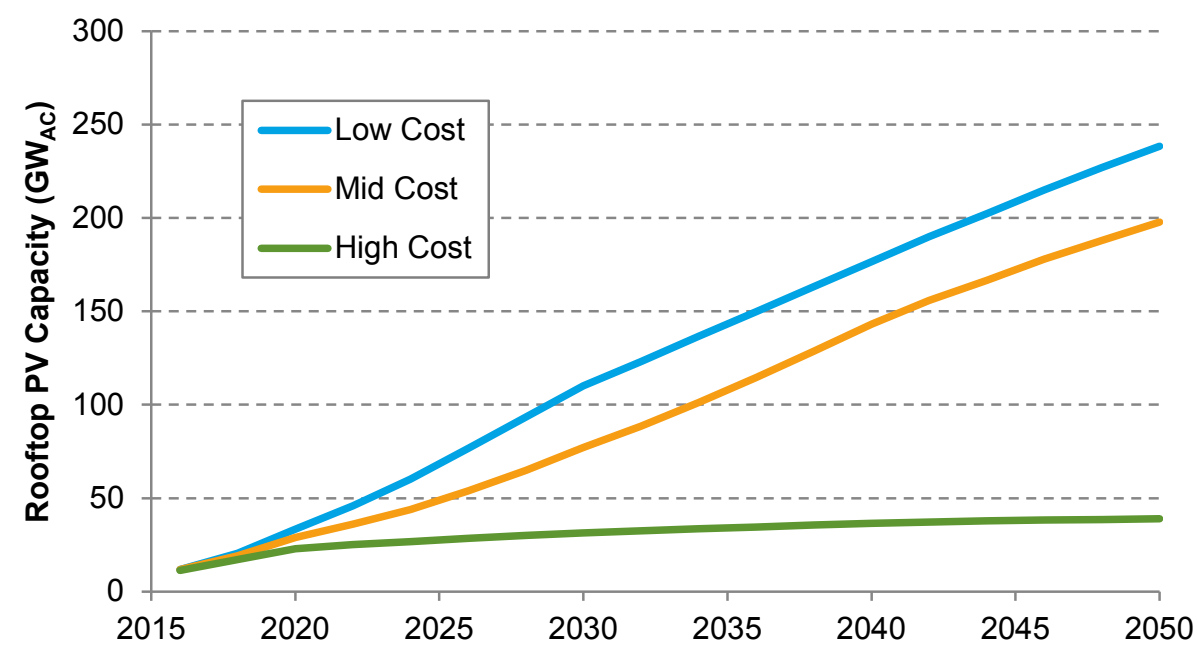

Figure 8. Prescribed distributed PV deployment used in the ReEDS as determined by dGen, with costs from the 2016 Annual Technology Baseline (NREL 2016)

\footnotetext{
${ }^{16}$ https://nsrdb.nrel.gov/
} 


\subsubsection{Concentrating Solar Power}

Concentrating solar power (CSP) technology options in ReEDS encompass a subset of possible thermal system configurations, with and without thermal storage, as shown in Table 3 . The two system types access the same resource potential, which is divided into five resource classes based on direct normal insolation (DNI) (Table 4).

Table 3. Characteristics of CSP Technology Storage Options

\begin{tabular}{lllll}
\hline System & Configuration & Dispatchability & Capacity Value & Curtailments \\
\hline No Storage & solar multiple: 1.4 & insolation-dependent & variable/ & variable/ \\
& & & statistical & statistical \\
\multirow{2}{*}{ With Storage } & $\begin{array}{l}6-12 \text { storage hours, } \\
\text { solar multiple: } 1.6-2.7\end{array}$ & dispatchable & firm & none \\
& & & \\
\hline
\end{tabular}

The CSP resource classes are defined by power density of DNI, developable land area having been filtered based on land cover type, slope, and protected status. CSP resource in each resource region is therefore represented as a supply curve of MW of solar collector potential, assuming a heliostat density of $62 \mathrm{MW} / \mathrm{km}^{2}$. Performance for each CSP resource class was developed using typical DNI year (TDY) hourly resource data (Habte et al. 2014) from representative sites of each resource region. The TDY weather files are processed through the CSP modules of SAM to develop performance characteristics for each CSP resource class and representative CSP system considered in ReEDS.

Table 4. Capacity Factor Groups for Concentrating Solar Power plants using a solar multiple of 1.4

\begin{tabular}{|c|c|c|}
\hline $\begin{array}{l}\text { Resource } \\
\text { Class }\end{array}$ & $\begin{array}{l}\text { DNI range: } \\
\mathrm{kWh} / \mathrm{m}^{2} / \text { day }\end{array}$ & $\begin{array}{l}\text { Average Group } \\
\text { Net CF }(2010)^{a}\end{array}$ \\
\hline Class 1 & $5-6.25$ & 0.315 \\
\hline Class 2 & $6.25-7.25$ & 0.393 \\
\hline Class 3 & $7.25-7.5$ & 0.428 \\
\hline Class 4 & $7.5-7.75$ & 0.434 \\
\hline Class 5 & $>7.75$ & 0.448 \\
\hline
\end{tabular}

The representative CSP system without storage in ReEDS is a 100-MW trough system with a solar multiple of 1.4. As CSP systems without storage are non-dispatchable, output capacity factors are defined directly from SAM results. The average annual capacity factors for the solar fields of these systems range from $20 \%$ (Class 1 resource) to $31 \%$ (Class 5 resource).

The representative system for CSP with storage is a trough-based configuration and switches to a tower-based configuration in $2025^{17}$ with a molten salt heat transfer fluid and a thermal storage

\footnotetext{
${ }^{17}$ This transition from troughs to towers is representative only and is not an indication of expected or predicted technology adoption. In reality, multiple system configurations will likely be deployed. The year of this representative transition can be changed by a user.
} 
tank between the heliostat array and the steam turbine. CSP with storage is optimally built within ReEDS by considering three major design components (field, turbine, storage) within six constraints as shown in Figure 9 for tower systems. These constraints ensure the systems can be assumed to be fully dispatchable within the energy limitations imposed by the following:

- For a given turbine, the storage tank must hold energy for 6-12 hours of output (horizontal lines). ${ }^{18}$

- A maximum solar multiple of 3.0 is assumed for trough systems and one of 2.5 is assumed for tower systems (vertical green line).

- Upper and lower bounds on annual system capacity factor create lower and alternate upper limits on solar multiple (vertical orange and blue lines); ReEDS assumes the array must be sized to produce an average annual capacity factor between $40 \%$ and $65 \%$.

- A minimum storage-to-solar-multiple ratio ensures curtailments are not excessive; in other words, the storage tank size must keep pace with increasing solar multiples to avoid excessive curtailments (diagonal line-derived from the data in Figure 10).

The data in Figure 10 show the turbine capacity factor for a range of CSP system configurations (field, turbine, and storage) as simulated in SAM. The capacity factor erodes for high solar multiple systems lacking sufficient storage due to curtailments. This relationship between storage and solar multiple was used to define the minimum storage to solar multiple ratio constraint in Figure 9 (diagonal line).

ReEDS considers CSP-with-storage system configurations within the resulting feasible space (hashed lines in Figure 9). Higher solar multiples result in higher annual average capacity factors, and more storage allows the systems to be more flexible, although both options increase capital costs per kilowatt of installed turbine capacity.

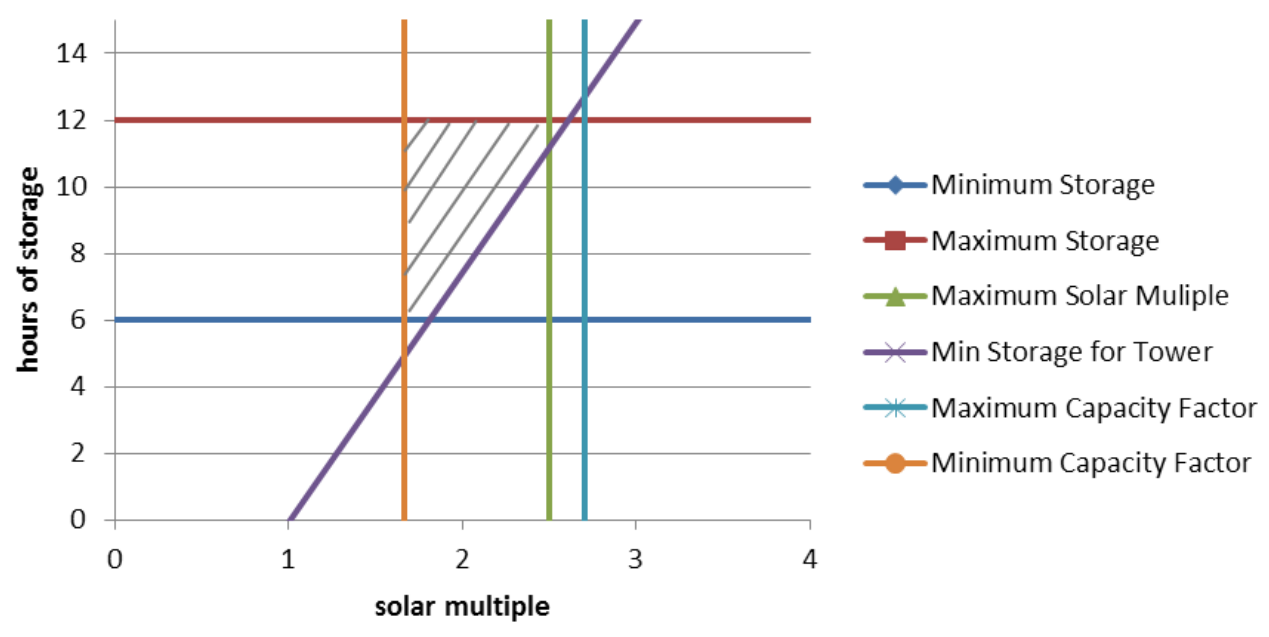

Figure 9. ReEDS constraints and corresponding feasible space (hashed line) for CSP with storage

\footnotetext{
${ }^{18}$ This limit on storage duration is in not a technical limit, and shorter duration storage has been considered for CSP.
} 


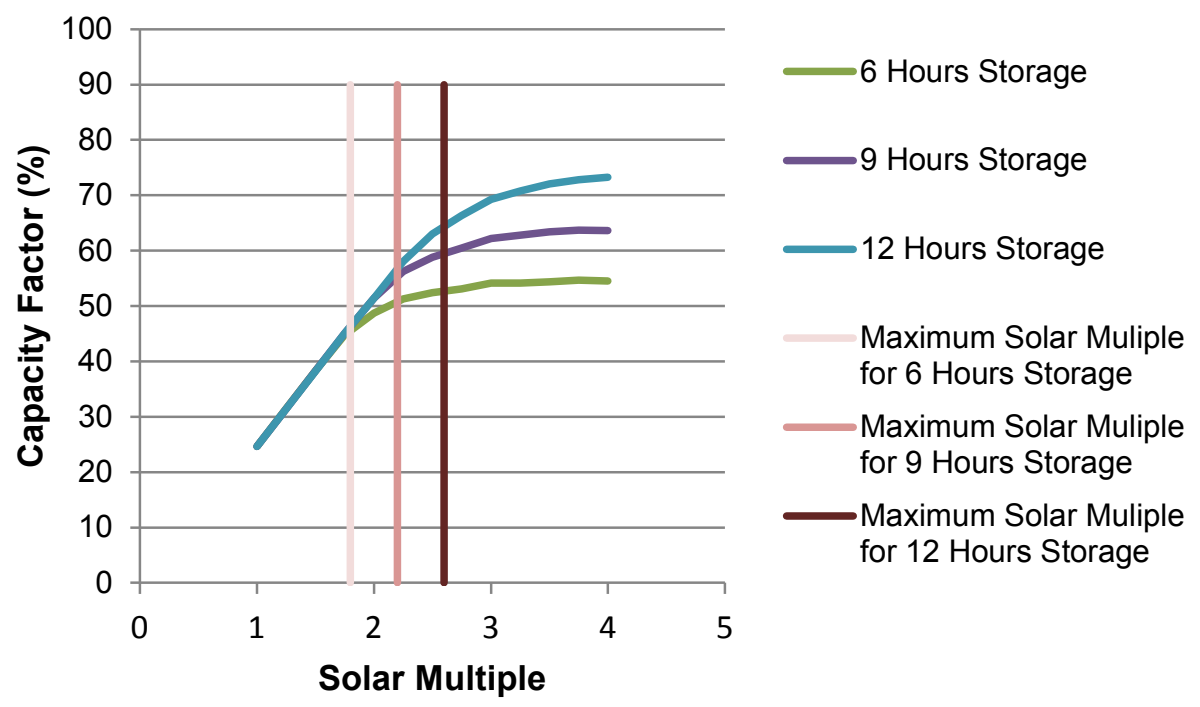

Figure 10. Capacity factor trends versus solar multiple

For CSP with storage, plant capacity factors by time-slice are an output of the model, not an input, as ReEDS is allowed to dispatch collected CSP energy independent of irradiation. Instead, the profile of power input from the collectors (solar field) of the CSP plants are model inputs, based on SAM simulations from the TDY weather files.

Because CSP resource quality and land availability are highly variable within the CSP resource regions, the CSP resource potential is structured into supply curves - as it is for other technologies_-distinguishing resource quality and accessibility (see Section 5.3).

\subsubsection{Geothermal}

The default geothermal resource assumption allows for new construction of identified hydrothermal and near-hydrothermal-field enhanced geothermal systems (near-field EGS) plants. While undiscovered hydrothermal and deep EGS resources are not included in the base assumptions, they can be modeled as additional resource in ReEDS. The identified hydrothermal and near-field EGS supply curves are based on the analysis described in (Augustine 2011) and are shown in Figure 11. Generally, the hydrothermal and near-field EGS resource potential is derived from the U.S. Geological Survey's 2008 Geothermal Resource Assessment (Williams, Reed, and Mariner 2008), while the deep EGS resource potential is based on an update of the EGS potential from the Massachusetts Institute of Technology (Tester et al. 2006). As with other technologies, geothermal cost and performance projections are from the 2016 Annual Technology Baseline (NREL 2016).

Hydrothermal resource represents potential resource sites that involve tapping existing hot water. The hydrothermal potential included in the base supply curve consists of only identified sites. EGS sites are geothermal resources that have sufficient temperature but lack the natural permeability, in-situ fluids, or both to be hydrothermal systems. Near-field EGS is a subset of EGS that implies proximity to existing or known hydrothermal sites. Capital costs for geothermal potential do not change through time. 

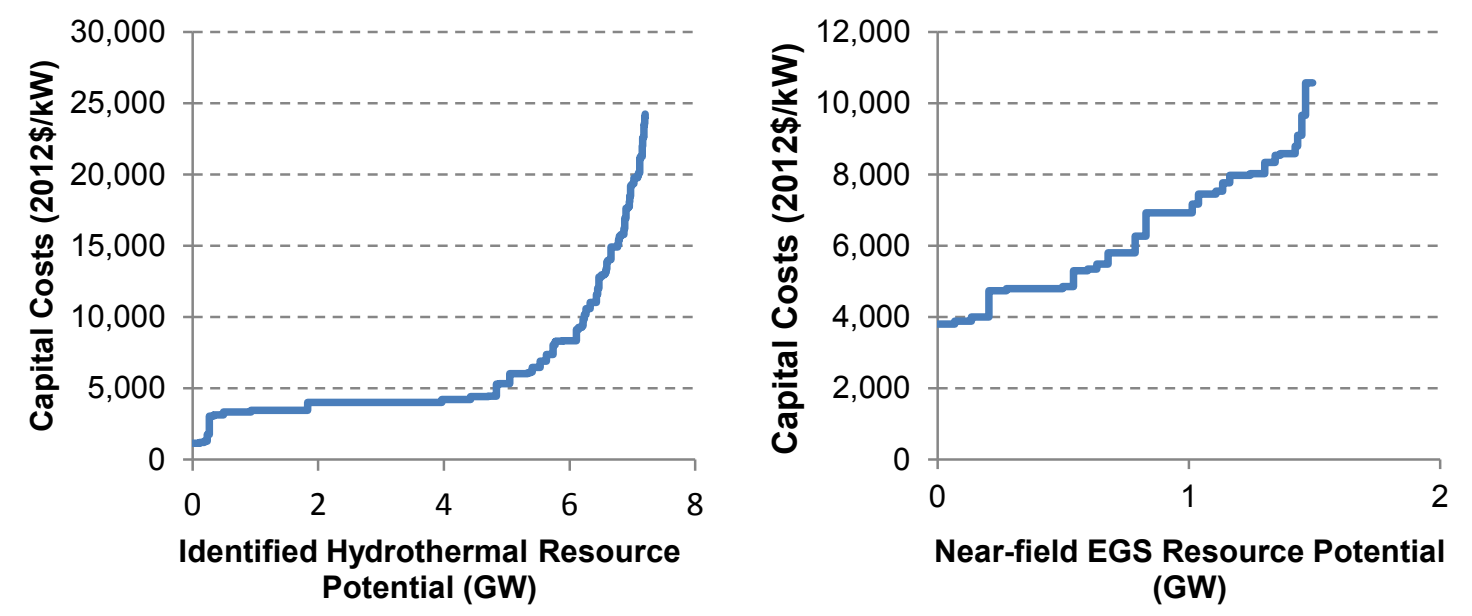

Figure 11. National capital cost supply curves for new identified hydrothermal and near-field EGS capacity used in the base model assumptions

\subsubsection{Hydropower}

The model includes approximately $76 \mathrm{GW}$ of existing hydropower capacity for the model start year (2010). From this nominal capacity, seasonal capacity adjustments for Western Electricity Coordinating Council (WECC) regions from the Transmission Expansion Planning Policy Committee (TEPPC) 2024 Common Case (WECC 2013; WECC 2015) are used to better match realistic seasonal variations in maximum capacity due to changes in water availability and operating constraints. These data are not available for non-WECC regions. Existing hydropower energy potential for 2016 and beyond is defined using region-specific seasonal hydropower capacity factors averaged for 2006-2015 as reported by the National Hydropower Asset Assessment Program (NHAAP), ${ }^{19}$ totaling $270 \mathrm{TWh} / \mathrm{yr}$. Capacity factors for 2010-2014 model years are calibrated so that modeled generation matches historical generation. PHS, both existing and new, is discussed in Section 2.3 on storage technologies.

There are three categories of new hydropower resource potential represented in the model.

1. Upgrade and expansion potential for existing hydropower

2. Potential for powering non-powered dams (NPD)

3. New stream-reach development potential (NSD)

The supply curves for each are discussed in detail in the Hydropower Vision report (DOE 2016b), particularly Chapter 3 and Appendix B.

ReEDS does not currently distinguish between different types of hydropower upgrades, so upgrade potential is represented generically as a potential for capacity growth that is assumed to have the same energy production potential per capacity (i.e., capacity factor) as the corresponding existing hydropower capacity in the region. Upgrade resource is derived from a combination of limited resource assessments and case studies by the Reclamation Hydropower

\footnotetext{
${ }^{19}$ http://nhaap.ornl.gov/content/nhaap-data-sources
} 
Modernization Initiative (HMI), U.S. Army Corps of Engineers (Corps), and NHAAP Hydropower Advancement Project (Montgomery, Watson, and Harza 2009; Bureau of

Reclamation 2011), with upgrades at federal facilities not included in the HMI assumed to be the HMI average of $8 \%$, and upgrades at non-federal facilities assumed to be the NHAAP average of $10 \%$. Rather than making all upgrade potential available immediately, upgrade potential is made available over time at the earlier of (1) Federal Energy Regulatory Commission (FERC) license expiration (if applicable) and (2) turbine age reaching 50 years. This feature better reflects institutional barriers and industry practices surrounding hydropower facility upgrades. The total upgrade potential from this methodology is $6.9 \mathrm{GW}(27 \mathrm{TWh} / \mathrm{yr})$.

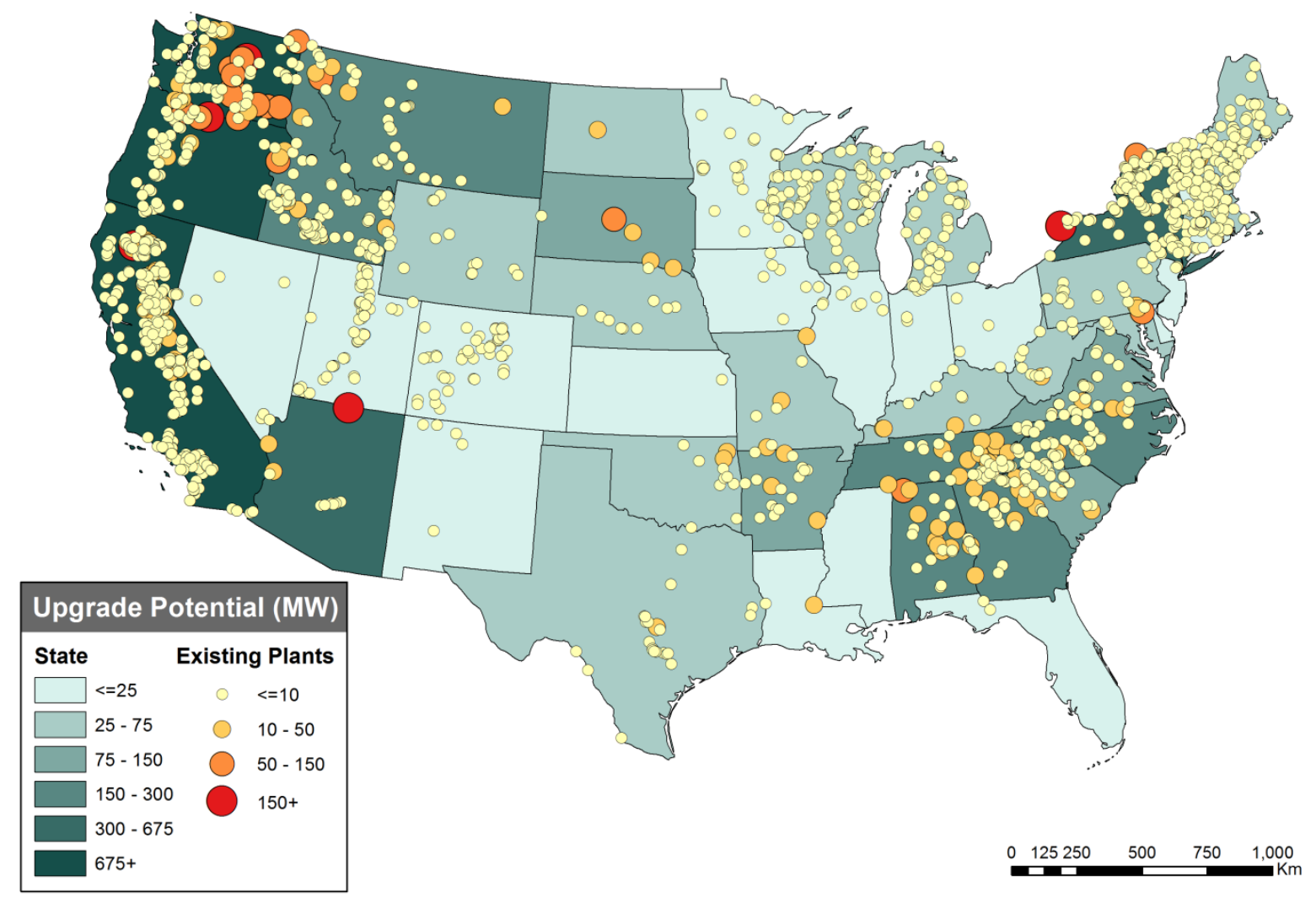

Figure 12. Modeled hydropower upgrade resource potential (DOE 2016b)

NPD resource in ReEDS is derived from the 2012 NHAAP NPD resource assessment (Hadjerioua, Wei, and Kao 2012; Hadjerioua et al. 2013), where the modeled resource of 5.0 $\mathrm{GW}(27 \mathrm{TWh} / \mathrm{yr})$ reflects an updated site sizing methodology, data corrections, and an exclusion of sites under $500 \mathrm{~kW}$ to allow better model resolution for more economic sites. 


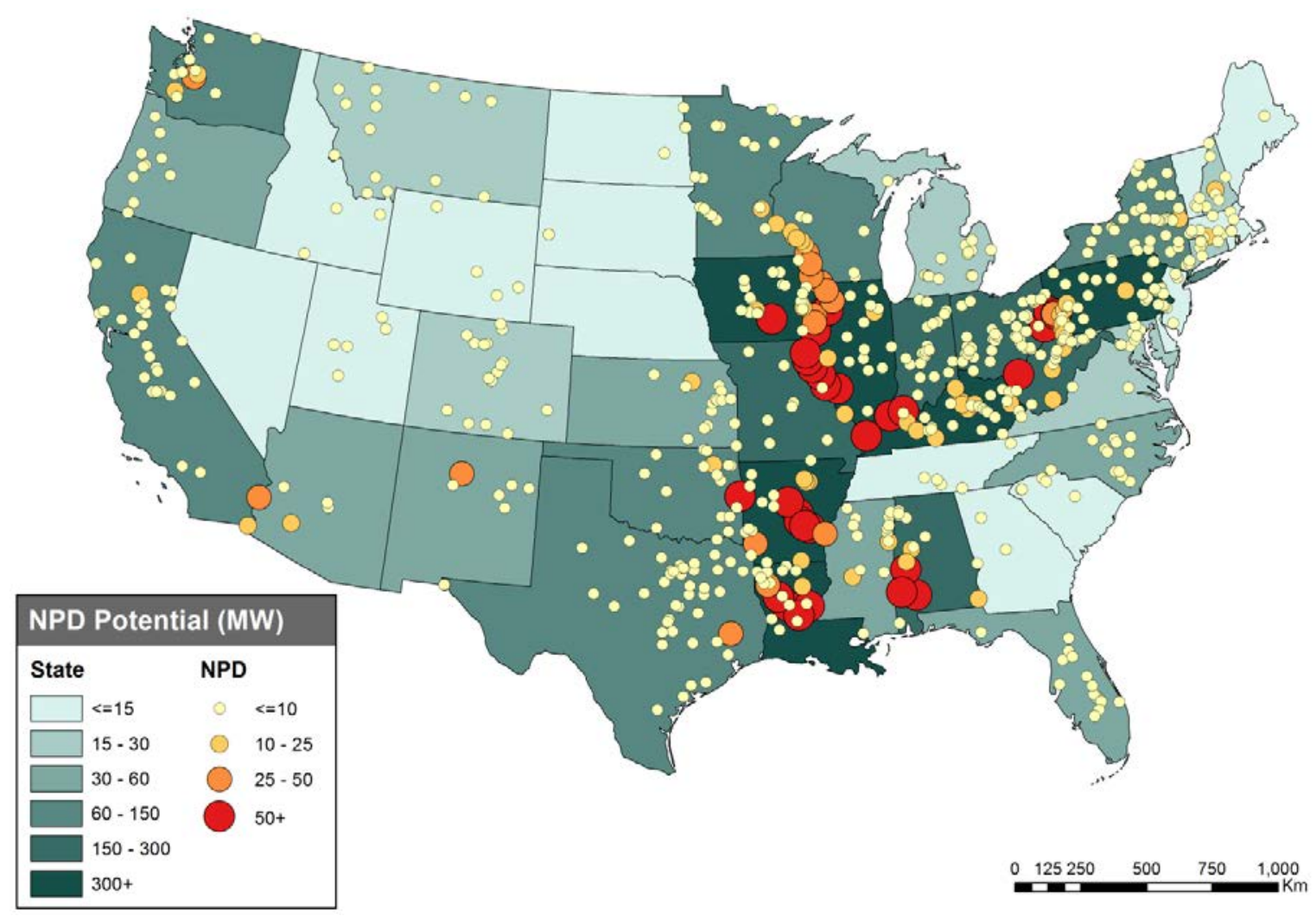

Figure 13. Modeled non-powered dam resource potential (DOE 2016b)

NSD resource is based on the 2014 NHAAP NSD resource assessment (Kao et al. 2014), where the modeled resource of $30.7 \mathrm{GW}(176 \mathrm{TWh} / \mathrm{yr})$ reflects the same sizing methodology as NPD and a sub $1 \mathrm{MW}$ site exclusion, again to improve model resolution for lower-cost resource. The NSD resource assumed "low head" sites inundating no more than the 100-year floodplain and excludes sites within areas statutorily barred from development — national parks, wild and scenic rivers, and wilderness areas. 


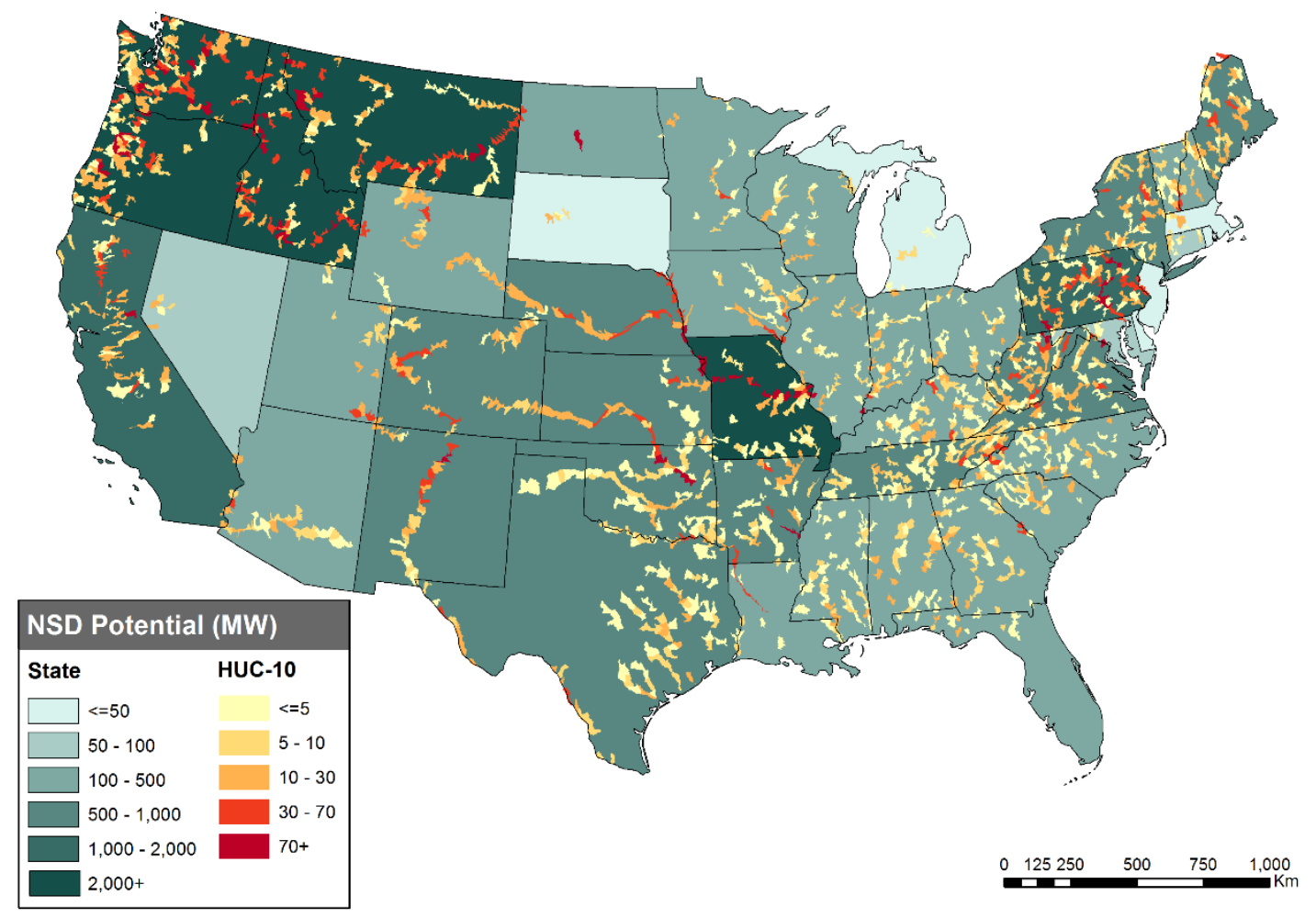

Figure 14. Modeled new stream-reach development resource potential (DOE 2016b).

The combined hydropower capacity coupled with the costs from the 2016 Annual Technology Baseline (NREL 2016) results in the supply curve shown in Figure 15.

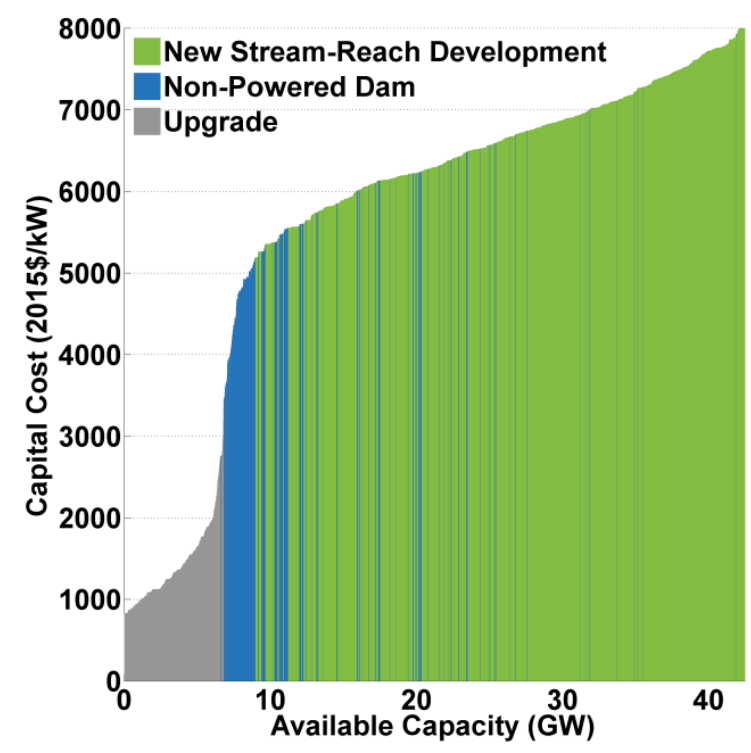

Figure 15. National hydropower supply curve of capital cost versus cumulative capacity potential 
The hydropower operating parameters and constraints included in ReEDS do not fully reflect the complex set of operating constraints on hydropower in the real world. Detailed site-specific considerations involving a full set of water management challenges are not possible to represent directly in a model with the scale and scope of ReEDS, but several available parameters allow a stylized representation of actual hydropower operating constraints.

Each hydropower category can be further differentiated into "dispatchable" or "nondispatchable" capacity, with "dispatchable" defined in ReEDS as the ability to provide the following services:

1. Diurnal load following within the capacity and average daily energy limits for each season

2. Planning (adequacy) reserves with full rated capacity

3. Operating reserves up to a specified fraction of rated capacity if the capacity is not currently being utilized for energy production.

"Non-dispatchable" capacity, on the other hand, provides:

1. Constant energy output in each season such that all available energy is utilized

2. Planning reserves equal to the output power for each season

3. No operating reserves.

Dispatchable capacity is also parameterized by a fractional minimum load, with the maximum fractional capacity available for operating reserves as 1 minus the fractional minimum load. Only the existing fleet and its corresponding upgrade potential are differentiated by dispatchability using data from the TEPPC 2024 Common Case for WECC and NHAAP Hydropower Market Report elsewhere (WECC 2013; WECC 2015; Uria-Martinez, O’Connor, and Johnson 2015). All WECC facilities that do not follow load are assumed non-dispatchable, and all non-WECC facilities in the following NHAAP categories are non-dispatchable: run-of-river, run-ofriver/peaking (downstream), and regulating. This methodology chooses only the most obvious facilities as non-dispatchable while leaving all other existing and upgrade capacity as dispatchable. In total, $43 \%$ of existing capacity and $49 \%$ of upgrade potential is assumed nondispatchable.

The same TEPPC database is used to define region-specific fractional minimum capacity for dispatchable existing and upgrade hydropower in WECC. Lacking minimum capacity data for non-WECC regions, 0.5 is chosen as a reasonable fractional minimum capacity.

Both the NPD and NSD resource assessments implicitly assume inflexible, run-of-river hydropower, so all NPD and NSD resource potential is assumed non-dispatchable. Further sitespecific analysis could allow re-categorizing portions of these resources as dispatchable, but $100 \%$ non-dispatchable remains the default assumption.

\subsubsection{Biopower}

ReEDS can generate electricity from biomass either in dedicated biomass integrated gasification combined cycle (IGCC) plants or cofired with coal in facilities that have been retrofitted with an 
auxiliary fuel feed. These cofire-ready coal plants can use biomass in place of coal to supply the fuel for up to $15 \%$ of the plant's electricity generation. A cofire retrofit costs $\$ 290 / \mathrm{kW}$ based on EIA’s Electricity Market Module assumptions (EIA 2014b, 101).

Dedicated and cofired plants source feedstock from the same biomass supply curves, which are derived from the U.S. Billion-Ton Update report (DOE 2011). The biomass types from the study included in the supply curves are crop and forest residues (including forest residues from federal lands) and energy crops.

\subsubsection{Marine Hydrokinetic Wave}

ReEDS does have a representation of marine hydrokinetic wave technologies, but this capability is not utilized in any of the recent or current ReEDS modeling work.

\subsection{Conventional Fossil Energy Technologies}

ReEDS includes all major categories of conventional generation technologies within its operating fleet or investment choices. Coal technologies are subdivided into pulverized and gasified (IGCC) categories, with the pulverized plants further divided by whether or not they have $\mathrm{SO}_{2}$ scrubbers. Pulverized coal plants have the option of adding a second fuel feed for biomass. New IGCC plants can only be constructed with CCS technology. ${ }^{20}$ Certain existing coal units have the option of retrofitting CCS capability.

Natural gas generators are categorized as combustion turbine (CT), combined cycle (CC), or gas$\mathrm{CC}$ with CCS. There are also nuclear (steam) generators, landfill gas generators, ${ }^{21}$ and oil/gas steam generators, though the latter two are not offered as options for new construction. The model includes consideration of distinguishing characteristics of each conventional-generating technology, including costs, efficiency, and operational differences.

Each modeled technology is characterized by its capital cost, O\&M costs, and heat rates or capacity factors. Regional variations and adjustments are included and described in Section 2.4. This section outlines the capital, fixed O\&M, variable O\&M, and heat rates for all technologies modeled.

Cost and performance assumptions for all new conventional technologies and certain renewable technologies (e.g., biopower and geothermal) are largely based on projections from the AEO 2016 Reference scenario. ${ }^{22}$ The National Energy Modeling System (NEMS) Electricity Market Module, which is used for AEO analyses, represents technological learning endogenously, with costs falling as more capacity of that type is built. Because ReEDS does not include endogenous learning, the technology cost projections used in ReEDS reflect technology growth in the AEO 2016 Reference scenario. The AEO assumptions include a projected materials price index (MPI)

\footnotetext{
${ }^{20}$ New coal plants without CCS plants are not allowed due the U.S. Environmental Protection Agency's proposed New Source Performance Standard. CCS plants in ReEDS are assumed to be $90 \%$ capture plants, meaning that they capture $90 \%$ of the $\mathrm{CO}_{2}$ emissions in the flue gas. Transportation and sequestration of the $\mathrm{CO}_{2}$ is not considered.

${ }^{21}$ Landfill gas generators are classified are conventional generators, but can count towards renewable portfolio standard requirements.

${ }^{22}$ Where AEO includes two separate projections (advanced and conventional) for any single ReEDS technology, ReEDS uses an average of those figures to represent a medium level of technological advancement.
} 
that also influences capital costs over time; we remove the MPI from our projections for all technologies. In addition, technology projections beyond the AEO 2016 horizon of 2040 are assumed to continue through 2050 .

ReEDS conventional technologies are characterized by the following parameters:

- Capital cost $(\$ / \mathrm{MW})$

- Fixed and variable operating costs (dollars per megawatt-hour [\$/MWh])

- Fuel costs (dollars per million British thermal units [\$/MMBtu])

- Heat rate (MMBtu/MWh)

- Construction period (years) and expenses

- Equipment lifetime (years)

- Financing costs (such as interest rate, loan period, debt fraction, and debt-servicecoverage ratio)

- Tax credits (investment or production)

- Minimum turndown ratio (\%)

- Quick-start capability and cost $(\%, \$ / \mathrm{MW})$

- Spinning reserve capability

- Planned and unplanned outage rates (\%).

Not all parameters are given in this document. For those parameters not included here, see Short et al. (2011). Cost and performance assumptions are based on the NREL Annual Technology Baseline (NREL 2016). Financing parameters and calculations are discussed in Section 9.1

\subsubsection{Conventional Technology Performance Considerations}

Generating technologies are distinguished by operating characteristics, including heat rates, ramp costs, ability to provide spinning and "quickstart" reserves, minimum turndown, and fuel and operating costs. In general, natural gas plants, especially combustion turbines, are better suited for ramping and reserve provision, while coal and nuclear plants are designed for steady, baseload operation.

The existing fleet in ReEDS is a description of the operational generating capacity on December 31, 2016, extracted from the ABB unit database (ABB 2016). In particular, ReEDS extracts summer nameplate capacity, location, and heat rate to characterize the existing fleet. ReEDS uses a modified "average" heat rate for existing stock: a small, technology-specific increase on the full-load heat rate to accommodate for units not always operating at their design point. The modifiers, shown in Table 5, are based on the relationship between full-load and average heat rates for generators in the Ventyx database. Coal adjustment factors also take into account the historical observed fleet-wide heat-rates, which are calculated using EIA form 923. 
Table 5. Multipliers Applied to Full-Load Heat Rates to Approximate Heat Rates for PartLoad Operation

\begin{tabular}{lc}
\hline Technology & Adjustment Factor \\
\hline Coal (all) & 1.0674 \\
Gas-CC & 1.0545 \\
Gas-CT & 1.1502 \\
OGS & 1.1704 \\
\hline
\end{tabular}

Emissions rates from conventional plants are a function of the fuel emission rate and the plant heat rate. Burner-tip emissions rates are shown in Table 6 . The coal $\mathrm{CO}_{2}$ emissions rate is the average of the bituminous and subbituminous emissions rate. ${ }^{23}$

Table 6. Emissions Rate by Generator Type in Pounds per MMBtu ${ }^{a}$

\begin{tabular}{lcccc}
\hline Generator & $\begin{array}{l}\mathbf{S O}_{2} \\
\text { Emissions } \\
\text { Rate }\end{array}$ & $\begin{array}{l}\mathbf{N O}_{\mathbf{x}} \\
\text { Emissions } \\
\text { Rate }\end{array}$ & $\begin{array}{l}\text { Mercury } \\
\text { Emissions } \\
\text { Rate }\end{array}$ & $\begin{array}{l}\mathbf{C O}_{2} \\
\text { Emissions } \\
\text { Rate }\end{array}$ \\
\hline Hydropower & 0.0098 & 0.15 & 0 & 0 \\
\hline Gas-CT & 0.0033 & 0.02 & 0 & 117.00 \\
\hline Gas-CC & 0.0033 & 0.02 & 0 & 11.70 \\
\hline Gas-CC-CCS & 0.2 & 0.19 & $4.3612 \mathrm{E}-06$ & 210.55 \\
\hline $\begin{array}{l}\text { Pulverized Coal with } \\
\text { Scrubbers (pre-1995) }\end{array}$ & 0.1 & 0.08 & $4.3612 \mathrm{E}-06$ & 210.55 \\
\hline $\begin{array}{l}\text { Pulverized Coal with } \\
\text { Scrubbers (post-1995) }\end{array}$ & 1.11 & 0.19 & $5.30785 \mathrm{E}-06$ & 210.55 \\
\hline $\begin{array}{l}\text { Pulverized Coal } \\
\text { without Scrubbers }\end{array}$ & 0.0555 & 0.085 & $4.3612 \mathrm{E}-07$ & 210.55 \\
\hline IGCC Coal & 0.0555 & 0.085 & $4.3612 \mathrm{E}-07$ & 21.06 \\
\hline Coal-CCS & 0.299 & 0.1723 & 0 & 137.00 \\
\hline Oil/Gas Steam & 0 & 0 & 0 & 0 \\
\hline Nuclear & 0 & 0 & 0 & 0 \\
\hline Geothermal & 0.08 & 0 & 0 & 0 \\
\hline Biopower & & 0 & 0 & 0 \\
\hline
\end{tabular}

${ }^{a}$ The assumed $\mathrm{CO}_{2}$ pollutant rate for land-fill gas is zero, so the optimization does not see the emissions benefits of land-fill gas. However, ReEDS can track land-fill gas emission and the benefits as a post-processing calculation. Landfill gas is assumed to have negative effective carbon emissions because the methane gas would be flared otherwise, thereby producing the less potent $\mathrm{CO}_{2}$.

${ }^{23}$ See https://www.eia.gov/tools/faqs/faq.cfm?id=74\&t=11, accessed November 11, 2016. 


\subsection{Storage and Demand-side Technologies}

\subsubsection{Storage}

ReEDS includes three utility-scale energy storage options: PHS, batteries, and CAES. All three storage options are capable of load shifting (arbitrage), providing planning and operating reserves, and reducing curtailment of VRE. Load shifting can be done only within a season's representative day, and it is accomplished by charging the reservoir during inexpensive timeslices and discharging at peak times. The nameplate capacity of storage is assumed to contribute to planning reserves, and capacity not otherwise committed can be utilized as spinning or nonspinning reserves. For the latter, CAES can only contribute as quick-start (non-spinning) reserves (see Section 7 on how reserves are differentiated in ReEDS), whereas PHS and batteries can contribute to both spinning and non-spinning reserves.

The ReEDS framework also allows for thermal energy storage. This technology represented as chilled water and ice storage units in buildings, where cold water or ice is produced during cooler hours when loads are lower in the summer and used to replace or supplement the air conditioning during the warmer hours. Only units for commercial buildings are considered. A supply curve for thermal energy storage units was developed at the NERC subregions level. The model restricts the use of thermal energy storage devices by the regional cooling load profile. In particular, the power delivered by a thermal energy storage device is assumed to be available only during times of high cooling load (e.g., summer afternoons). Thermal energy storage technologies can contribute to operating and planning reserves and reduce curtailment.

Although storage is neither directly linked nor co-located with renewable energy technologies in ReEDS, it can play an important role in reducing curtailed electricity from variable generation resources. The contribution of storage in reducing curtailment is calibrated using the REFlex model (Denholm et al. 2010). The curtailment calculation in ReEDS takes into account the finite energy storage assumed ( 7.2 hours for batteries, 8 hours for PHS, and 15 hours for CAES reservoirs).

Existing PHS totals $22.2 \mathrm{GW}$, and ReEDS includes the existing 100-MW CAES facility in Alabama. New PHS and CAES are location-restricted due to hydrology and topography (for PHS) and geology (for CAES). In contrast, utility-scale batteries are not restricted to any subset of regions. New PHS potential is derived from FERC license applications since $1980^{24}$ with an additional $750 \mathrm{MW}$ of high-cost "artificial" resource placed in each region to prevent overconstraining PHS expansion in regions without FERC applications while remaining consistent across all regions. In total, there is 108.7 GW FERC-based PHS resource and $100.5 \mathrm{GW}$ artificial PHS resource in ReEDS. FERC-based PHS capital costs are based on O'Connor et al. (2015), and artificial capacity is assumed to be $\$ 3,500 / \mathrm{kW},{ }^{25}$ which is near the upper bound of greenfield PHS resource sized at $750 \mathrm{MW}$ (Figure 17). PHS fixed OM costs are also based on O'Connor et al. 2015, and round-trip efficiency is assumed to be $80 \%$ for all existing and new capacity. CAES site development costs are estimated based on the underground geology, where domal salt is the least costly resource at $\$ 990 / \mathrm{kW}(22.6 \mathrm{GW}$ available), bedded salt is the next most

\footnotetext{
${ }^{24}$ See "Preliminary Permits," FERC, updated October 11, 2016, http://www.ferc.gov/industries/hydropower/geninfo/licensing/pre-permits.asp.

${ }^{25}$ In $2015 \$$
} 
costly resource at $\$ 1,160 / \mathrm{kW}(37.0 \mathrm{GW})$, and aquifers (porous rock) are the most costly resource at $\$ 1,330 / \mathrm{kW}(61.6 \mathrm{GW})$ (Black \& Veatch 2012). ${ }^{26}$ CAES requires a natural gas fuel input when supplying power output, and its heat rate is assumed to be 4.91 MMBTU/MWh. This additional fuel input (to the electrical power input during compression) results in a round-trip efficiency of $125 \%$.

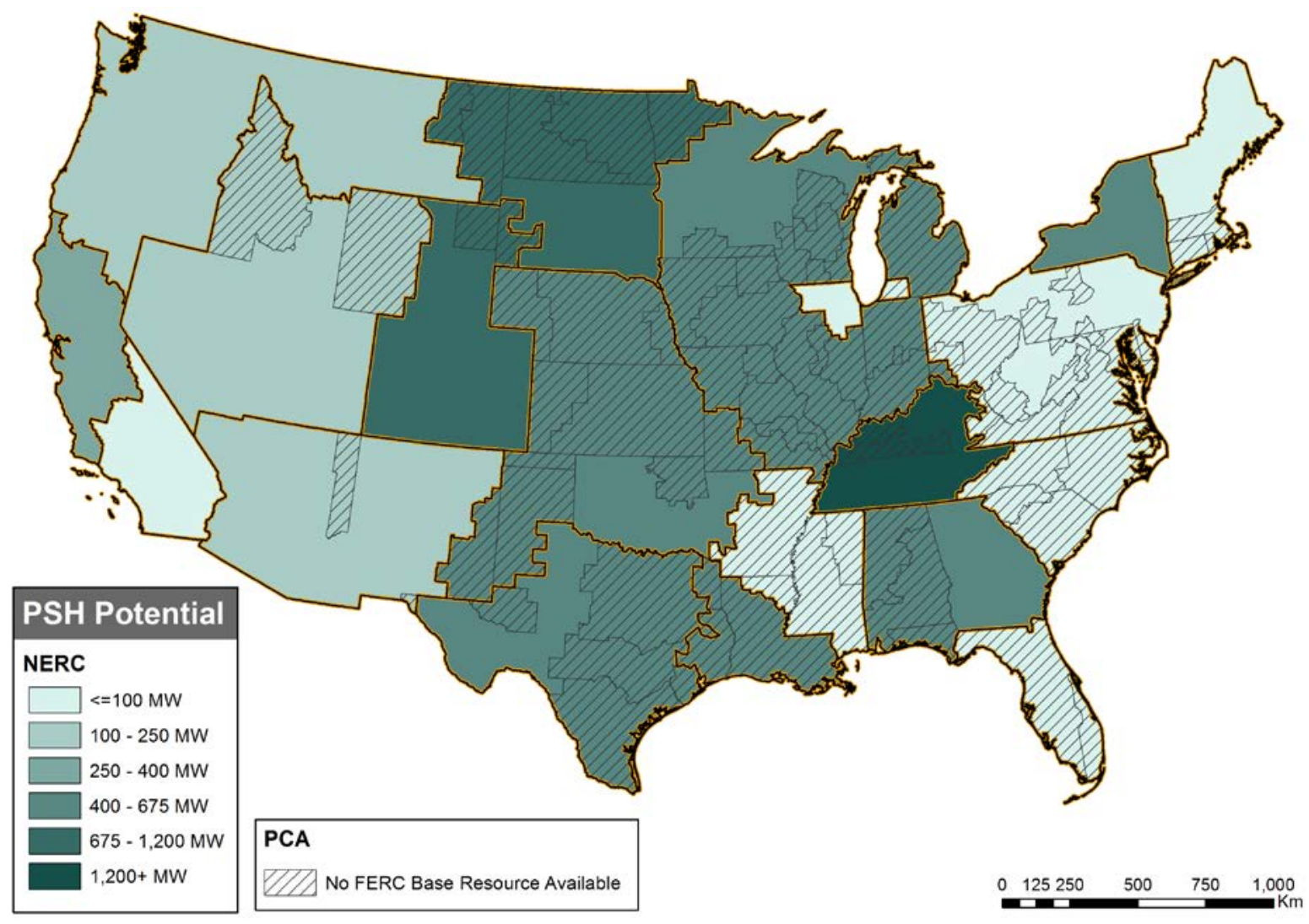

Figure 16. Modeled new PHS resource potential (DOE 2016b)

${ }^{26}$ Values in $2015 \$$ 


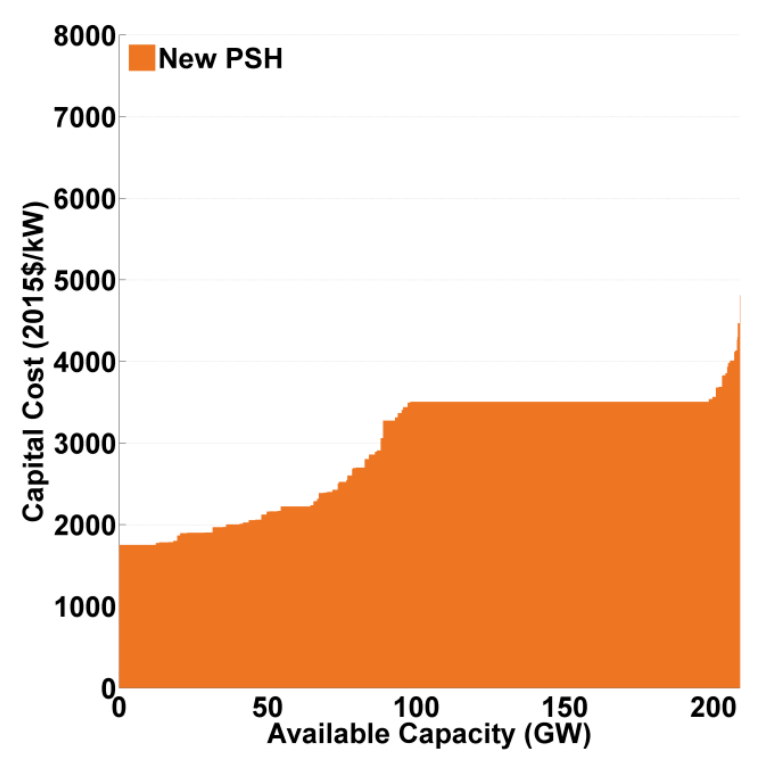

Figure 17. National PHS supply curve of capital cost versus cumulative capacity potential

Battery cost and performance assumptions are based on a 12-MW, 7.2-hour, sodium-sulfur (NaS) flow battery described in the Electric Power Research Institute and U.S. Department of Energy's Electricity Storage Handbook (Akhil et al. 2013). In contrast to all other generator technologies in ReEDS, which outlast the 20-year evaluation window of the model, the battery is assumed to last 15 years. As a result, its capital cost is uprated by 1.15 to account for the equipment lifetime shortfall. The 1.15 uprate is based on a cash-flow calculation using the default ReEDS financing assumptions. The base (15-year) overnight capital cost starts at $\$ 3425 / \mathrm{kW}$ in 2010 and declines at $0.5 \%$ per year. Round trip efficiency is taken to be $75 \%$ (Akhil et al. 2013).

\subsubsection{Interruptible Load}

Interruptible load represents the load that utilities can control under conditions set forth by contracts between the utility and a demand entity. In ReEDS, interruptible load can only be used to satisfy operating reserve requirements and counted toward contingency and forecast-error reserve requirements; interruptible load is not counted toward frequency regulation reserve requirements. Due to the coarse time-slices of ReEDS, the frequency with which interruptible load (and any other reserve services) is called upon is unknown.

Interruptible load is represented by supply curves, as shown in Table 7. Variations in availability of interruptible load for a given year reflect the ranges between NERC subregions. In addition, for each NERC subregion, a supply curve is developed to represent the range in costs. For example, in 2030 the first megawatt costs $\$ 3.36 / \mathrm{kW}$ in the NERC subregion with the most abundant interruptible load resource (i.e., $17 \%$ of peak demand), whereas the last megawatt of available interruptible load costs over 10 times as much. The interruptible supply curves are based on a resource assessment by (FERC 2009) and cost data from EIA (2009). 
Table 7. Supply Curve for Interruptible Load

\begin{tabular}{lll}
\hline Year & $\begin{array}{l}\text { Costs } \\
\text { (\$/kW per year) }\end{array}$ & $\begin{array}{l}\text { Availability } \\
\text { (\% of Peak Demand) }\end{array}$ \\
\hline 2010 & $\$ 3.36-\$ 37.10$ & $1 \%-8 \%$ \\
2020 & $\$ 3.36-\$ 37.10$ & $11 \%-17 \%$ \\
2030 & $\$ 3.36-\$ 37.10$ & $11 \%-17 \%$ \\
2040 & $\$ 3.36-\$ 37.10$ & $16 \%-24 \%$ \\
2050 & $\$ 3.36-\$ 37.10$ & $16 \%-24 \%$ \\
\hline
\end{tabular}

\subsubsection{Demand Response}

Demand response allows shifting of electricity use during hours with high electricity prices or critical load hours with respect to reliability. In addition to load shifting, demand response can provide spinning reserves and "quick-start" for contingency reserves and frequency regulation. Demand response cost and availability are implemented exogenously, but this feature is typically not used in ReEDS scenarios.

\subsubsection{Plug-in Electric Vehicles}

Because ReEDS does not include vehicle choice or transportation sector modeling, the deployment of plug-in electric vehicles or plug-in hybrid electric vehicles (and their associated charging infrastructure) is input into ReEDS. ${ }^{27}$ The number of plug-in vehicles is simply translated in the model into additional annual demand for electricity. This annual demand can be met through a fixed charging profile over the 17 time-slices within a year in ReEDS, through an endogenously determined dynamic profile, or through some combination of the two. The endogenous profile allows for time-of-day flexibility within seasons but does not allow for load shifting across seasons. Ultimately, this profile is driven by the net load and is determined simultaneously with investment and operation of dispatchable and non-dispatchable resources within each time-slice of ReEDS.

In addition to not modeling vehicle deployment, the ReEDS model does not consider vehicle-togrid or reserve services from vehicles. Plug-in vehicles cannot be used to meet the planning reserve requirements, and, in fact, can increase the reserve requirements through increasing peak demand. Likewise, these vehicles cannot contribute to meeting operating reserve requirements. However, dynamically charged plug-in vehicles are allowed one operational benefit in ReEDSadjusting load to better match generation profiles.

\subsubsection{Energy Efficiency}

Energy efficiency investment decisions are not modeled endogenously, although, past efforts have used exogenously specified trajectories (Bird et al. 2011).

\footnotetext{
${ }^{27}$ For details and an example of how transportation electrification can be represented in ReEDS, see Appendix K of (NREL 2012).
} 


\subsection{Capital Stock}

\subsubsection{Retirements}

Renewable energy generator retirements are based on assumed lifetimes. Once a generator has reached its lifetime, it is retired. Renewable energy lifetime assumptions are shown in Table 8. When a renewable energy plant is retired, the resource associated with that plant is made available and ReEDS can choose to rebuild a renewable energy generator using the newly available resource.

Table 8. Lifetimes of Renewable Energy Generators

\begin{tabular}{lcl}
\hline Technology & $\begin{array}{c}\text { Lifetime } \\
\text { (Years) }\end{array}$ & Source \\
\hline Land-based Wind & 24 & Wind Vision (DOE 2015) \\
Offshore Wind & 24 & Wind Vision (DOE 2015) \\
Solar Photovoltaic & 30 & SunShot Vision (DOE 2012) \\
Concentrating Solar Power & 30 & SunShot Vision (DOE 2012) \\
Geothermal & 30 & Renewable Electricity Futures Study, Vol. 1 (Mai et al. \\
Hydropower & 100 & 2012) \\
Biopower & 45 & Tydropower Vision (DOE 2016b) \\
Marine Hydrokinetic & 20 & Previsic et al. (2012) \\
\hline
\end{tabular}

Conventional generation retirements in ReEDS are primarily a function of plant age and assumed lifetimes. Retirement year of generating units are taken from the ABB Velocity Suite database that seeds ReEDS (ABB 2016). In general, coal plants that are smaller than a 100-MW nameplate are retired after 65 years; coal plants that are larger than a 100-MW nameplate-and all ultrasupercritical facilities-are retired after 75 years. Natural gas- and oil-fired units typically have a 55 -year lifetime. Nuclear plants are assumed to be granted a single service life extension period, giving existing nuclear plants a 60-year life. No refurbishment costs or increased O\&M costs are applied to extend the nuclear or fossil plant life. Plant lifetime retirements are overwritten if an official plant retirement date occurs before the lifetime retirement date.

In addition to age-based retirements, additional long-term retirements can occur based on plant utilization. Modeled utilization-based coal retirements represent a proxy for economic-based considerations and accelerate coal retirements. This utilization-based retirement is implemented by comparing each BA's coal fleet capacity annual factor to a minimum utilization threshold. If the capacity factor is beneath the threshold in a given year, capacity is retired such that the remaining BA capacity, assuming the same annual production, would operate at the capacity factor threshold. The utilization-based retirement is not active until 2020 and becomes increasingly stringent over time. ${ }^{28}$ The oldest and least efficient extant units are retired preferentially in this scheme.

\footnotetext{
${ }^{28}$ The capacity factor threshold starts at 0.01 in 2020 , increases linearly to 0.50 in 2040 , and stays at that value until 2050.
} 
While all generator types retire at the end of their defined equipment lifetimes, the site-specific technologies that have resource supply curves (wind, solar, geothermal) require some special consideration. ReEDS assumes the transmission interconnection equipment remains operational beyond the defined lifetime of the renewable generators. A consequence of this is that retired renewable capacity can be replaced without incurring interconnection costs and, with all other considerations being equal, re-powered or re-built renewable capacity has lower cost than new "green-field" capacity of the same type.

\subsubsection{New Growth}

The construction and operation of new renewable energy units is a model decision. However, any plants that are listed as under construction or in testing phases in the unit database that seeds ReEDS (ABB 2016) become prescribed builds. In other words, ReEDS is forced to build any under-construction units, with the units coming online in the anticipated online year listed in the database.

We impose penalties on (1) component costs for all technologies based on excessive national growth and (2) installation costs for wind, CSP, and utility-scale PV based on excessive regional growth. ${ }^{29}$ The growth penalties are based on the installed capital cost and the increase in new construction over previous years.

Similar to EIA (1998), we use a step-wise growth penalty cost function shown in Figure 18. The rate of installations can increase by $44 \%$ of the base capacity in every model year before growth cost penalties apply. The base capacity is defined as the maximum of (1) $90 \%$ of the previous base, (2) the minimum base, and (3) installations and upgrades from the previous model year. Table 9 summarizes the minimum base values used.

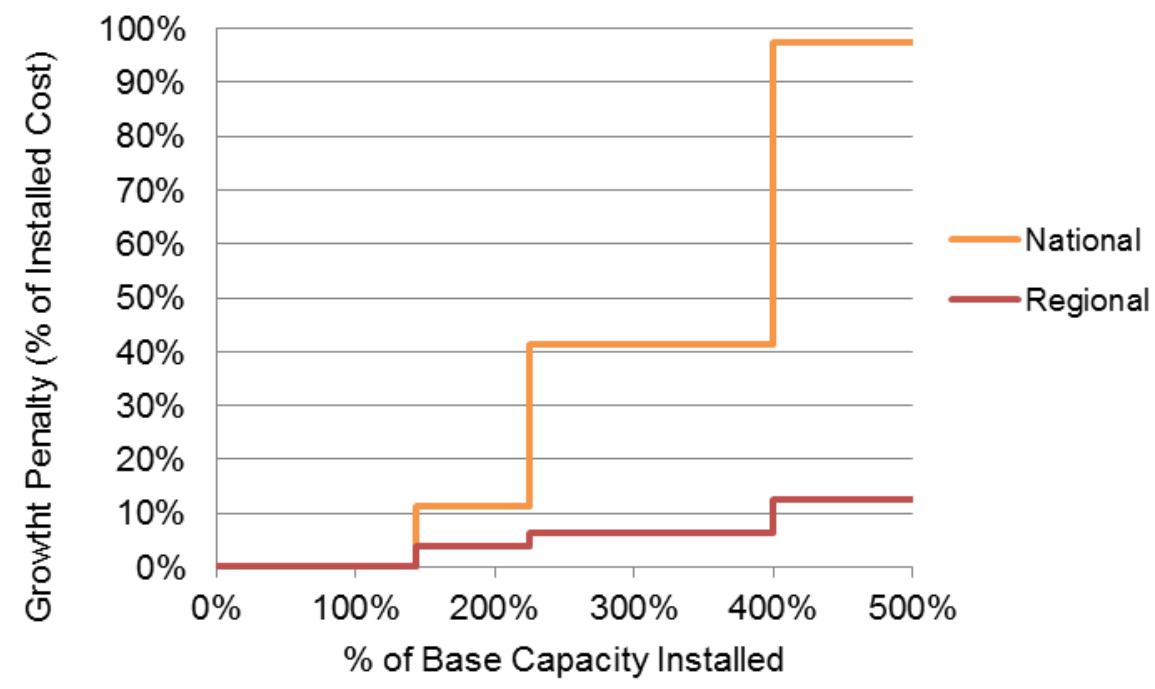

Figure 18. National and regional growth penalty cost curve

\footnotetext{
${ }^{29}$ For wind, CSP, and UPV, we assume the breakdown of total cost is $75 \%$ for components and $25 \%$ for installation.
} 
Table 9. Minimum Base Values for Assessing Excessive Growth

\begin{tabular}{|c|c|c|c|}
\hline Technology & Region & Minimu & Im Base (MW) \\
\hline \multirow[t]{4}{*}{ Conventional $^{\mathrm{a}}$} & National & 400: & Geothermal \\
\hline & & 500: & $\begin{array}{l}\text { Natural gas combustion turbine, } \\
\text { natural gas combined cycle with } \\
\text { CCS, coal with CCS, and marine } \\
\text { hydrokinetic }\end{array}$ \\
\hline & & 1,000: & $\begin{array}{l}\text { natural gas combined cycle, } \\
\text { hydro, biopower }\end{array}$ \\
\hline & & $2,000:$ & Nuclear \\
\hline \multirow[t]{2}{*}{ Wind } & National & $1,000^{b}$ & \\
\hline & Resource region & $200^{c}$ & \\
\hline \multirow[t]{2}{*}{ CSP } & National & $1,000^{d}$ & \\
\hline & Resource region & $200^{\mathrm{e}}$ & \\
\hline \multirow[t]{2}{*}{ Utility-scale PV } & National & $1,000^{d}$ & \\
\hline & $\mathrm{BA}$ & $600^{f}$ & \\
\hline
\end{tabular}

${ }^{a}$ Minimum base for conventional plants based on the approximate size of a new plant

${ }^{b}$ Roughly based on the average of annual wind installations in the United States from 1999 to 2005

${ }^{c}$ Assuming one wind farm built in a single wind resource region is about $200 \mathrm{MW}$

${ }^{d}$ Using the same value as wind

${ }^{e}$ Assuming one CSP system built in a single CSP resource region is about $200 \mathrm{MW}$

${ }^{\mathrm{f}}$ Assuming three PV systems, about $200 \mathrm{MW}$ each, built in a single BA

\subsection{Regional Parameter Variations and Adjustments}

For most generation technologies, regional cost multipliers are applied to reflect variations in installation costs across the United States (see Figure 19). These regional multipliers are applied to the base overnight capital cost of the associated technology presented in earlier sections. The regional multipliers are technology-specific and are usually derived from the EIA/SAIC report (EIA 2013a) that is the source of capital cost assumptions for the NEMS model. While the regional costs presented in the EIA/SAIC report are based on particular cities, the regional multipliers for ReEDS are calculated by interpolating between these cities and using the average value over the ReEDS regions for each technology. The multipliers are technology-specific and are applied to the base capital cost of each technology within ReEDS. 


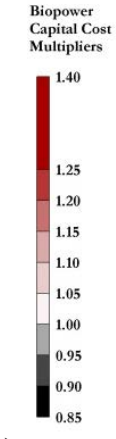

(a)

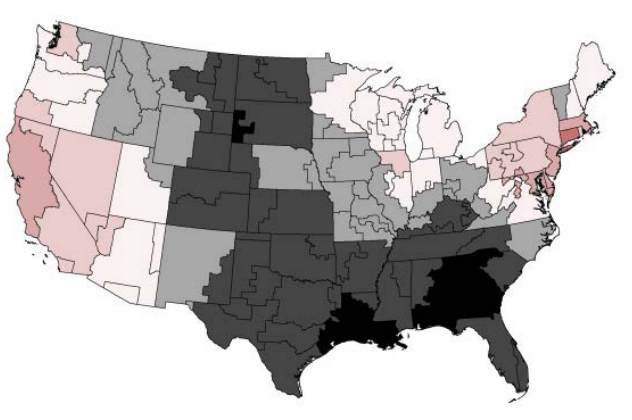

(b)
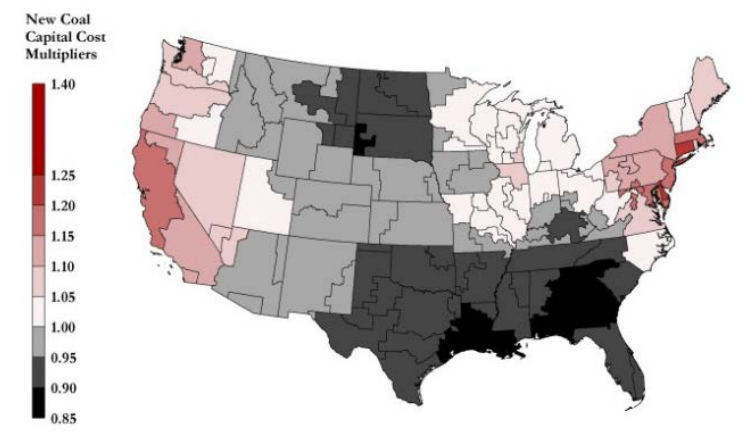

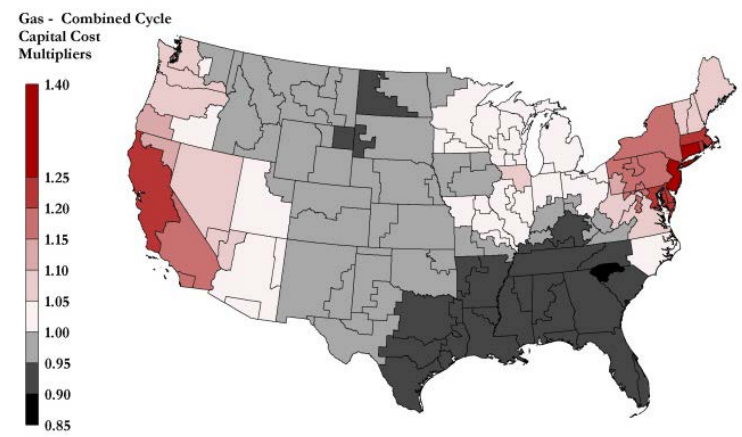

(c)

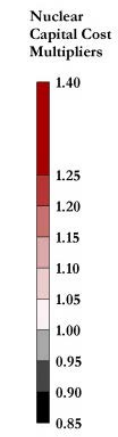

(e)

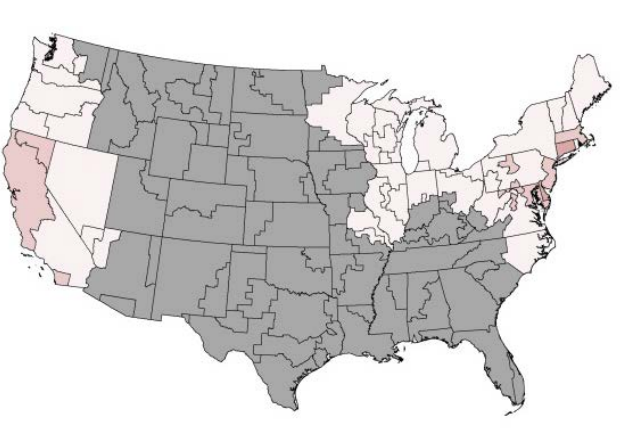

(f)

(d)
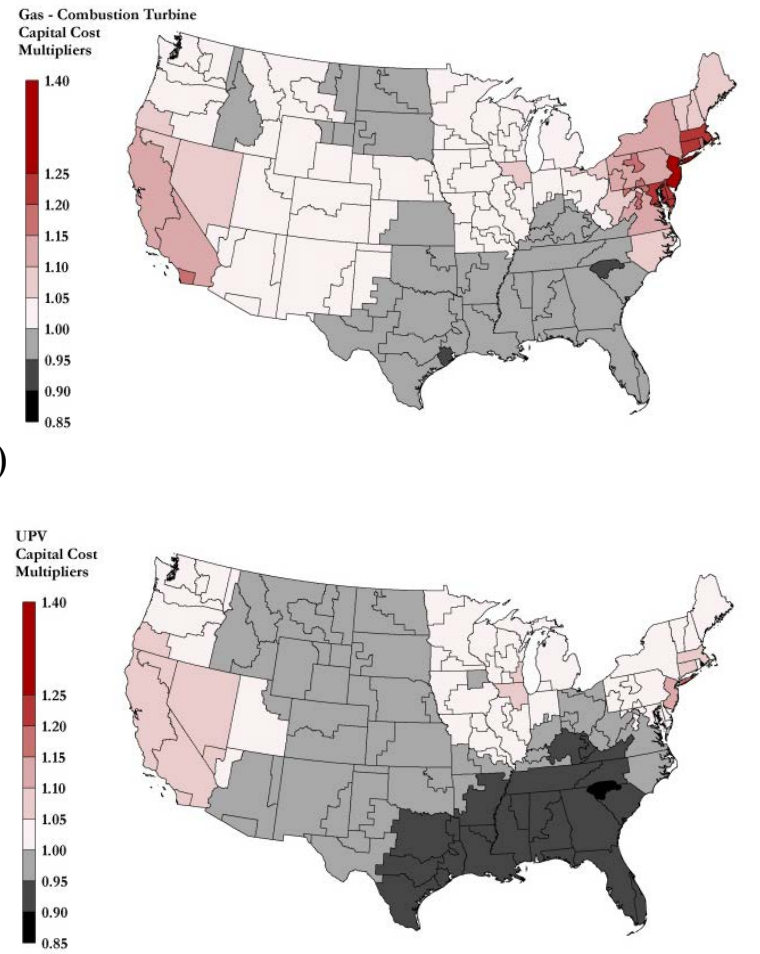

)
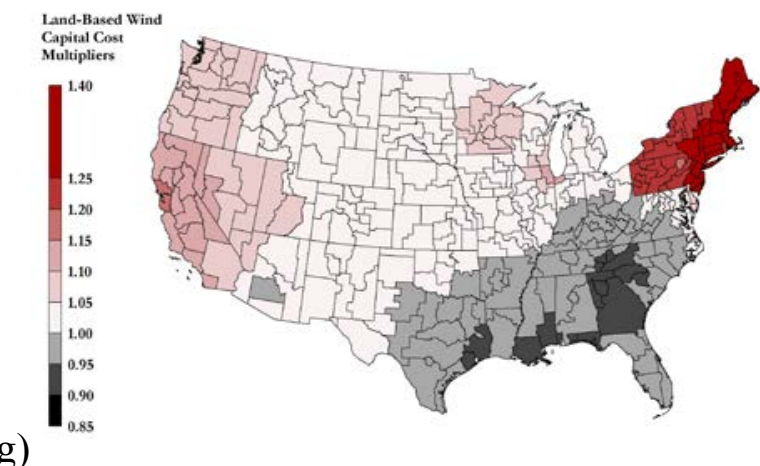

(g)

Figure 19. Maps of regional capital cost multipliers for the various technology types

Regions shown in white in (h) do not apply to offshore wind. 


\section{Fuel Prices}

Natural gas, coal, and uranium prices in ReEDS are based on AEO 2016 scenarios (EIA 2016). Default prices are based on the AEO 2016 Reference scenario. Because AEO 2016 extends only to 2040 , ReEDS fuel prices are assumed to be constant between 2040 and $2050 .{ }^{30}$ Coal prices include regional price multipliers for each of the nine EIA census divisions. Low and high natural gas price alternatives are taken from the AEO 2016 Low and High Oil and Gas Resource and Technology scenarios. Low and high coal price alternatives are derived from the AEO 2014 Low and High Coal Price scenarios ${ }^{31}$ by increasing or decreasing the AEO 2016 Reference scenario coal prices according to the same ratio as was exhibited in the AEO 2014 coal price trajectories. ReEDS includes only a single uranium price trajectory. Base fuel price trajectories are shown in Figure 20. Biomass fuel prices are represented using supply curves with five bins in each region. The costs and resource availability are based on the U.S. Billion-Ton Update study (DOE 2011). Biomass costs range from \$1.91/MMBtu to \$18.33/MMBtu (in 2014\$).
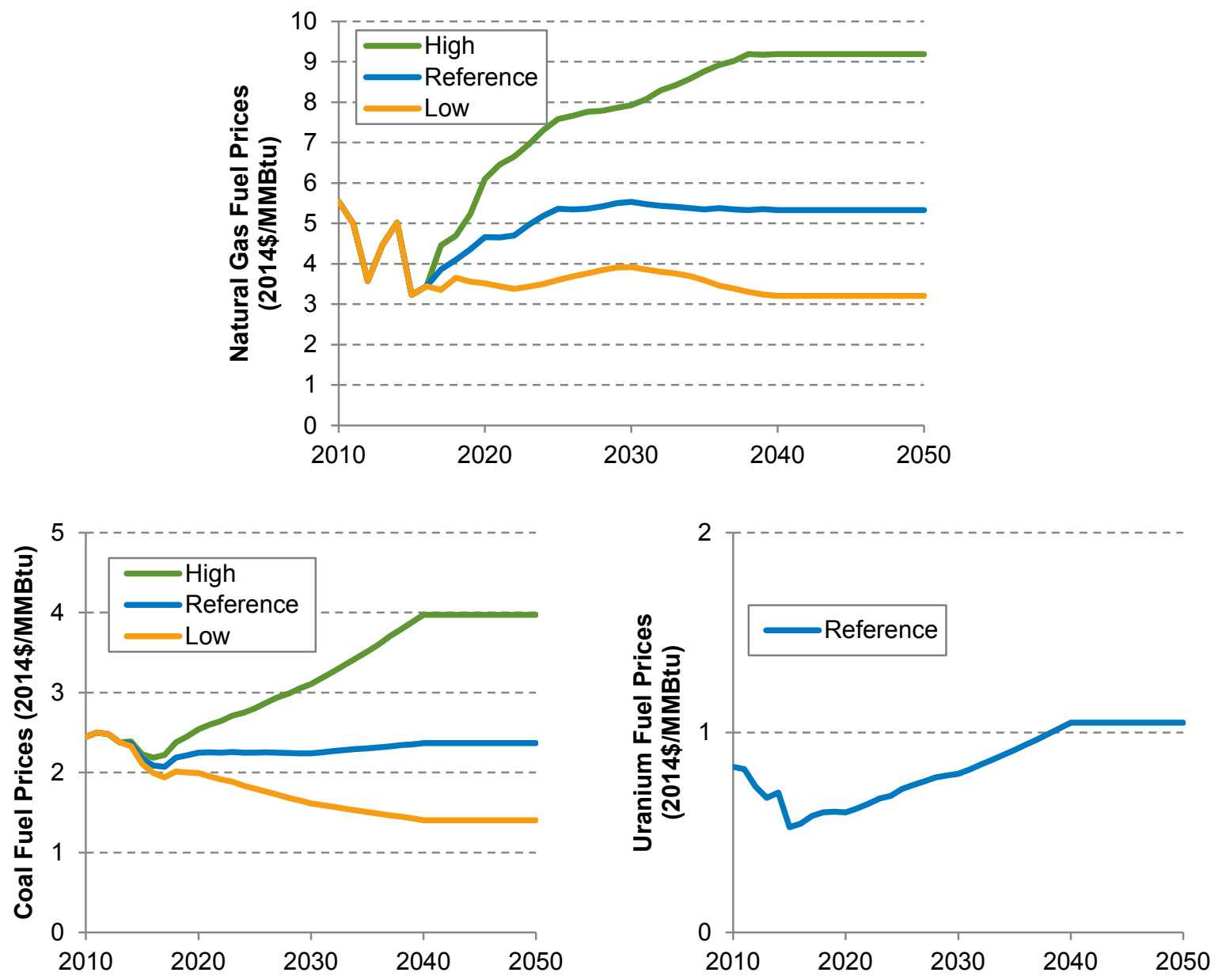

Figure 20. Fuel price assumptions

\footnotetext{
${ }^{30}$ Base natural gas prices are assumed constant during this period, but the prices estimated in ReEDS will vary by year with quantity.

31 The AEO 2014 was the last time the low and high coal price scenarios were published.
} 
Coal and uranium are assumed to be perfectly inelastic; the price is pre-determined and insensitive to the ReEDS demand for the fuel. With natural gas, however, the price and demand are linked. Actual natural gas prices in ReEDS are based on the AEO scenario prices but are not exactly the same; instead, they are price-responsive to ReEDS natural gas demand. In each year, each census division is characterized by a price-demand "set point" taken from the AEO Reference scenario but also by two elasticity coefficients, namely regional $\left(\beta_{\mathrm{r}}\right)$ and national $\left(\beta_{\mathrm{n}}\right)$ elasticity coefficients for the rate of regional price change with respect to (1) the change in the regional gas demand from its set-point and (2) the overall change in the national gas demand from the national price-demand set point respectively. The set of regional and national elasticity coefficients are developed through a regression analysis across an ensemble of AEO scenarios ${ }^{32}$ to estimate changes in fuel prices driven solely by electric sector natural gas demand (as described in Logan et al. (2013) and Cole, Medlock III, and Jani (2016), though the coefficients have since been updated). The regional supply curves reflect natural gas resource, infrastructure, and non-electric sector demand assumptions embedded within the AEO modeling. For details, see the section in the appendix titled, "Natural Gas Supply Curves."

In addition to the natural gas supply curve representation, ReEDS includes targeted fuel price foresight for new natural gas capacity investments. Specifically, the effective investment cost for new natural gas combined cycle capacity includes an extra term representing the present value of the difference between flat natural gas prices and expected future natural gas prices.

Finally, the natural gas fuel prices include a seasonal price adjustor, making winter prices higher than the natural gas prices seen during the other seasons of the year. For details, see the section in the appendix titled, "Seasonal Natural Gas Price Adjustments."

\footnotetext{
${ }^{32}$ The elasticity coefficients are derived from all 31 scenarios of AEO 2014, but the price-demand set points are taken from any one single scenario of AEO 2016.
} 


\section{Thermal Cooling Water}

In addition to representing a full suite of power generation technologies, ReEDS further differentiates power technologies by cooling system type in order to better characterize and constrain electric sector water requirements. The cooling system impacts the cost and performance of the thermal generators, and water withdrawal and consumption rates are used in conjunction with water availability and cost to appropriately constrain and track the water requirements of new capacity expansion. The ReEDS cooling water formulation is discussed in Macknick et al. (2015), which forms the basis of this section.

\subsection{Cooling System Characteristics}

Cooling systems implemented in the ReEDS model fall into one of four categories: oncethrough, pond, recirculating, and dry cooling systems. Individual power plant cooling systems are derived from a database developed by the (Union of Concerned Scientists 2012). Within each ReEDS BA, existing generation capacity by power generation technology is disaggregated into power-cooling system technology categories based on 2008 generation data from the database. When the database does not contain information on cooling systems for certain fuel types within a particular BA, cooling technology is assumed using the following rules:

1. If there are other units of the same fuel type at the same plant with assigned cooling technology, assume the same cooling technology.

2. If (1) does not apply and there are other thermal units at the same plant with assigned cooling technology, assume the same cooling technology.

3. If neither (1) nor (2) apply, and no additional information is available, assume recirculating cooling.

Table 10 lists the allowable power-cooling technology combinations under the current cooling technology representation. Allowed combinations must be consistent with the existing fleet and also reflect allowed cooling technologies for new builds. New builds are not permitted to use once-through cooling due to pending U.S. Environmental Protection Agency (EPA) regulations and industry trends, so technologies that do not exist using once-through cooling (e.g., CCS technologies) are not allowed to use once-through cooling. In addition, new capacity may not use cooling ponds because designs are too site-specific for a reasonable general model representation. Only existing pond cooling facilities are characterized. Dry cooling is not allowed for nuclear or CCS due to their exceptionally large cooling requirements. 
Table 10. Allowed Power and Cooling Technology Combinations in ReEDS

\begin{tabular}{|c|c|c|c|c|c|}
\hline \multirow[b]{2}{*}{ Power Technology } & \multicolumn{5}{|c|}{ Cooling Technology Allowed } \\
\hline & $\begin{array}{l}\text { Once- } \\
\text { Through }\end{array}$ & Recirculating & Dry & $\begin{array}{l}\text { Cooling } \\
\text { Pond }\end{array}$ & None \\
\hline Hydropower & No & No & No & No & Yes \\
\hline Gas-CT & No & No & No & No & Yes \\
\hline Gas-CC & Yes & Yes & Yes & Yes & No \\
\hline Gas-CC-CCS & No & Yes & Yes & No & No \\
\hline $\begin{array}{l}\text { Pulverized coal } \\
\text { with scrubbers } \\
\text { (pre-1995) }\end{array}$ & Yes & Yes & Yes & Yes & No \\
\hline $\begin{array}{l}\text { Pulverized coal } \\
\text { without scrubbers }\end{array}$ & Yes & Yes & Yes & Yes & No \\
\hline $\begin{array}{l}\text { Pulverized coal } \\
\text { with scrubbers (post- } \\
\text { 1995) }\end{array}$ & Yes & Yes & Yes & Yes & No \\
\hline IGCC coal & Yes & Yes & Yes & Yes & No \\
\hline Coal-CCS & Yes & Yes & No & No & No \\
\hline Oil/gas steam & Yes & Yes & Yes & Yes & No \\
\hline Nuclear & Yes & Yes & No & Yes & No \\
\hline Geothermal & No & No & No & No & Yes \\
\hline Biopower & Yes & Yes & Yes & Yes & No \\
\hline $\begin{array}{l}\text { Cofired coal } \\
\text { (pre-1995) }\end{array}$ & Yes & Yes & Yes & Yes & No \\
\hline $\begin{array}{l}\text { Cofired coal } \\
\text { (post-1995) }\end{array}$ & Yes & Yes & Yes & Yes & No \\
\hline Landfill gas & No & No & No & No & Yes \\
\hline PV & No & No & No & No & Yes \\
\hline Wind & No & No & No & No & Yes \\
\hline CSP & No & Yes & Yes & No & No \\
\hline
\end{tabular}


The cooling system affects capital and O\&M costs through cost multipliers, and performance effects are implemented using heat rate multipliers. Cost and performance characteristics are derived from Woldeyesus, Macknick, and Colman (forthcoming), and baseline input data to ReEDS assume recirculating cooling (Black \& Veatch 2012). In general, once-through cooling systems are the least expensive and have the highest efficiencies. Recirculating cooling systems generally have higher capital and operating costs and are less efficient than once-through cooling systems, but they are less expensive and more efficient than dry cooling systems. Pond-cooled systems have various configurations that can resemble either recirculating or once-through cooling systems; thus, they generally have characteristics that fall between those of recirculating and once-through systems. Table 11- Table 15 summarize the cooling technology parameterization by generation technology type.

Table 11. Capital Cost Multipliers for Power-Cooling Technology Combinations

\begin{tabular}{lllll}
\hline & $\begin{array}{l}\text { Once- } \\
\text { Through }\end{array}$ & Recirculating & Dry & $\begin{array}{l}\text { Cooling } \\
\text { Pond }\end{array}$ \\
\hline Gas-CC & 0.978 & 1.000 & 1.102 & 0.978 \\
Gas-CC-CCS & $\mathrm{n} / \mathrm{a}$ & 1.000 & $\mathrm{n} / \mathrm{a}$ & $\mathrm{n} / \mathrm{a}$ \\
Pulverized coal with scrubbers (pre-1995) & 0.981 & 1.000 & 1.045 & 0.981 \\
Pulverized coal without scrubbers & 0.981 & 1.000 & 1.045 & 0.981 \\
Pulverized coal with scrubbers & 0.981 & 1.000 & 1.045 & 0.981 \\
(post-1995) & 0.988 & 1.000 & 1.033 & 0.988 \\
IGCC coal & 0.982 & 1.000 & $\mathrm{n} / \mathrm{a}$ & $\mathrm{n} / \mathrm{a}$ \\
Coal-CCS & 0.981 & 1.000 & 1.045 & 0.981 \\
Oil/gas steam & 0.981 & 1.000 & $\mathrm{n} / \mathrm{a}$ & 0.981 \\
Nuclear & 0.981 & 1.000 & 1.045 & 0.981 \\
Biopower & 0.981 & 1.000 & 1.045 & 0.981 \\
Cofired coal (pre-1995) & 0.981 & 1.000 & 1.045 & 0.981 \\
Cofired coal (post-1995) & $\mathrm{n} / \mathrm{a}$ & 1.000 & 1.050 & $\mathrm{n} / \mathrm{a}$ \\
\hline CSP & & &
\end{tabular}


Table 12. Operations and Maintenance Cost Multipliers for Power-Cooling Technology Combinations

\begin{tabular}{lllll}
\hline & $\begin{array}{l}\text { Once- } \\
\text { Through }\end{array}$ & Recirculating & Dry & $\begin{array}{l}\text { Cooling } \\
\text { Pond }\end{array}$ \\
\hline Gas-CC & 0.996 & 1.000 & 1.021 & 0.996 \\
Gas-CC-CCS & $\mathrm{n} / \mathrm{a}$ & 1.000 & $\mathrm{n} / \mathrm{a}$ & $\mathrm{n} / \mathrm{a}$ \\
Pulverized coal with scrubbers (pre-1995) & 0.989 & 1.000 & 1.051 & 0.989 \\
Pulverized coal without scrubbers & 0.989 & 1.000 & 1.051 & 0.989 \\
Pulverized coal without scrubbers (post-1995) & 0.989 & 1.000 & 1.051 & 0.989 \\
IGCC coal & 0.996 & 1.000 & 1.021 & 0.996 \\
Coal-CCS & 0.993 & 1.000 & $\mathrm{n} / \mathrm{a}$ & $\mathrm{n} / \mathrm{a}$ \\
Oil/gas steam & 0.989 & 1.000 & 1.051 & 0.989 \\
Nuclear & 0.989 & 1.000 & $\mathrm{n} / \mathrm{a}$ & 0.989 \\
Biopower & 0.989 & 1.000 & 1.051 & 0.989 \\
Cofired coal (pre-1995) & 0.989 & 1.000 & 1.051 & 0.989 \\
Cofired coal (post-1995) & 0.989 & 1.000 & 1.051 & 0.989 \\
CSP & $\mathrm{n} / \mathrm{a}$ & 1.000 & 1.050 & $\mathrm{n} / \mathrm{a}$ \\
\hline
\end{tabular}

Table 13. Heat Rate Multipliers for Power-Cooling Technology Combinations

\begin{tabular}{lllll}
\hline & $\begin{array}{l}\text { Once- } \\
\text { Through }\end{array}$ & Recirculating & Dry & $\begin{array}{l}\text { Cooling } \\
\text { Pond }\end{array}$ \\
\hline Gas-CC & 0.980 & 1.000 & 1.050 & 0.980 \\
Gas-CC-CCS & $\mathrm{n} / \mathrm{a}$ & 1.000 & $\mathrm{n} / \mathrm{a}$ & $\mathrm{n} / \mathrm{a}$ \\
Pulverized coal with scrubbers (pre-1995) & 0.985 & 1.000 & 1.050 & 0.985 \\
Pulverized coal without scrubbers & 0.985 & 1.000 & 1.050 & 0.985 \\
Pulverized coal with scrubbers (post-1995) & 0.985 & 1.000 & 1.050 & 0.985 \\
IGCC Coal & 0.980 & 1.000 & 1.050 & 0.98 \\
Coal-CCS & 0.800 & 1.000 & $\mathrm{n} / \mathrm{a}$ & $\mathrm{n} / \mathrm{a}$ \\
Oil/Gas Steam & 0.985 & 1.000 & 1.050 & 0.985 \\
Nuclear & 0.973 & 1.000 & $\mathrm{n} / \mathrm{a}$ & 0.973 \\
Biopower & 0.985 & 1.000 & 1.050 & 0.985 \\
Cofired Coal (pre-1995) & 0.985 & 1.000 & 1.050 & 0.985 \\
Cofired Coal (post-1995) & 0.985 & 1.000 & 1.050 & 0.985 \\
CSP & $\mathrm{n} / \mathrm{a}$ & 1.000 & $1.000^{\mathrm{a}}$ & $\mathrm{n} / \mathrm{a}$ \\
\hline
\end{tabular}

${ }^{a}$ There are currently no data to inform a heat rate multiplier for CSP. 
Water withdrawal and consumption rates for power technology-cooling system combinations are defined in terms of volumes of water withdrawn and consumed per unit of electricity generation (i.e., gallons per MWh of electricity generated) (Macknick et al. 2012).

Table 14. Water Withdrawal Rates for Power-Cooling Technology Combinations (gal/MWh)

\begin{tabular}{lllll}
\hline & $\begin{array}{l}\text { Once- } \\
\text { Through }\end{array}$ & Recirculating & Dry & $\begin{array}{l}\text { Cooling } \\
\text { Pond }\end{array}$ \\
\hline Gas-CC & 11,380 & 255 & 2 & 5950 \\
Gas-CC-CCS & $\mathrm{n} / \mathrm{a}$ & 506 & $\mathrm{n} / \mathrm{a}$ & $\mathrm{n} / \mathrm{a}$ \\
Pulverized coal with scrubbers (pre-1995) & 36,350 & 1,005 & 0 & 12,225 \\
Pulverized coal without scrubbers & 36,350 & 1,005 & 0 & 12,225 \\
Pulverized coal with scrubbers (post-1995) & 27,088 & 587 & 0 & 17,914 \\
IGCC Coal & 18,136 & 393 & 0 & 9,635 \\
Coal-CCS & 56,483 & 1,224 & $\mathrm{n} / \mathrm{a}$ & $\mathrm{n} / \mathrm{a}$ \\
Oil/gas steam & 35,000 & 1,203 & 0 & 5,950 \\
Nuclear & 44,350 & 1,101 & $\mathrm{n} / \mathrm{a}$ & 7,050 \\
Biopower & 35,000 & 878 & 0 & 450 \\
Cofired coal (pre-1995) & 35,000 & 878 & 0 & 450 \\
Cofired coal (post-1995) & 35,000 & 878 & 0 & 450 \\
CSP trough/tower & $\mathrm{n} / \mathrm{a}$ & $906 / 786$ & $78 / 26$ & $\mathrm{n} / \mathrm{a}$ \\
\hline
\end{tabular}

Table 15. Water Consumption Rates for Power-Cooling Technology Combinations (gal/MWh)

\begin{tabular}{lllll}
\hline & $\begin{array}{l}\text { Once- } \\
\text { Through }\end{array}$ & Recirculating & Dry & $\begin{array}{l}\text { Cooling } \\
\text { Pond }\end{array}$ \\
\hline Gas-CC & 100 & 205 & 2 & 240 \\
Gas-CC-CCS & $\mathrm{n} / \mathrm{a}$ & 378 & $\mathrm{n} / \mathrm{a}$ & $\mathrm{n} / \mathrm{a}$ \\
Pulverized coal with scrubbers (pre-1995) & 250 & 687 & 0 & 545 \\
Pulverized coal without scrubbers & 250 & 687 & 0 & 545 \\
Pulverized coal with scrubbers (post-1995) & 113 & 479 & 0 & 545 \\
IGCC coal & 90 & 380 & 0 & 32 \\
Coal-CCS & 217 & 921 & $\mathrm{n} / \mathrm{a}$ & $\mathrm{n} / \mathrm{a}$ \\
Oil/gas steam & 240 & 826 & 0 & 240 \\
Nuclear & 269 & 672 & $\mathrm{n} / \mathrm{a}$ & 610 \\
Biopower & 300 & 553 & 0 & 390 \\
Cofired coal (pre-1995) & 300 & 553 & 0 & 390 \\
Cofired coal (post-1995) & 300 & 553 & 0 & 390 \\
CSP trough/tower & $\mathrm{n} / \mathrm{a}$ & $906 / 786$ & $78 / 26$ & $\mathrm{n} / \mathrm{a}$ \\
\hline
\end{tabular}


ReEDS also allows capacity to upgrade from more withdrawal-intensive cooling technologies to less withdrawal-intensive technologies. Doing so could be advantageous if the value of reducing water needs in water-constrained regions offsets any cost and performance penalty.

\subsection{Water Access Constraints}

Water availability is constrained in each BA through a requirement for new capacity to purchase sufficient water access to satisfy the withdrawal requirements of the fuel technology-cooling system combination and the size of the facility. Sufficient water access is defined as enough water for a power plant to operate at full capacity at any time throughout the year. This conservative method ensures new power plant builds have secured more than enough water than they would realistically use in a year so that they can operate at maximum output during the annual low-flow condition. The ReEDS model calculates actual water withdrawals and consumption separately from the purchases of water access based on the actual operation of the power fleet. It is important to distinguish between constraining water access, which affects capacity expansion only, and constraining operational water availability, which would influence operation. Operational water availability constraints in ReEDS are the subject of ongoing work.

Each BA has unique water access availability and cost for up to five resource categories: unappropriated freshwater, appropriated freshwater (western United States only), fresh groundwater, brackish groundwater, and wastewater. Multiple types of water resources can be purchased to meet the demand for new generation capacity. Water access availability of retiring power plants is returned to the pool of available water access for new power plants at the price of appropriated water access.

\subsection{Cooling Water Availability and Cost}

Water availability and cost are defined using supply curves developed by Tidwell, Zemlick, and Klise (2013). Resource assessment methodologies are unique to each water category as detailed in that report as well as by Macknick et al. (2015). Water access costs include capital and O\&M costs necessary to procure each water type. Where available, unappropriated freshwater is the lowest-cost resource, typically followed by fresh groundwater, appropriated freshwater, wastewater, and brackish groundwater. Many regions in the West have no unappropriated freshwater and limited fresh groundwater and appropriated freshwater, making these regions more likely to require higher-cost wastewater or brackish groundwater resources. Figure 21 shows regional water availability and cost for each type of water represented in ReEDS. 


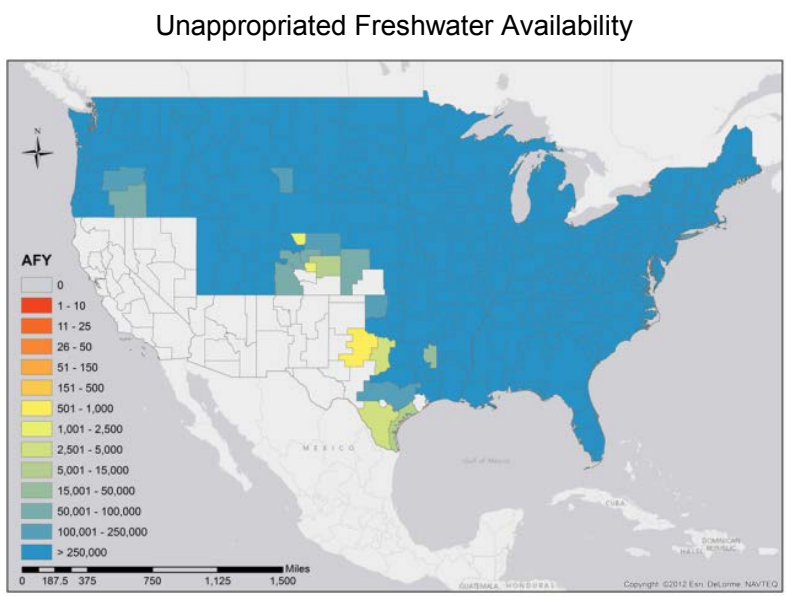

Fresh Groundwater Availability

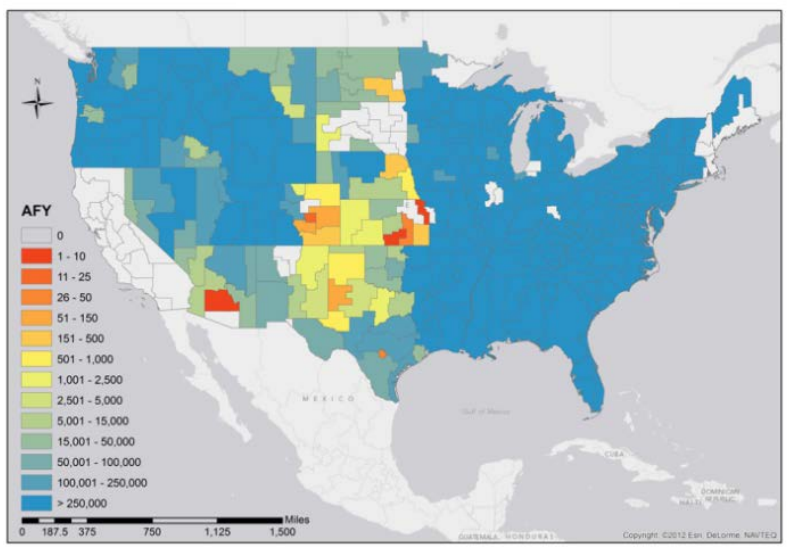

Appropriated Freshwater Availability

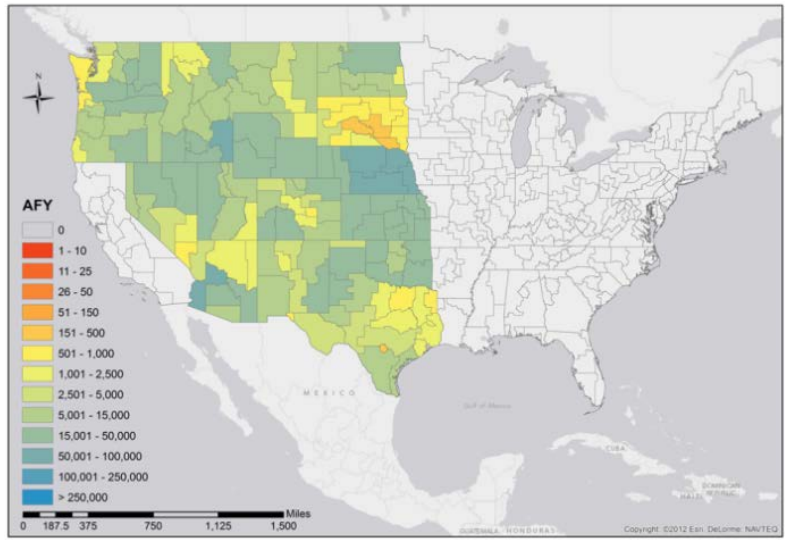

Fresh Groundwater Cost

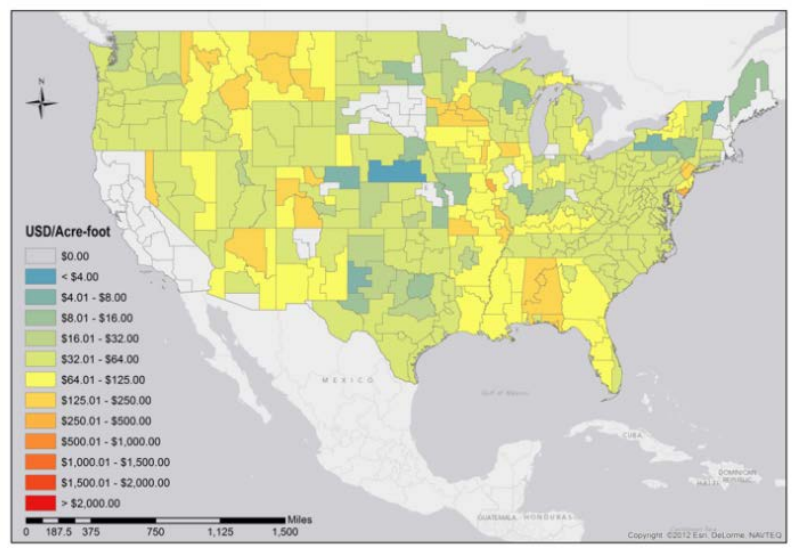

Appropriated Freshwater Cost

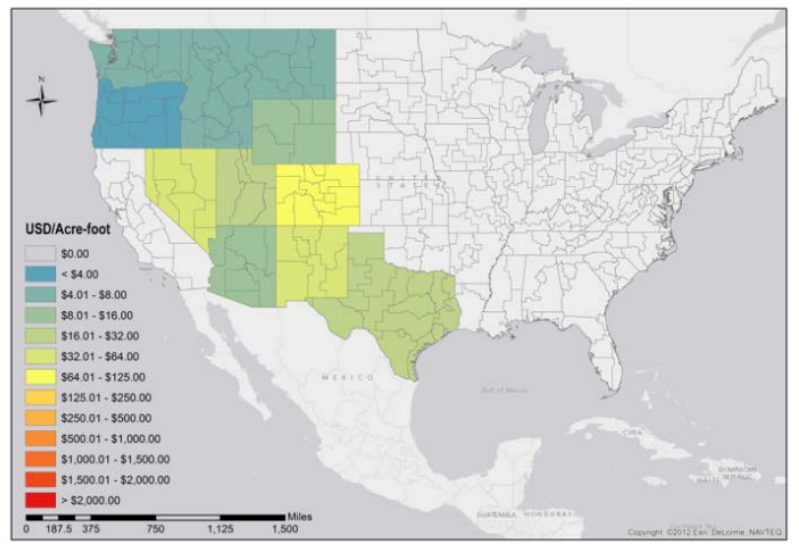

This report is available at no cost from the National Renewable Energy Laboratory (NREL) at www.nrel.gov/publications. 
Wastewater Availability

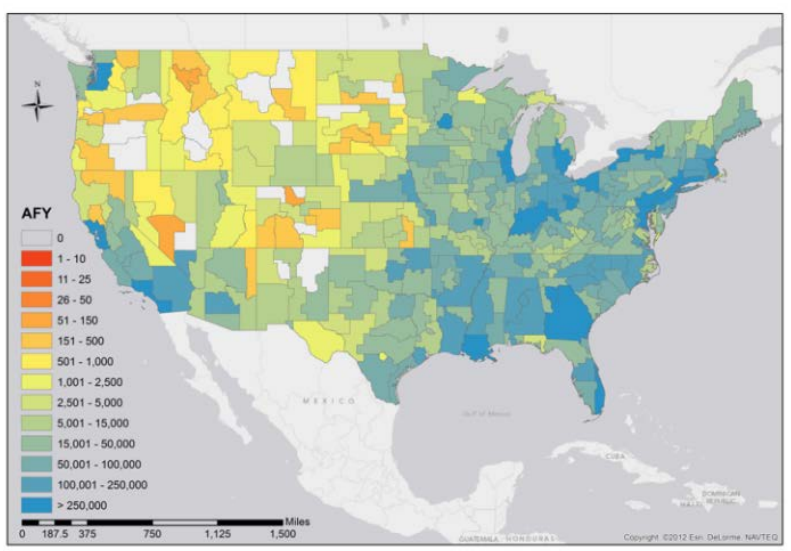

Brackish Groundwater Availability

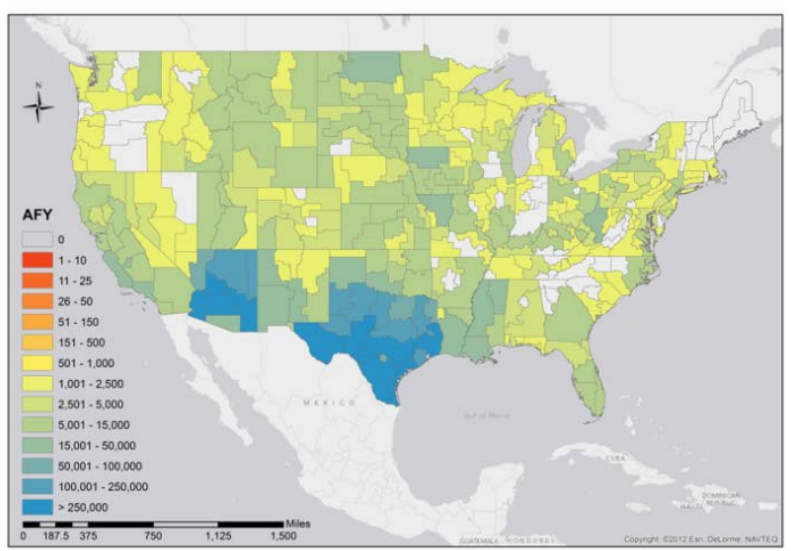

Wastewater Cost

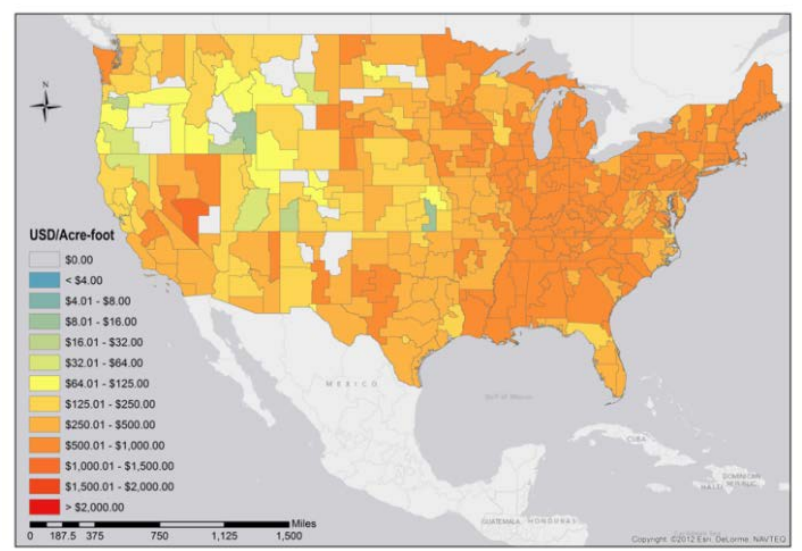

Brackish Groundwater Cost

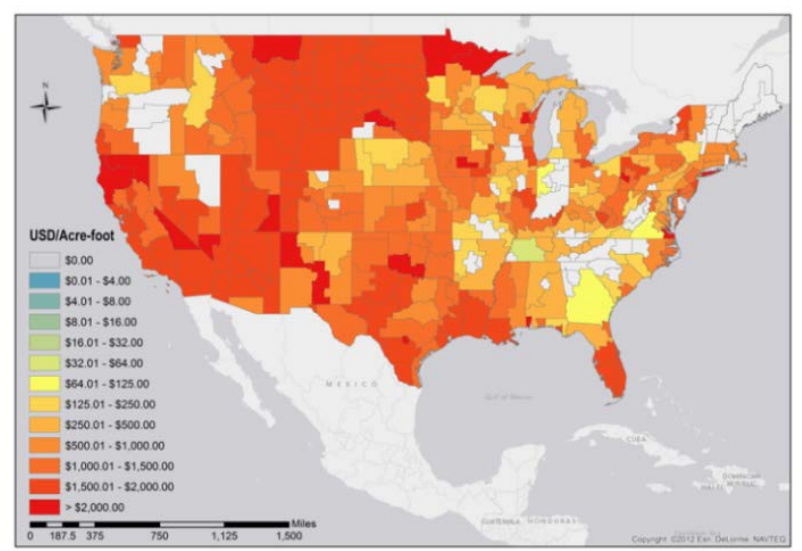

Figure 21. Water availability and cost for each water type (AFY = acre-feet per year) (Tidwell, Zemlick, and Klise 2013) 


\section{Transmission}

\subsection{Transmission System}

ReEDS uses a reduced network with 134 nodes (center-to-center of ReEDS BAs) connected by roughly 300 aggregate lines, shown in Figure 22. Each line has a nominal carrying capacity limit that is determined for the start-year (2010) based on power-flow analysis using ABB's GridView model and NERC-reported limits (NERC 2010). In later years, ReEDS is able to build additional capacity to increase these carrying capacities. Transmission expansion is limited before 2020 to lines for which new construction is already planned (EEI 2010b). After 2020, that limitation is dropped. ReEDS considers transmission flow limits when dispatching generation in each of the 17 time-slices and in contracting firm capacity for system adequacy needs.

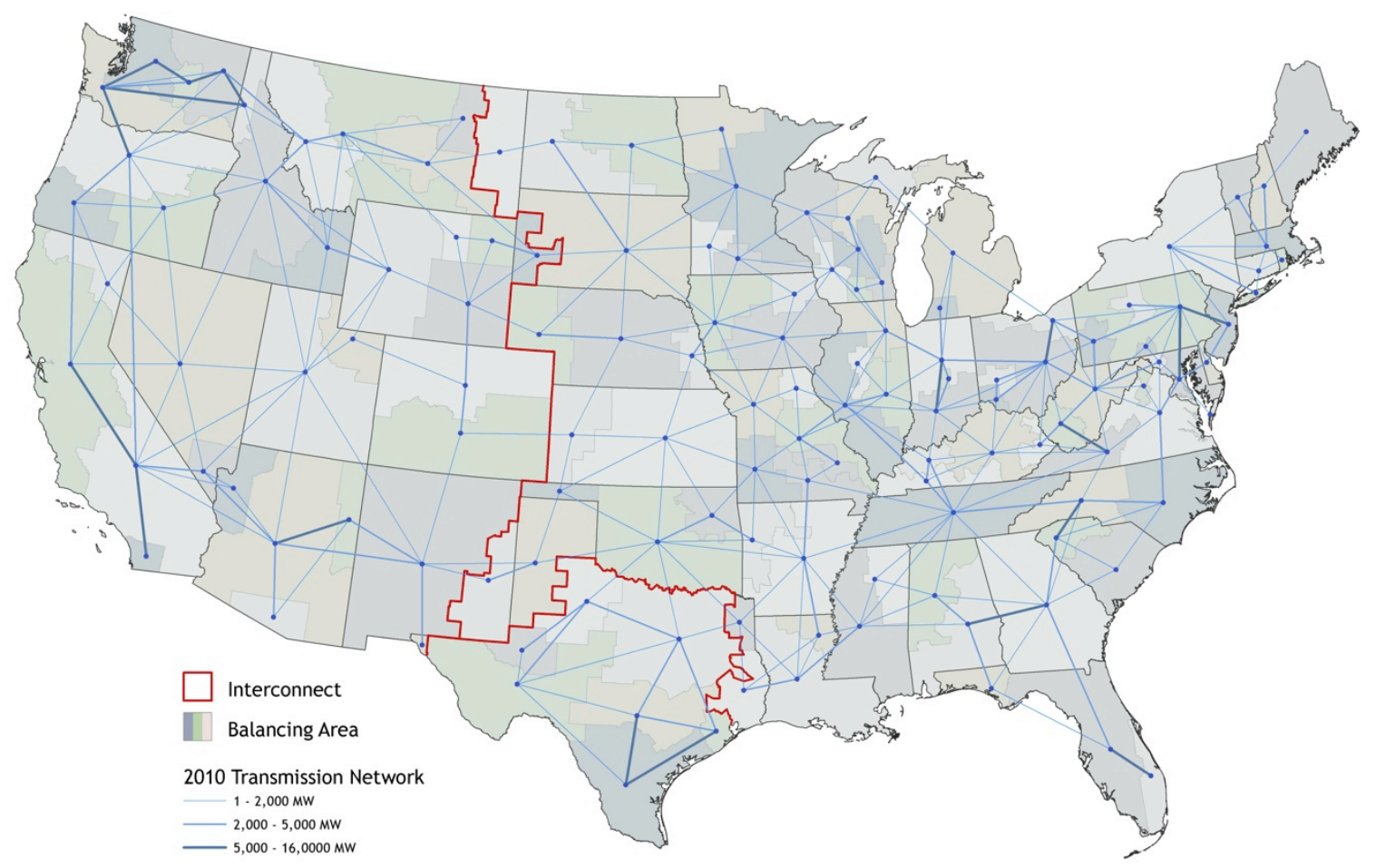

Figure 22. Existing long-distance transmission infrastructure as represented in ReEDS

Transmission network flows in ReEDS are determined by a linearized DC power-flow model (Stott, Jardim, and Alsaç 2009). The power-flow model is a linear approximation of DC power flow using effective line susceptances, ${ }^{33}$ which is approximated as transmission capacity over distance, to distribute power injected at a node. As in a real power system, the flows are all interdependent and determined by the topology of the network, including the generators, loads, and lines. Changing the pattern of generation affects the flows on all loop-forming AC lines within an interconnect. A few notable DC transmission connections in the U.S. power system are

\footnotetext{
${ }^{33}$ Susceptances are approximated as a proportionality of line capacity divided by distance. Specifically in ReEDS, susceptances are (10* Line Capacity in MW)/Distance (as measured using a Cartesian distance approximation).
} 
distinguished from the AC networks in ReEDS by granting them flow control, as they are not subject to Kirkoff's voltage laws. ${ }^{34}$

ReEDS can choose to build additional transmission capacity on the network to reduce congestion. Adding capacity on a transmission corridor will also increase that line's susceptance in subsequent years and thus increase the proportion of a power injection that takes that route. ${ }^{35}$

ReEDS does not address AC-power-flow issues of voltage, frequency, or limiting phase angle differences. Intra-BA transmission and distribution networks are similarly ignored, effectively assuming away transmission congestion within each region.

Transmission and distribution losses are considered in the model. There are bulk transmission losses of $1 \%$ per 100 miles for power that traverses between BAs. In addition, distribution losses of 5.3\% are added to the input end-use demand (Section 7.1) to "gross up" to busbar load. Distribution losses do not apply to rooftop PV, as they are assumed to be downstream within distribution networks, but they do apply at a lower rate to DUPV systems, which are assumed to connect directly to low-voltage distribution substations (Section 7.1).

Wind, CSP, and PV technologies are highly sensitive to location and often require spur lines to connect remote locations to the bulk transmission system. The GIS supply curve algorithm described in Section 5.3 estimates spur line distances and costs for potential development sites for these technologies, which are then grouped into supply curve steps. These spur lines, which are distinct from the inter-BA bulk transmission system for ReEDS, are assumed to link remote sites to the larger transmission system and to load centers. All other technologies are assumed to be built close to existing transmission infrastructure, and they therefore need only a nominaldistance spur line. Because the plant envelope used to determine technology capital cost assumptions includes the onsite switchyard, a short spur line, and relevant upgrades at the substation (EIA 2013a), those technologies incur no additional grid interconnection cost.

\subsection{Transmission Cost}

The long-distance and spur-line transmission costs in ReEDS are based on regional line voltage and cost premium assumptions. For long-distance interregional transmission lines, an assumed voltage $(345 \mathrm{kV}, 500 \mathrm{kV}$, or $765 \mathrm{kV})$ is applied for each region. The voltage assumption in each BA for long-distance transmission is taken from the highest voltage line currently operating in the BA from the Homeland Security Infrastructure Project (HSIP 2012). For BAs where the highest voltage of currently operating transmission lines is less than $500 \mathrm{kV}$, the voltage in the future is assumed to be $765 \mathrm{kV}$, and the associated costs for $765-\mathrm{kV}$ lines are used for all years. For BAs where the highest voltage of currently operating transmission lines is $500 \mathrm{kV}$, the costs for $500-\mathrm{kV}$ lines are used. The only exception to these rules for voltages in the Eastern Interconnection are for BAs in New England (Connecticut, Maine, Massachusetts, New

\footnotetext{
${ }^{34}$ Those DC connections include the nine AC-DC-AC interconnect interties, the Pacific DC Intertie that links Columbia River hydropower to Southern California loads, the Intermountain HVDC line between Utah and Southern California, as well as future DC projects along defined corridors.

${ }^{35}$ ReEDS includes scenario options that make transmission more expensive and/or increase transmission losses, with both options aimed at representing additional unmodeled barriers to transmission. See Cole, Mai, et al. (2016).
} 
Hampshire, Rhode Island, and Vermont), which are assumed to use $345-\mathrm{kV}$ transmission lines for all years.

Each voltage class is associated with a base capital cost sourced from the Phase II Eastern Interconnection Planning Collaborative (EIPC) report: \$2,333/MW-mile, \$1,347/MW-mile, and $\$ 1,400 / \mathrm{MW}$-mile for $345-\mathrm{kV}, 500-\mathrm{kV}$, and $765-\mathrm{kV}$ transmission lines respectively (EIPC 2012). ${ }^{36}$ All wind and solar spur line costs are based on $230-\mathrm{kV}$ line costs, assumed to be $\$ 3,667 / \mathrm{MW}-$ mile (ibid). ${ }^{37}$

In addition to the base transmission costs, regional multipliers are also applied and are largely based on assumptions from EIPC (2012). Regional transmission cost multipliers are the average of the EIPC report's high and low multipliers in each North American Electricity and Environmental Model region, and they are associated with the assumed voltage within the region. BAs in ERCOT and the Western Interconnection (excluding Canada and California) are assumed to have a regional transmission multiplier of one (1). Long-distance transmission costs in BAs in the California Independent System Operator are 2.25 times the cost of the other baseline costs for the rest of the Western Interconnection. For long-distance transmission between BAs with different transmission costs, the average cost is used. The same process is applied for wind and solar spur line costs.

Figure 23 and Figure 24 show the regional long-distance and spur-line transmission costs, respectively, that result from the previously described steps and assumptions.

\footnotetext{
${ }^{36}$ The base transmission costs for ReEDS are converted to $\$$ MW-mile according to new transmission line cost and capacity assumptions for single circuit conductors for each voltage in EIPC (2012). The costs reported are in 2010\$ as used by the EIPC.

${ }^{37}$ Wind and solar spur line costs are applied within the development of the resource supply curves.
} 


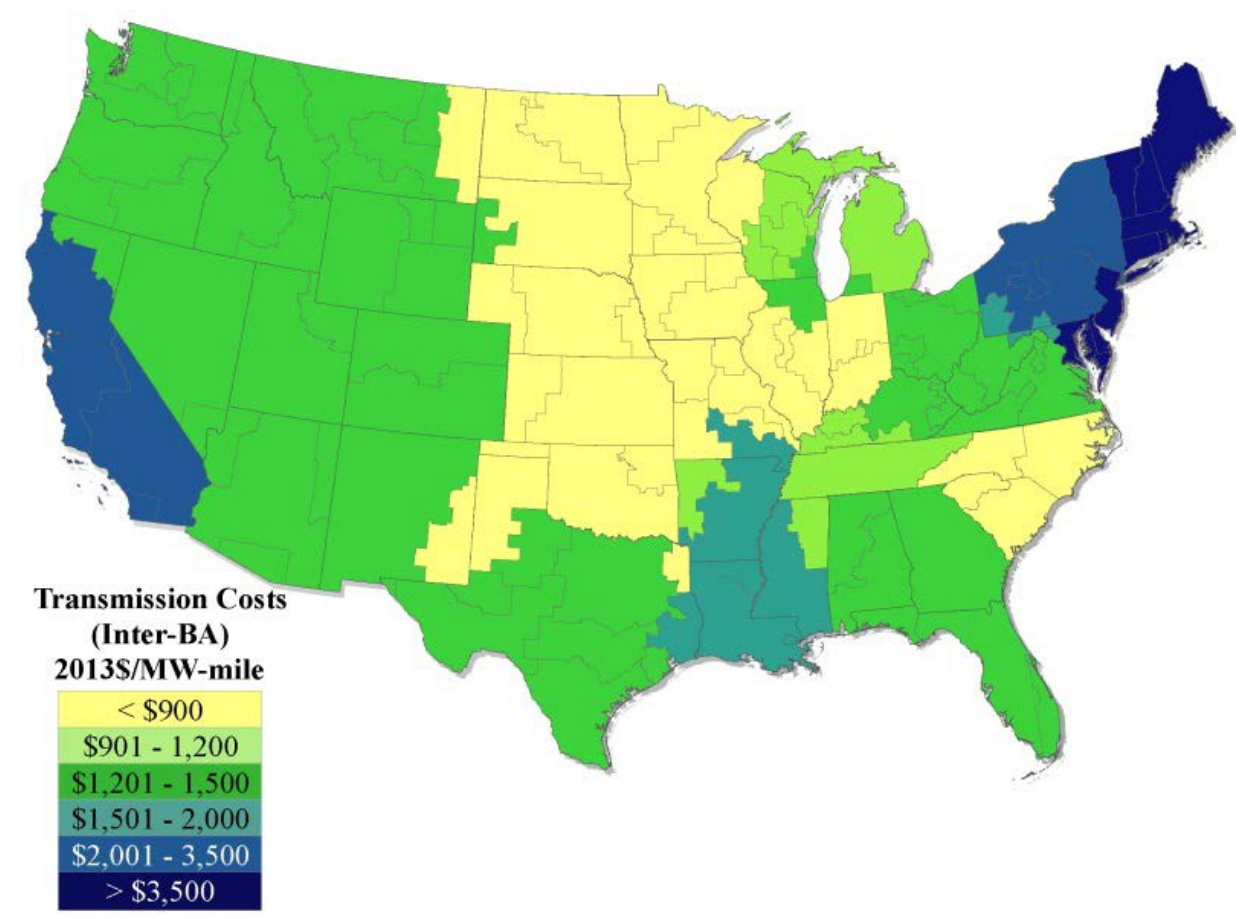

Figure 23. Map of long-distance transmission costs

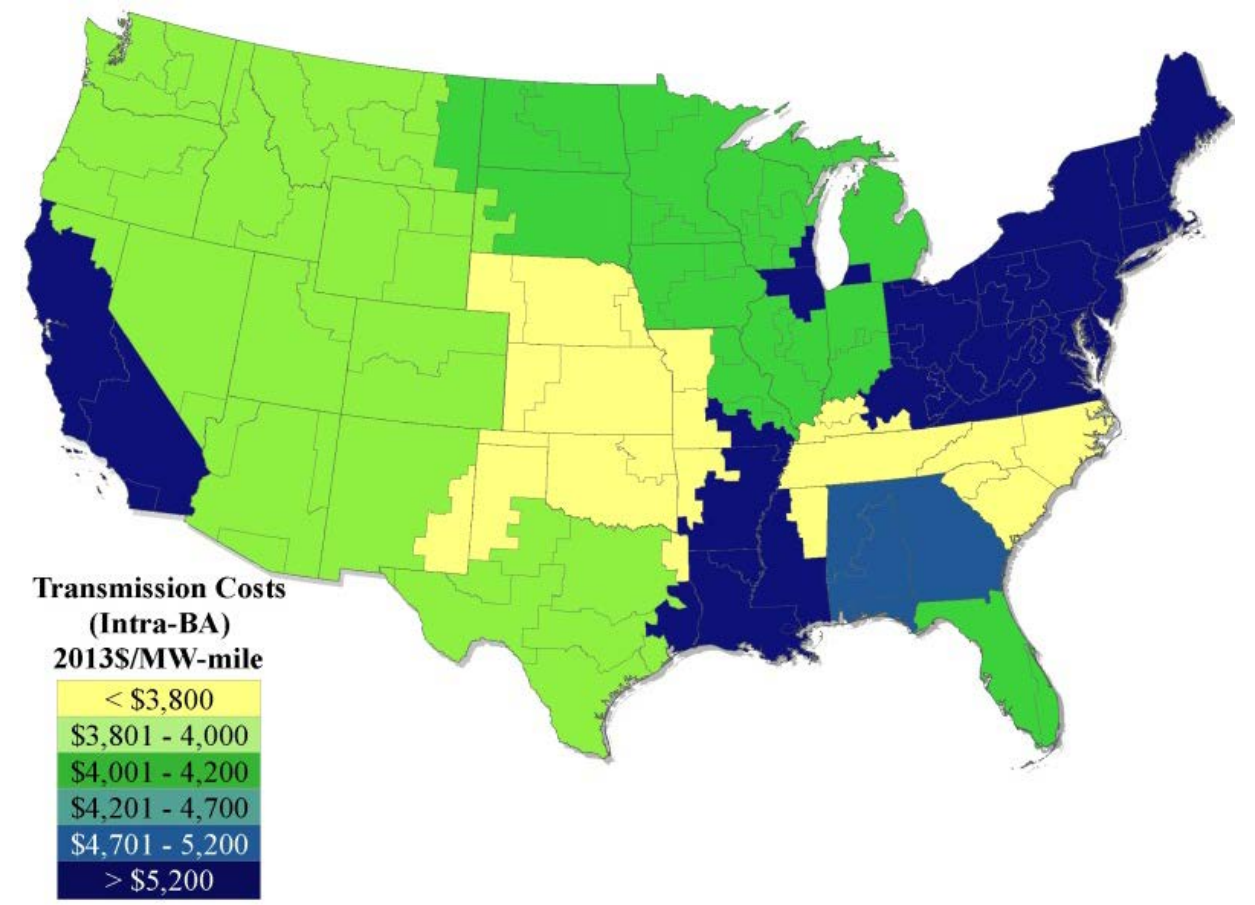

Figure 24. Map of spur-line transmission costs 


\subsection{Spur Lines}

To supplement the resource assessments that seed ReEDS with renewable potential, GIS analysis adds an accessibility dimension to the supply curves for wind, PV, and CSP technologies based on the expected cost of linking renewable resource sites to the transmission network. Having the two-dimensional supply curves allows ReEDS to make internal decisions about tradeoffs between resource quality and interconnection cost.

The geospatial site-connection algorithm evaluates each potential link from a wind or solar resource site to an electricity infrastructure feature, and the model assigns to the link a cost of development. For the algorithm, 200-m gridded wind sites used for the resource assessment are aggregated into $3 \mathrm{~km} \times 3 \mathrm{~km}$ cells to reduce the number of points used in the next step. CSP sites are similarly grouped into $1.35 \mathrm{~km}$ x $1.35 \mathrm{~km}$ cells, and PV sites are grouped into $3.15 \mathrm{~km} \mathrm{x}$ $3.15 \mathrm{~km}$ cells. Each resource site and each link is characterized by a levelized cost of energy that includes the expected cost of interconnection.

The resource supply curves are the result of successively selecting the least-cost site-toinfrastructure link and allocating that site to the infrastructure component until the transmission lines are saturated. At the start, each transmission line is assumed to have $10 \%$ of its nominal carrying capacity available for renewable connections, and each time a link is added, the remaining headroom is decremented by the capacity of the site being tied in. As the available capacity at transmission infrastructure features decreases, resource sites have to look farther afield for available linkages.

The resource supply curves are described in detail in (DOE 2015) and Previsic et al. (2012). 


\section{International Electricity Trade}

In our default model version used for a majority of recent analyses, ReEDS' geographic scope covers only the contiguous U.S. states and represents electricity trade with Canada exogenously. Imports and exports are specified by Canadian province based on the National Energy Board's Canadian Electricity Futures Reference Scenario (NEB 2016); these are shown in Figure 25 (values after 2040 are held at the 2040 value). Each province is required to send electricity to or receive electricity from any of the ReEDS BAs that have connecting transmission lines to that province. Thus, the total amount of energy imported from and exported to each Canadian province is exogenous; the ReEDS model can choose which BAs supply or receive that electricity. Electricity flows in 2010-2014 are taken from historical data (Canadian Electricity Association 2015). Canadian imports are assumed to be from hydropower and are counted toward RPS requirements where allowed by state RPS regulations. Canadian imports also count toward reserve margin requirements.

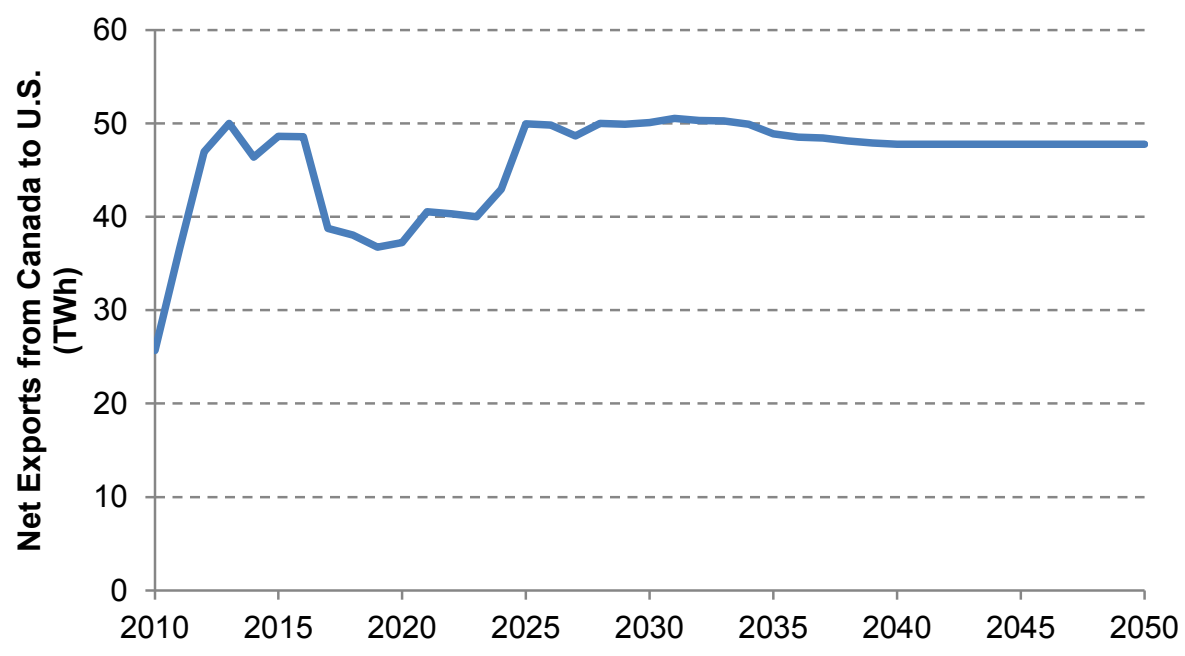

Figure 25. Net exports from Canada to the United States

A limited amount of trade with Mexico is represented endogenously in that several Mexican plants along the Mexico-California border are included in ReEDS with transmission lines that connect to the southern California BAs. These plants are operated using the same framework as all other plants in ReEDS and can send power into California. ReEDS is not allowed to build new plants in Mexico to serve U.S. load except for plants that are already under construction and are under contract to send their power to the United States. Renewable energy generated in Mexico and sent to California is eligible to be counted toward the California RPS. Other than these interties between Mexico and California, all other U.S.-Mexico interties are not currently modeled. Section 10 discusses separate model versions that explicitly include the Canadian electricity system. 


\section{Electricity System Operation and Reliability}

ReEDS finds the least-cost way of building and operating the electricity system while meeting certain requirements that are dominated by the need to meet electricity load while maintaining system adequacy and operational reliability.

\subsection{Electricity Load}

The primary constraint in ReEDS is to serve electricity load in each BA and time-slice. The enduse electricity load projection used in ReEDS is exogenously defined, based on scenarios from AEO 2016 (EIA 2016) and calibrated in 2010 to load data from Ventyx (2014). Specifically, hourly load profiles from Ventyx transmission zones are summarized and averaged to the 17 time-slice load profiles for the model BAs. These 2010 profiles are then scaled to ensure a match with the state-level annual load data from EIA's "Electricity Data Browser" (EIA 2015a). The regional growth factors for years after 2010 are calculated from the AEO 2016 Reference scenario electricity consumption by census division (EIA 2016). ${ }^{38}$ For each model year in ReEDS, the regional load profiles are increased by regional growth factors. ${ }^{39}$

The end-use load, described in the previous paragraph, is defined at the meter level. ReEDS includes transmission system losses in its algorithms but not distribution losses, so the load target for ReEDS is busbar load, requiring end-use load to be grossed up to account for distribution losses. The 5.3\% distribution loss factor is estimated based on a combination of EIA and ReEDS numbers. ReEDS is required to generate sufficient power in each time-slice and BA (allowing for transmission of power but accounting for losses) to meet this busbar load.

\subsection{Resource Adequacy}

Resource adequacy is "the ability of supply- and demand-side resources to meet the aggregate electrical demand" (NERC 2016). Planning reserve requirements ensures adequate resource is available at all times. In practice, this is enforced by requiring the system to have sufficient firm capacity to meet the forecasted peak demand plus a reserve margin. Each technology is assigned a capacity value reflecting its expected availability when power is needed. For conventional generators, the capacity value matches the nameplate capacity. For VRE technologies (i.e., wind and solar), ReEDS estimates the capacity value for each region/class bin via a statistical effective load carrying capability (ELCC) calculation performed between solves.

The ELCC calculation is based on the relationship between VRE output and load, accounting for existing contributions from other VRE sources and the correlations among those sources. It can be described as the amount of additional load that can be accommodated by adding those generators while maintaining a constant loss-of-load probability. Before each model year, ReEDS calculates both the ELCC of all existing VRE capacity and a hypothetical ELCC for any

\footnotetext{
${ }^{38}$ The demand growth factors from AEO's census divisions are applied to the ReEDS NERC-level regions. Due to differences in AEO's census divisions and the similarly sized NERC regions in ReEDS, the projected national load in ReEDS does not agree exactly with AEO's demand projections, but the differences are small.

${ }^{39}$ For years after 2040 for which AEO does not have projections, the average growth rate projected between 2030 and 2040 is used. Demand profiles and annual consumption can be altered with different plug-in hybrid electric vehicle and rooftop PV scenarios; however, absent these demand-side technologies, the profiles are assumed to be the same as those from 2010 .
} 
candidate VRE capacity that might be built in the coming year. These ELCC/capacity value calculations are documented in Short et al. (2011).

The reserve margin fractions applied in ReEDS are based on reserve margin requirements for NERC reliability subregions (NERC 2010). Each BA must meet the requirement, but BAs are allowed to engage in bilateral contracts for firm capacity as long as space remains on transmission lines after accounting for power flows and operating reserve contracts. Conventional technologies are assumed to be firm and their contracts follow their power flow.

\subsection{Operational Reliability}

In addition to ensuring adequate capacity to satisfy long-term planning reserve requirements, ReEDS requires operational reliability - that is, the ability to continue operating the bulk-power system in the event of a sudden disturbance (NERC 2016). In practice, ancillary reserve requirements ensure there is sufficient flexibility from supply-side and demand-side technologies to rebalance fluctuations in generation and demand. For ancillary services below the four-hour to eight-hour resolution of ReEDS time-slices, the model assumes statistically computed reserve requirements for load and variable supply and requires that capacity with adequate flexibility is available to handle such events; these methods are documented in Short et al. (2011). All ancillary reserve requirements must be satisfied in each BA in each time-slice; however, reserve provision can be shared between BAs in the same manner as firm capacity is traded.

The flexibility of generators and storage technologies depend on the ability of the plant to change its output and the time scales necessary to do so. Given start-up times and ramp rates, technologies are classified to be able to offer varying amounts of spinning or quick-start reserves (see Table 16). Spinning reserves can be provided by generation and storage technologies that are turned on but not fully dispatched in a given time-slice. The amount of capacity that may be counted toward the requirements depends on the amount that can be ramped up quickly (e.g., within 10 minutes). Technologies that can start generating power quickly from a cold state (again, within 10 minutes; e.g., natural gas combustion turbines), have the option of offering quick-start reserves. In addition, demand-side interruptible load can also contribute to reserve requirements, if enabled in a scenario. 
Table 16. Flexibility parameters of the ReEDS generation technologies

\begin{tabular}{lccc}
\hline & $\begin{array}{c}\text { Spinning } \\
\text { Reserve } \\
\text { Fraction }\end{array}$ & $\begin{array}{c}\text { Quick Start } \\
\text { Fraction }\end{array}$ & $\begin{array}{c}\text { Minimum } \\
\text { Plant Load } \\
\text { Fraction }\end{array}$ \\
\hline Gas-CT & 0.833 & 1.0 & 0 \\
Gas-CC & 0.5 & 0.35 & 0 \\
Gas-CC-CCS & 0.5 & 0.35 & 0 \\
Pulverized coal with scrubbers (pre-1995) & 0.2 & 0 & 0.4 \\
Pulverized coal without scrubbers & 0.2 & 0 & 0.5 \\
Pulverized coal with scrubbers (post-1995) & 0.2 & 0 & 0.4 \\
IGCC Coal & 0.5 & 0 & 0.5 \\
Coal-CCS & 0.5 & 0 & 0.5 \\
Oil/Gas Steam & 0.15 & 0 & 0.5 \\
Nuclear & 0.1 & 0 & 1.0 \\
Biopower & 0.063 & 0 & 0.4 \\
Geothermal & 0.15 & 0 & 0.9 \\
Land-fill Gas & 0 & 0 & 0.4 \\
Cofired Coal (pre-1995) & 0.2 & 0 & 0.4 \\
Cofired Coal (post-1995) & 0.2 & 0 & 0.4 \\
Hydropower & Varies & Varies & Varies \\
\hline
\end{tabular}

The operating reserve requirements in ReEDS represent multiple ancillary services covering contingency, frequency regulation, and VRE forecast error reserves (Short et al. 2011).

- Contingency reserve requirements: These requirements ensure that an unanticipated change to the operational status of generators or transmission lines (e.g., changes due to unforeseen outages) will not cause an extended disruption to electricity end users. In ReEDS, the contingency reserve requirement is set at $6 \%$ of demand in each time-slice based on assumptions from (Zavadil et al. 2004). At least half of this requirement must be met with spinning reserves or interruptible load, while the other half can be met by quickstart units. The relevant time scale for contingency events is about 10 minutes.

- Frequency regulation reserve requirements: These requirements ensure that subminute deviations between demand and generation can be minimized. Due to the short time scales involved, only spinning reserves can satisfy the frequency regulation requirements. In ReEDS, this requirement is set at $1.5 \%$ of average demand in each timeslice based on assumptions from (Zavadil et al. 2004).

- VRE forecast error reserve requirements: These requirements ensure stability of the system despite uncertainties in forecasting for wind and PV. Generally, forecast error 
reserve requirements increase as wind and PV penetration grows. ${ }^{40}$ The forecast error reserve requirements for wind and PV in ReEDS are assumed to be two standard deviations (Zavadil et al. 2004) of their respective aggregate forecast errors in each BA. The reserve requirements are held constant throughout the year. Forecasts for wind are assumed to be simple hourly persistence forecasts, based on simulated wind power output data (EnerNex 2011; General Electric 2010) for each wind resource class of each ReEDS region. In other words, wind forecast errors are simply the differences between simulated power outputs from one hour to the next. PV forecasts for a given hour are modified persistence forecasts that use the output from the previous hour as well as the average change between those two hours over the previous 15 days to account for the known apparent daily solar trajectory. Because forecast errors occur over longer timescales (roughly an hour) than contingency or frequency regulation events, ReEDS assumes up to $5 / 6$ of the requirement can be met by quick-start units, and the remainder must be met by a combination of spinning reserves and interruptible load (Zavadil et al. 2004).

\subsection{Curtailment}

Curtailment is a reduction - typically involuntary - in the output of a generator from what it could otherwise produce given available resources. Most renewable generators, being resource dependent and lacking fuel costs, are subject to curtailment of output that reduces plant revenue, in particular, when there is ample generating capacity committed, insufficient load to absorb it locally, and limited options to export surplus power via the transmission network. The economics of investment in renewable generators can be impacted by the amount of curtailment to which a plant will be subject, so ReEDS estimates curtailment fractions for both existing renewable generators and candidate sites.

The ReEDS curtailment calculation is a statistical estimate of expected surplus generation given the expected load level, expected VRE output, expected minimum turndown level for committed thermal units in each regional transmission operator region and time-slice (see Table 16), and the variances and correlations of the preceding factors. Recommitting thermal capacity from one year to the next can change curtailment patterns by changing the minimum stable output level of the thermal fleet. Similarly, adding new storage capacity can reduce curtailment levels by effectively increasing the available load.

Short et al. (2011) describe the calculation details for curtailment in ReEDS. The only difference in the current version of ReEDS is that storage is no longer explicitly included in the statistical calculations for the existing and marginal VRE curtailments. Instead, the contribution of all storage toward reducing curtailment via charging by region and time-slice is captured within a storage effectiveness parameter. This parameters varies between 0 (no reduction in curtailment) and 1 (full reduction in curtailment for energy placed into storage) as a function of load and renewable energy generation (Figure 26). Details about this parameter can be found in Cole, Marcy, et al. (2016).

\footnotetext{
${ }^{40} \mathrm{CSP}$ without storage is considered to have enough thermal inertia (about 30 minutes) not to require additional operating reserves.
} 


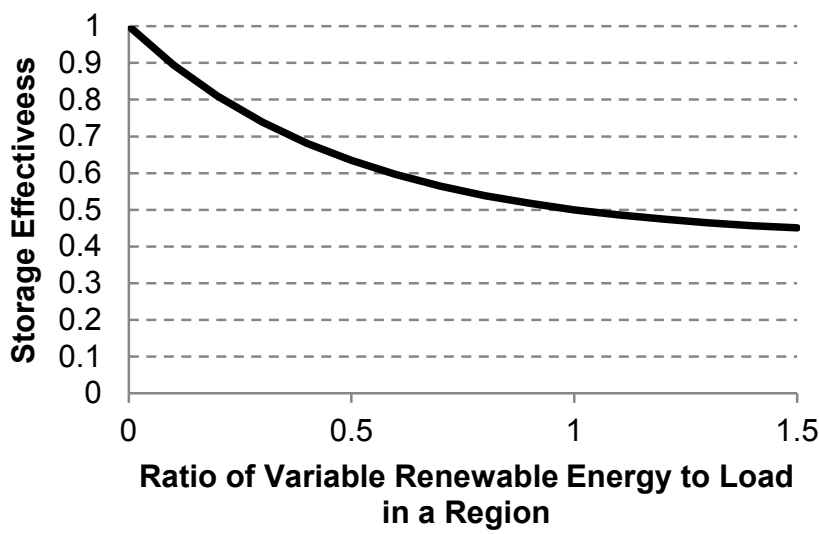

Figure 26. Example of storage effectiveness as a function of load and renewable energy generation (Cole, Marcy, et al. 2016) 


\section{Policy Descriptions}

Policies modeled in ReEDS include federal and states-level emission standards, tax incentives, and renewable portfolio standards. This section primarily focuses on existing policies, but Section 8.4 does discuss additional frameworks that exist in the model.

\subsection{Federal and State Emission Standards}

\subsubsection{New Source Performance Standards}

The U.S. Environmental Protection Agency's New Source Performance Standards (promulgated through Section 111(b) of the Clean Air Act) require that new capacity have an annual average $\mathrm{CO}_{2}$ emissions below 1400 pounds $\mathrm{CO}_{2} / \mathrm{MWh}$ (at least as low as those of new natural gas combined cycle technology). Therefore, we do not allow ReEDS to build new coal without CCS because ReEDS does not have any non-CCS coal technologies represented that can meet this emission limit.

\subsubsection{Existing Source Performance Standard: Clean Power Plan}

The EPA's Clean Power Plan, promulgated through Section 111(d) of the Clean Air Act, is designed to reduce $\mathrm{CO}_{2}$ emissions to $32 \%$ below 2005 levels by 2030 through rate- and massbased standards for existing sources. Existing sources are defined as any fossil fuel-fired steamgenerating unit that commenced construction as of January 8, 2014. In ReEDS, we identify these affected fossil generators as existing source pollutant technologies. Generating units that commenced construction after January 8, 2014 (or are built endogenously by ReEDS) are considered new source pollutant technologies.

The $\mathrm{CO}_{2}$ emission targets for the interim (2022-2029) and final (2030) compliance periods are taken from the EPA technical support documents (U.S. Environmental Protection Agency 2015). For regulatory purposes, compliance with the Clean Power Plan with these emission targets must be met on the state level, though trading across states is permitted by the rule. ${ }^{41}$ No Clean Power Plan emissions limits are enforced in the pre-compliance years (prior to 2022); however, ReEDS uses foresight of the future cost of $\mathrm{CO}_{2}$ emissions to inform decisions for new investment. ${ }^{42}$ Beyond 2030, we assume the targets remain constant at the 2030 level (the Clean Power Plan does not specify what the targets will be post-2030).

For mass-based compliance ${ }^{43}$ in ReEDS, available allowances must meet or exceed $\mathrm{CO}_{2}$ emissions from sources that are covered by the Clean Power Plan. Total available allowances in a given year are the sum of the following allowance streams: (1) allowances initially allocated to generators (equal to the mass-based target for that year), (2) excess allowances from prior

\footnotetext{
${ }^{41}$ The default representation of the Clean Power Plan in ReEDS allows for national trading so that some states can under-comply with the rule as long as other states over-comply (Cole, Mai, et al. 2016). Accordingly, this document focuses on that case. However, ReEDS has the capability to model any scope of compliance trading along spatial and technological dimensions.

${ }^{42}$ These future $\mathrm{CO}_{2}$ emissions costs are exogenously specified, but were calibrated based on several iterations of model runs.

${ }^{43}$ Mass-based compliance is based on the mass of $\mathrm{CO}_{2}$ emitted, while rate-based compliance is based on the $\mathrm{CO}_{2}$ emission rate.
} 
compliance years, and (3) early action allowances (described below). ${ }^{44} \mathrm{We}$ assume the allowances are purchased from an auction at the marginal $\mathrm{CO}_{2}$ price, which is equal to the shadow value of the model Clean Power Plan emissions constraint. The cost of allowances is incorporated into the electricity price.

For rate-based compliance in ReEDS, available emission rate credits (ERC) must offset the total ERCs required. Available ERCs are created from:

- Over-complying covered sources (i.e., sources with emission rates below their compliance targets)

- Shifts from coal to natural gas resources ${ }^{45}$

- Qualifying zero-emitting resources ${ }^{46}$

- Energy efficiency in low-income communities (exogenously specific level of efficiency)

- Qualifying biomass ${ }^{47}$

- Biogenic portion of municipal solid waste ${ }^{48}$

- ERCs from prior years

- Early action credits.

We do not capture ERCs from non-affected CHP, ERCs from transmission and distribution improvements, or ERCs from other sources. The total ERCs required is defined by the EPA as:

$$
\text { ERCs Req } d=\frac{\sigma_{i}-s_{i}}{s_{i}} \cdot x_{i}
$$

where

- $\sigma_{i}=$ emission rate of source $i$, (tons $\mathrm{CO}_{2}$ per $\mathrm{MWh}$ )

- $s_{i}=$ emission rate standard of source $i$, (tons $\mathrm{CO}_{2}$ per $\mathrm{MWh}$ )

- $x_{i}=$ generation of source $i,(\mathrm{MWh})$.

For under-complying sources (i.e., $\sigma_{i}>s_{i}$ ), the amount of ERCs required is a positive number, meaning these sources must purchase ERCs. For over-complying sources (i.e., $\sigma_{i}<s_{i}$ ), the

\footnotetext{
${ }^{44}$ We define excess allowances in this context to consist only of allowances allocated through the mass-based targets. In practice, early-action allowances are also banked for use in future model years and are treated equivalently to excess allowances. Banked allowances (both excess and early-action) are allocated equally over future model years through 2030 .

${ }^{45}$ These ERCs are referred to as "gas-shift" ERCs in the EPA-proposed Federal Implementation Plan and are only applicable under subcategory rate compliance (U.S. Environmental Protection Agency 2016).

${ }^{46}$ Qualifying zero-emitting resources include renewable and nuclear that was installed after 2012. For renewable resources, we do not track vintage; therefore, we exclude generation from those sources in 2012. Currently, we do not adjust the exclusions for retirements. For nuclear, under construction units include Vogtle, Watts Bar, and VC Summer.

${ }^{47}$ We assume every megawatt-hour generated from biomass qualifies as an ERC.

${ }^{48}$ We represent the combustion of the biogenic portion of municipal solid waste as the landfill gas technology.
} 
amount of ERCs required is a negative number, meaning these sources generate ERCs that can be sold. Gas-shift ERCs are defined as:

$$
E R C_{g s}=\frac{s_{\text {coal }}-\sigma_{i}}{s_{\text {coal }}} \cdot x_{i} \cdot I G F \quad \forall \quad i \in I_{\text {gas }} \text { s.t. } \sigma_{i}<s_{\text {coal }} \text {, }
$$

where

- $\sigma_{i}=$ emission rate of source $i$, (tons $\mathrm{CO}_{2}$ per $\mathrm{MWh}$ )

- $s_{\text {coal }}=$ emission rate standard of coal, (tons $\mathrm{CO}_{2}$ per $\left.\mathrm{MWh}\right)$

- $x_{i}=$ generation of source $i,(\mathrm{MWh})$

- $I G F=$ incremental generation factor as specified by EPA.

We include the cost of ERCs in the electricity price, represented as tax and subsidy components (Fischer 2001), as follows:

- $\operatorname{Tax}[\$ / \mathrm{MWh}]=\frac{\left(P_{e r c} \cdot \sigma \cdot x\right)}{x}=P_{e r c} \cdot \sigma$

- $\quad$ Subsidy $[\$ / \mathrm{MWh}]=-\frac{\left(P_{e r c} \cdot s \cdot x\right)}{x}=-P_{e r c} \cdot s$

\subsubsection{Clean Energy Incentive Program}

The Clean Energy Incentive Program is a voluntary program under the Clean Power Plan that is intended to incentivize the early adoption of energy efficiency in low-income communities and the deployment of renewable energy. Early adoption of eligible projects ${ }^{49}$ creates early action credits (EACs) which are drawn from the pool of state allowances/ERCs from future compliance periods and matched by an EPA pool up to an equivalent of 300 million tons of $\mathrm{CO}_{2}$.

We convert EACs to allowances assuming a conversion rate of 0.8 ton/MWh as described in the EPA Federal Implementation Plan. This means that one megawatt-hour of generation/savings from eligible renewable energy/energy efficiency equals 0.8 ton of EACs for mass-based policy; and one megawatt hour of renewable energy/energy efficiency equals one megawatt-hour of EACs for rate-based policy. In total, the national EAC budget for a rate-based policy (in MWh) equals 300 million tons divided by 0.8 ton/MWh, or 375 million $\mathrm{MWh}$.

Eligible energy efficiency/renewable energy projects earn EACs for energy saved and renewable energy generated in 2020 and 2021, ${ }^{50}$ which can be banked and used for compliance in any future year. Each megawatt-hour of energy generated from renewable energy gets one-half of an EAC each from the state pool and the EPA match pool. Each megawatt-hour of energy saved from energy efficiency gets one EAC each from the state pool and the EPA match pool.

\footnotetext{
${ }^{49}$ Projects eligible for EACs include energy efficiency, wind, and solar projects constructed after the submittal of a state compliance plan. Assuming all states submit a state compliance plan by the end of 2016, renewable energy and energy efficiency projects built in the 2018 and 2020 model years are eligible for EACs.

${ }^{50}$ By convention, the 2022 model year represents 2022 and 2021. Because we need to determine the amount of generation from eligible renewable energy from 2021 prior to the 2022 model year, we assume the dispatch in 2020 is representative of the 2021 dispatch.
} 
To incentivize wind and solar under the Clean Energy Incentive Program, we apply a $\mathrm{CO}_{2}$ tax on new capacity that is not wind or solar to represent the expected advantage that wind and solar enjoy from acquiring (and eventually selling) early-action credits or allowances. Note that this tax does not incentivize the displacement of existing sources by wind or solar in the earlyaction period.

\subsubsection{CAIR/CSAPR}

ReEDS applies the Clean Air Interstate Rule (CAIR) and Cross-State Air Pollution Rule (CSAPR) using caps on power plant emissions to the states in the eastern half of the United States over which the rules are imposed. CAIR annual emission caps for $\mathrm{SO}_{2}$ and $\mathrm{NO}_{\mathrm{x}}$ are applied for 27 states in the entire eastern United States from 2010 to 2014. From 2016 onward, CSAPR annual emission allowance budgets for $\mathrm{SO}_{2}$ and $\mathrm{NO}_{\mathrm{x}}$ are applied at the state level, with CSAPR Phase 1 caps applied in 2016 and relatively more stringent Phase 2 caps applied from 2018 (EPA 2016). In addition to the annual $\mathrm{NO}_{\mathrm{x}}$ caps, CSAPR also applies ozone season specific cap for few states. ReEDS applies an annual estimate of these ozone season caps. ReEDS also models the interstate cap and trade for $\mathrm{SO}_{2}$ and $\mathrm{NO}_{\mathrm{x}}$ allowance budgets within the respective $\mathrm{SO}_{2}$ and $\mathrm{NO}_{\mathrm{x}}$ groups. States can only purchase additional emission credits up to their assurance limits, which is fixed at $18 \%$ of state allowance budget. Even though states can go up to $118 \%$ of their allowance budget, the total emissions allowance at the group level must be respected.

\subsubsection{Mercury and Air Toxic Standards}

In addition to these air pollution control policies, ReEDS also considers the impact of the EPA's Mercury and Air Toxic Standards (MATS) that limit pollutants from individual power plants. In contrast to the CAIR and CSAPR implementations that apply at regional scale, MATS is applied on individual plants by requiring the coal fleet to either retrofit into compliance in 2016 or retire the plants. All these retrofit decisions are taken outside the ReEDS and are appropriately represented in terms of:

- Re-estimating the available coal fleet capacity in each category after accounting for the retrofits (i.e., coal-unscrubbed and coal-scrubbed capacities post-MATS)

- Accounting for the appropriate retrofit costs and their impacts on the system planning costs and electricity prices

- Accounting for the change in generation emission factors (i.e., estimating average coal fleet $\mathrm{SO}_{2}$ emission factors after plants comply with MATS limits [0.2 lb/MMBTU]).

While MATS is primarily designed to limit mercury, hydrogen chloride and particulate matter, there are also alternate limits in terms of other metallic/non-metallic pollutants, including $\mathrm{SO}_{2}$. Therefore, ReEDS models the consequence of MATS compliance in terms of $\mathrm{SO}_{2}$ emission factor change for the major technologies that are expected to undergo retrofits. While ReEDS does not control mercury emissions, it does track them over the planning horizon and the MATS compliance effects are incorporated by reducing mercury emission factors for these generation technologies by $90 \%$ during post-MATS period.

Regarding the retrofit decisions taken outside the ReEDS model, the following logic is adopted and applied on each coal unit in the ABB Velocity Suite database (which informs the capacity 
data in ReEDS), and the ReEDS coal fleet capacities are accordingly updated for the 2016 model year:

- Low-cost option: no retrofit if (1) any coal plant is set to retire before or during 2016 or (2) its $\mathrm{SO}_{2}$ emission factor is within $20 \%$ of the MATS limit (to accommodate coal switching or other low-cost strategies)

- Mid-cost option: retrofit with dry sorbent injection if (1) the plant is set to retire before 2025 , or the plant is small in size $(<200 \mathrm{MW})$, or (2) the plant is $<300 \mathrm{MW}$ and its $\mathrm{SO}_{2}$ emission factor is within $200 \%$ of the MATS limit, or (3) the plant already has a flue-gas desulfurization retrofitted, or (4) there is a planned dry sorbent injection retrofit as per the ABB Velocity Suite database

- High-cost option: retrofit with flue-gas desulfurization if (1) the plant does not meet any of the criteria above (i.e., it is large and will be around for a while) or (2) there is a planned flue-gas desulfurization retrofit as per the ABB Velocity Suite database.

These upgrades are mandated in ReEDS. The appropriate capacity-weighted retrofit costswhich are estimated based on the capital and operational costs ${ }^{51}$ of the flue-gas desulfurization and dry sorbent injection retrofits - are applied to the system cost and the calculated electricity price (EIA 2015b). ${ }^{52}$ The above assumptions and representation of MATS in ReEDS have at least three broad caveats and their associated implications on the ReEDS model results:

1. The national-scale $\mathrm{SO}_{2}$ emissions could be conservative, as the alternative $\mathrm{SO}_{2}$ limit of MATS has been targeted for compliance. In reality, units may comply with primary mercury and hydrogen chloride limits while still having $\mathrm{SO}_{2}$ above the MATS alternate limits.

2. Alternative low-cost compliance strategies, such as adopting low-sulfur or low- hydrogen chloride coal switching are not considered in ReEDS.

3. The retrofit decisions are not based on a full-fledged economic analysis considering unit size, lifetime, O\&M cost, or other factors.

\subsubsection{California AB-32}

California's Assembly Bill 32 (AB-32) is modeled as a cap on electricity-system $\mathrm{CO}_{2}$ emissions from generators either located in California or serving load in the state. Direct $\mathrm{CO}_{2}$ emissions from generators located in California count toward the cap. $\mathrm{CO}_{2}$ from imported electricity is estimated through an accounting of imported energy and carbon intensity of the states from which that energy originated.

The AB-32 emission budget is based on EIA (2013b) reference scenario $\mathrm{CO}_{2}$ emissions from the California electric sector that fall under their treatment of AB-32. A scaling factor is applied to account for the disparity of 2010 California emissions as modeled in ReEDS and NEMS. The

\footnotetext{
${ }^{51} \mathrm{O \& M}$ costs are estimated for individual retrofits as a function of unit size (MW), heat rate, pre-MATS emission rate, removal efficiency, limestone or sorbent injection rate, waste rate, limestone cost, waste disposal cost, auxiliary power cost, water cost, labor rate, and other factors.

52 The O\&M costs were taken from documentation of EPA's Integrated Planning Model (IPM) Versions 5.1, 5.2, and 5.5, which are no longer available online.
} 
allowance budget declines linearly from 64.8 million metric tons $\mathrm{CO}_{2}$ in 2012 to 59.8 in 2020, and it remains flat thereafter. Newer carbon policies, including extensions of California's carbon targets can be implemented by updating the annual state $\mathrm{CO}_{2}$ caps modeled in ReEDS.

\subsubsection{Regional Greenhouse Gas Initiative}

The Regional Greenhouse Gas Initiative cap-and-trade program limits the $\mathrm{CO}_{2}$ emissions for fossil fuel-fired power plants in nine states: Connecticut, Delaware, Maine, Maryland, Massachusetts, New Hampshire, New York, Rhode, Island, and, Vermont.

We enforce allowance budgets from the update model rule adopted in $2013 .^{53} \mathrm{We}$ ignore provision for privately banked allowances and therefore use the unadjusted budgets: 165 million short tons in 2012, declining to 91 million by 2014, and declining $2.5 \%$ per year from 2015 to 2020. We assume the budget remains constant beyond 2020. We do not model banking of allowances, emissions offsets, or recycling of initiative allowance revenues.

\subsection{Federal and State Tax Incentives}

Existing federal tax incentives for renewable energy are included in ReEDS. These include the current (as of 2016) renewable tax credits - particularly the production tax credit (PTC) and the investment tax credit (ITC) - and the Modified Accelerated Cost Recovery System (MACRS) depreciation schedules. The most recent renewable tax credit extensions were passed in December 2015 as part of the Consolidated Appropriations Act, 2016. Our representations of the PTC and ITC are based on this act, including tax credit values, schedules, expirations, and technology eligibility (Mai et al. 2016). Current technology-specific depreciation schedules are modeled for all years, as we understand them to be permanent parts of the tax code.

Model representations of the latest tax credit extensions are complicated by the "commencedconstruction" provision in these policies, the annual ramp-down in tax credit value, and the twoyear modeling intervals used in ReEDS. Because ReEDS accounts for when plants come online rather than when they begin construction, we represent the commenced-construction provision by assuming the tax credit received by facilities corresponds to the value of the tax credits at the time the plant would typically start construction. For most purposes, we assume construction starts two years prior to the commercial operation date for utility-scale solar and wind and one year prior for commercial rooftop PV. However, due to recent guidance from the Internal Revenue Service (IRS) ${ }^{54}$ allows for a longer construction period (four years) for wind facilities to qualify for the PTC. It is unclear how the wind industry and wind deployment will react to this unprecedented IRS guidance. We conservatively represent a three-year construction period for wind in our PTC representation. No IRS guidance is available for the commenced-construction

\footnotetext{
53 “2012 Program Review," accessed September 16, 2016, https://www.rggi.org/design/program-review. For more information, see:

- "About the Regional Greenhouse Gas Initiative (RGGI)," fact sheet updated August 2016, https://www.rggi.org/docs/Documents/RGGI_Fact_Sheet.pdf

- "The RGGI CO2 Cap," https://www.rggi.org/design/overview/cap

- "Regional Greenhouse Gas Initiative,” December 2013, http://www.c2es.org/docUploads/rggi-brief-12-1813-updated.pdf.

54 "Beginning of Construction for Sections 45 and 48: Notice 2016-31," IRS 2016, https://www.irs.gov/pub/irsdrop/n-16-31.pdf.
} 
provision for the ITC incentive for utility solar, and we model it using a two-year construction period. ${ }^{55}$ For residential PV, the ITC is a placed-in-service tax credit, meaning the commencedconstruction provision does not apply. Furthermore, the effective value of the tax credit during each two-year model period is based on the average value of the tax credit available after accounting for these under construction periods. For example, an effective $28 \%$ ITC is modeled for utility-scale solar during the 2022 ReEDS model year (representing 2021-2022) based on the average of the $30 \%$ ITC available in 2019 and the $26 \%$ ITC available in $2020 .{ }^{56}$ Table 3 presents the effective wind PTC and solar ITC schedules modeled in ReEDS compared with the nominal schedule listed by the policy.

While not shown on Table 17, we also include tax credits for other renewable energy technologies in the modeled scenarios. The model representation of the tax credit extensions includes effective PTCs for biopower, geothermal, and hydropower lasting through the 20172018 model period to account for the commenced-construction deadline at the end of 2016. A PTC value of $2.3 \notin / \mathrm{kWh}$ is applied to biopower and geothermal, and a PTC of $1.2 \phi / \mathrm{kWh}^{57}$ is applied to new hydropower during this period. No tax credits are assumed for biopower and hydropower after 2018. A geothermal ITC of $10 \%$ is modeled for all years after 2018 . Another nuance not shown on Table 17 is the ITC option in lieu of the PTC for certain qualifying facilities, including offshore wind. For offshore wind, we include an effective ITC through the 2020 model year. ${ }^{58}$

\footnotetext{
${ }^{55}$ This is justified by the typically shorter construction periods for utility PV. Also, these assumptions are largely consistent with IRS guidance for commenced-construction provisions in earlier tax credit policies; see "Beginning of Construction for Sections 45 and 48: Notice 2015-25," Internal Revenue Service, U.S. Dept. of the Treasury, accessed January 28, 2016, https://www.irs.gov/pub/irs-drop/n-15-25.pdf.

${ }^{56}$ This representation may underestimate the tax credit value, as more projects may be moved forward to gain the higher tax credit value in earlier years. However, we conducted test scenarios and found little impact in renewable energy capacity deployment results when shifting the effective tax credit schedule slightly to account for this behavior.

${ }^{57}$ These values in implemented in ReEDS in $2015 \$$.

${ }^{58}$ The current legislation specifies a ramp-down schedule for the ITC that is available to offshore wind wherein a $30 \%$ ITC is available in 2016 and reduces by six percentage points annually through 2019 . However, we have not implemented the ability to model ITC ramp-downs for offshore wind. We include a full $30 \%$ offshore wind ITC for all model years from 2016 to 2020, but in most scenarios, no new offshore wind capacity is endogenously added during this period by the model. For this reason, we conclude that a more accurate representation of the ramp-down schedule would yield the same result.
} 
Table 17. Actual and Modeled Schedule of Wind and Solar Tax Credits from the Consolidated Appropriations Act, 2016

\begin{tabular}{|c|c|c|c|c|c|c|c|c|c|c|c|c|c|}
\hline \multicolumn{2}{|c|}{ Consolidated Appropriations Act, 2016} & 2015 & 2016 & 2017 & 2018 & 2019 & 2020 & 2021 & 2022 & 2023 & 2024 & 2025 & Future \\
\hline \multicolumn{2}{|l|}{ Wind PTC } & Full & Full & $80 \%$ & $60 \%$ & $40 \%$ & $0 \%$ & $0 \%$ & $0 \%$ & $0 \%$ & $0 \%$ & $0 \%$ & $0 \%$ \\
\hline \multirow{3}{*}{ Solar ITC } & Utility & $30 \%$ & $30 \%$ & $30 \%$ & $30 \%$ & $30 \%$ & $26 \%$ & $22 \%$ & $10 \%$ & $10 \%$ & $10 \%$ & $10 \%$ & $10 \%$ \\
\hline & Commercial/Third-Party-Owned & $30 \%$ & $30 \%$ & $30 \%$ & $30 \%$ & $30 \%$ & $26 \%$ & $22 \%$ & $10 \%$ & $10 \%$ & $10 \%$ & $10 \%$ & $10 \%$ \\
\hline & Residential Host-Owned & $30 \%$ & $30 \%$ & $30 \%$ & $30 \%$ & $30 \%$ & $26 \%$ & $22 \%$ & $0 \%$ & $0 \%$ & $0 \%$ & $0 \%$ & $0 \%$ \\
\hline \multicolumn{2}{|r|}{ Model Representation } & \multicolumn{2}{|c|}{ 2015-16 } & \multicolumn{2}{|c|}{ 2017-18 } & \multicolumn{2}{|c|}{ 2019-20 } & \multicolumn{2}{|c|}{ 2021-22 } & \multicolumn{2}{|c|}{ 2023-24 } & \multicolumn{2}{|c|}{ Future } \\
\hline \multicolumn{2}{|l|}{ Wind PTC } & \multicolumn{2}{|c|}{ Full } & \multicolumn{2}{|c|}{ Full } & \multicolumn{2}{|c|}{$90 \%$} & \multicolumn{2}{|c|}{$50 \%$} & \multicolumn{2}{|c|}{$0 \%$} & \multicolumn{2}{|c|}{$0 \%$} \\
\hline \multirow{3}{*}{ Solar ITC } & Utility & \multicolumn{2}{|l|}{$30 \%$} & \multicolumn{2}{|l|}{$30 \%$} & \multicolumn{2}{|l|}{$30 \%$} & \multicolumn{2}{|l|}{$28 \%$} & \multicolumn{2}{|l|}{$16 \%$} & \multicolumn{2}{|l|}{$10 \%$} \\
\hline & Commercial/Third-Party-Owned & \multicolumn{2}{|l|}{$30 \%$} & \multicolumn{2}{|l|}{$30 \%$} & \multicolumn{2}{|l|}{$30 \%$} & \multicolumn{2}{|l|}{$24 \%$} & \multicolumn{2}{|l|}{$10 \%$} & \multicolumn{2}{|l|}{$10 \%$} \\
\hline & Residential Host-Owned & \multicolumn{2}{|l|}{$30 \%$} & \multicolumn{2}{|l|}{$30 \%$} & \multicolumn{2}{|l|}{$28 \%$} & \multicolumn{2}{|l|}{$11 \%$} & \multicolumn{2}{|l|}{$0 \%$} & \multicolumn{2}{|l|}{$0 \%$} \\
\hline
\end{tabular}

Table is adapted from Mai et al. (2016) but updated to reflect the longer construction periods allowed for qualifying wind facilities. 
Several states also have production and investment incentives for renewable energy sources. The default values used in these states are listed in Table 18. While states in addition to North Dakota have ITCs in place, those programs are for small system installations and have dollar amount limits that render them of limited value for ReEDS' utility-scale investments.

Table 18. Default State Tax Incentives

\begin{tabular}{lccc}
\hline State & PTC (\$/MWh) & ITC (\%) & End Year \\
\hline Maryland & 8.5 & - & 2017 \\
North Dakota & - & 15 & 2017 \\
New Mexico & 10.0 & - & 2015 \\
Oklahoma & 5.0 & - & 2023 \\
Utah & 3.5 & - & - \\
\hline
\end{tabular}

\subsection{State Renewable Portfolio Standards}

ReEDS models state renewable portfolio standards (RPSs), including technology set-asides, and renewable energy certificate (RECs) that can count toward RPS compliance. RPS rules are complex and can vary significantly between states. The RPS representation in ReEDS attempts to model the primary impacts of these RPS rules but includes many simplifying assumptions.

Table 19 summarizes the RPS targets, technology set-asides, and REC trading within ReEDS.

The left side of Table 19 (pp. 67-68) shows the respective RPS targets and technology setasides for years 2020, 2025, and 2030 as a percentage of state electricity sales as modeled within ReEDS. These values - along with many other data that we use to represent nuanced RPS rules - are based on data compiled by Lawrence Berkeley National Laboratory, which takes into account the in-state REC multiplier incentives and load adjustments (e.g., sales weighted RPS targets considering different load serving entities subject to compliance, such as investor owned utilities, municipal utility, and co-operatives). ${ }^{59}$ Solar includes UPV and rooftop PV, wind includes both land-based and offshore technologies, and DG includes rooftop PV and groundmounted PV systems located within the distribution network. ${ }^{60}$ ReEDS also models alternative compliance payments for unmet RPS requirement for both main RPS targets and solar set-asides as is consistent with the available data.

Technology eligibility for state RPS requirements is appropriately modeled for each state. For instance, California's RPS does not allow in-state rooftop solar technologies to contribute toward its RPS. Additionally, every state has specific rules regarding hydropower generation's eligibility toward contributing RECs, which are usually based on each unit's vintage and size (e.g., small hydro with specific capacity cut-offs are eligible in some states). ReEDS models these in terms of allowable capacity fractions (estimated from ABB Velocity Suite database (ABB 2016)),

\footnotetext{
${ }^{59}$ See Barbose (2016) and https://emp.lbl.gov/projects/renewables-portfolio

${ }^{60}$ See Database of State Incentives for Renewables \& Efficiency (DSIRE) website at dsireusa.org. If data are unavailable, ReEDS forces RPS target to be met by using a default alternative compliance payments and solar alternative compliance payments of \$200/MWh and \$400/MWh respectively.
} 
which is imposed on each state's total hydro generation thereby limiting the amount of hydropower RECs that each state could generate. Additionally, ReEDS also imposes an upper limit on the total hydropower RECs that a state can use toward its RPS based on historical data as compiled and estimated by Lawrence Berkeley National Laboratory.

We also model restricted eligibility of existing renewable capacity to contribute to future RPS targets. In other words, while the amount of renewable generation in 2014 exceeds RPS requirements in that year, some of this renewable generation has contractual or other obligations that prevent it from being eligible to meet RPS requirements. This eligibility restriction, estimated by region and technology type, was estimated by Lawrence Berkeley National Laboratory. For the contiguous United States, we estimate that $25 \%$ of renewable generation in excess of RPS demand in 2014 is eligible to meet RPS demand after 2014. We do not model banking or borrowing of RECs.

Table 19 lists the allowable states from which each state may import RECs; interstate REC transactions that are required to be bundled with energy are marked with an asterisk. With the exception of California, ReEDS enforces an upper limit on the total RECs (both bundled and unbundled) that can be imported for that state's RPS compliance. For California alone, due to its unique out-of-state rules, ReEDS enforces two upper limits, one on the total unbundled REC imports and the other on the total bundled REC imports. There are a myriad of possibilities of interstate REC transactions, in terms of both which two states can transact and the quantity of those transactions. To constrain the solution space of ReEDS to credible values, the interstate REC trading modeling is based on historical observations (Holt 2016), as shown in the final two columns of Table 19. The out-of-state total REC import percentages for each state in are limited to those observed in 2012-2013 (Heeter 2015). 
Table 19. Effective State RPS Requirements in ReEDS

\begin{tabular}{|c|c|c|c|c|c|}
\hline \multirow[b]{2}{*}{ State } & \multicolumn{3}{|c|}{ RPS target / Solar / DG / Wind set-asides (\%) } & \multirow{2}{*}{$\begin{array}{l}\text { Allowable states for REC import, includes } \\
\text { Canadian provinces ('bundling requirement) }\end{array}$} & \multirow{2}{*}{$\begin{array}{l}\text { REC import limit } \\
\text { (\% of RPS target) }\end{array}$} \\
\hline & 2020 & 2025 & 2030 & & \\
\hline$A Z$ & $5.8 /-/ 1.7 /-$ & $8.7 /-/ 2.6 /-$ & $8.7 /-/ 2.6 /-$ & $\mathrm{CA}^{*}, \mathrm{CO}^{*}, \mathrm{NM}^{*}$ & 100 \\
\hline $\mathrm{CA}$ & $32.2 /-/-/-$ & $39 /-/-/-$ & $48.8 /-/-/-$ & 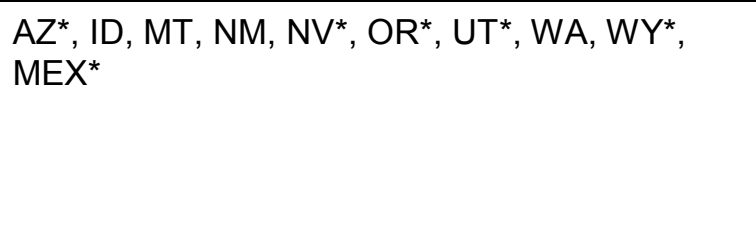 & $\begin{array}{l}25<2013 \\
15<2016 \\
10>2017 \\
\text { (only unbundled, } \\
100 \% \text { for bundled) }\end{array}$ \\
\hline $\mathrm{CO}^{\mathrm{a}}$ & $19.1 /-/ 0.8 /-$ & $19.5 /-/ 0.8 /-$ & $19.8 /-/ 0.8 /-$ & WY & 8 \\
\hline CT & $23 /-/-/-$ & $23 /-/-/-$ & $23 /-/-/-$ & $\begin{array}{l}\mathrm{MA}, \mathrm{ME}, \mathrm{NH}, \mathrm{NY}^{*}, \mathrm{RI}, \mathrm{VT}, \mathrm{NB}^{*}, \mathrm{NL}^{*}, \mathrm{NS}^{*}, \mathrm{QC}^{*} \\
\mathrm{NFI}^{*}, \mathrm{PEI}^{*}\end{array}$ & 59 \\
\hline$D E^{b}$ & $14.3 / 1.9 /-/-$ & 18.9/3/-/- & $19 / 3 /-/-$ & $\mathrm{IL}^{*}, \mathrm{IN}^{*}, \mathrm{MD}, \mathrm{PA}^{*}, \mathrm{VA}^{*}, \mathrm{WV} \mathrm{V}^{*}$ & 94 \\
\hline $\mathrm{IL}^{\mathrm{b}, \mathrm{c}}$ & $8 / 0.1 / 0.1 / 3.5$ & $11.9 / 0.2 / 0.1 / 5.2$ & $12.2 / 0.21 / 0.1 / 5.4$ & $\begin{array}{l}\text { IA, IN, MD, MN, MO, ND, NY, OH, PA, SD, VA, } \\
\text { WI, WV }\end{array}$ & 60 \\
\hline$M A^{b}$ & $14.8 / 3.5 /-/-$ & $19.1 / 3.6 /-/-$ & $23.4 / 3.6 /-/-$ & $\begin{array}{l}\mathrm{CT}, \mathrm{ME}, \mathrm{NH}, \mathrm{NY}^{*}, \mathrm{RI}, \mathrm{VT}, \mathrm{NB}^{*}, \mathrm{NL}^{*}, \mathrm{NS}^{*}, \mathrm{QC}^{*} \text {, } \\
\mathrm{NFI}^{*}, \mathrm{PEI}^{*}\end{array}$ & 62 \\
\hline$M D^{b, d}$ & 18.1/1.9/-/- & $20.6 / 2.1 /-/-$ & $23.1 / 2.4 /-/-$ & $\begin{array}{l}\mathrm{DE}, \mathrm{IA}, \mathrm{IL}^{*}, \mathrm{IN}^{*}, \mathrm{NC}^{*}, \mathrm{NY}^{*}, \mathrm{OH}^{*}, \mathrm{PA}^{*}, \mathrm{TN}^{*}, \mathrm{VA}^{*} \\
\text { WI8, } \mathrm{WV}^{*}\end{array}$ & 70 \\
\hline ME & $34.1 /-/-/-$ & $34.1 /-/-/-$ & $34 /-/-/-$ & $\begin{array}{l}\mathrm{CT}, \mathrm{MA}, \mathrm{NH}, \mathrm{RI}, \mathrm{VT}, \mathrm{NB}^{*}, \mathrm{NL}^{*}, \mathrm{NS}^{*}, \mathrm{QC}^{*}, \mathrm{NFI}^{*} \text {, } \\
\mathrm{PEI}^{*}\end{array}$ & 18 \\
\hline $\mathrm{Ml}$ & 8.6/-/-/- & $8.4 /-/ /--$ & 8.3/-//-- & IA, IN, MN, WI & 0 \\
\hline MN & $25.3 / 0.8 / 0.1 / 11.2$ & $28.1 / 0.8 / 0.1 / 11.2$ & $28.1 / 0.8 / 0.1 / 11.2$ & IA, MI, ND, SD, WI, MB, ON, SK & 24 \\
\hline $\mathrm{MO}^{\mathrm{b}}$ & 6.8/0.1/-/- & $10.1 / 0.2 / / /-$ & $10.1 / 0.2 /-/-$ & $\mathrm{IA}, \mathrm{KS}$, & 94 \\
\hline MT & $10.7 /-/-/-$ & $10.7 /-/-/-$ & $10.7 /-/ / /-$ & $\mathrm{ND}^{*}, \mathrm{OR}^{*}, \mathrm{WA}^{*}, \mathrm{BC}^{*}$ & 6 \\
\hline NC & $4.1 / 0.2 /-/-$ & $4.9 / 0.2 /-/-$ & $4.7 / 0.2 /-/-$ & $\begin{array}{l}\mathrm{AL}^{*}, \mathrm{FL}^{*}, \mathrm{GA}^{*}, \mathrm{LA}^{*}, \mathrm{MS}^{*}, \mathrm{OH}^{*}, \mathrm{PA}^{*}, \mathrm{SC}^{*}, \mathrm{TN}^{*} \\
\mathrm{VA}^{*}, \mathrm{WV}^{*}\end{array}$ & 43 \\
\hline $\mathrm{NH}^{\mathrm{b}}$ & $20 / 0.3 /-/-$ & 24.4/0.3/-/- & $24.4 / 0.3 /-/-$ & $\begin{array}{l}\mathrm{CT}, \mathrm{MA}, \mathrm{ME}, \mathrm{NY}^{*}, \mathrm{RI}, \mathrm{VT}, \mathrm{NB}^{*}, \mathrm{NL}^{*}, \mathrm{NS}^{*}, \mathrm{QC}^{*} \\
\mathrm{NFI}^{*}, \mathrm{PEI}^{*}\end{array}$ & 35 \\
\hline
\end{tabular}




\begin{tabular}{|c|c|c|c|c|c|}
\hline \multirow[b]{2}{*}{ State } & \multicolumn{3}{|c|}{ RPS target / Solar / DG / Wind set-asides (\%) } & \multirow{2}{*}{$\begin{array}{l}\text { Allowable states for REC import, includes } \\
\text { Canadian provinces ('bundling requirement) }\end{array}$} & \multirow{2}{*}{$\begin{array}{l}\text { REC import limit } \\
\text { (\% of RPS target) }\end{array}$} \\
\hline & 2020 & 2025 & 2030 & & \\
\hline $\mathrm{NJ}^{\mathrm{b}}$ & $23.5 / 3.4 /-/-$ & $24 / 4.3 /-/-$ & $24.1 / 6.7 /-/-$ & $\mathrm{DE}, \mathrm{IL}^{*}, \mathrm{IN}^{*}, \mathrm{MD}, \mathrm{OH}^{*}, \mathrm{PA}^{*} \mathrm{VA}^{*}, \mathrm{WV}^{*}$ & 76 \\
\hline NM & $16 / 2.8 / 0.4 / 4.1$ & $16 / 2.8 / 0.4 / 4.1$ & $16 / 2.8 / 0.4 / 4.1$ & - & 0 \\
\hline NV & 16.4/0.5/-/- & 21.1/0.6/-/- & 21.2/0.6/-/- & - & 100 \\
\hline NY & 7.2/-/0.6/- & $7.2 /-/ 0.6 /-$ & $7.2 /-/ 0.6 /-$ & $\mathrm{RI}^{*}, \mathrm{ON}^{*}, \mathrm{QC}^{*}$ & 4 \\
\hline $\mathrm{OH}^{\mathrm{b}}$ & $5.7 / 0.2 /-/-$ & $10.1 / 0.4 /-/-$ & $11.1 / 0.4 /-/-$ & $\mathrm{IN}^{*}, \mathrm{KY}^{*}, \mathrm{MI}^{*}, \mathrm{PA}^{*}, \mathrm{WV}^{*}$ & 57 \\
\hline $\mathrm{OR}^{\mathrm{b}}$ & $14.2 / 0.02 /-/-$ & 20.5/0.02/-/- & $26.2 / 0.02 /-/-$ & $\mathrm{CA}^{*}, \mathrm{ID}^{*}, \mathrm{MT}^{*}, \mathrm{UT}^{*}, \mathrm{WA}^{*}, \mathrm{WY}^{*}, \mathrm{BC}^{*}$ & 42 \\
\hline $\mathrm{PA}^{\mathrm{b}}$ & $7.8 / 0.5 /-/-$ & $7.8 / 0.5 /-/-$ & 7.8/0.5/-/- & $\mathrm{DE}, \mathrm{IL}, \mathrm{IN}, \mathrm{MD}, \mathrm{NC}, \mathrm{NJ}, \mathrm{OH}, \mathrm{VA}, \mathrm{WV}$ & 47 \\
\hline $\mathrm{RI}$ & $15.9 /-/-/-$ & $23.3 /-/-/-$ & $30.8 /-/-/-$ & 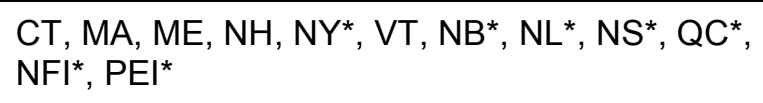 & 77 \\
\hline TX & $4.4 /-/-/-$ & $4.2 /-/-/-$ & $4 /-/-/-$ & - & 0 \\
\hline VT & $59 /-/ 2.8 /-$ & $63 /-/ 5.8 /-$ & 71/-/8.8/- & $\mathrm{CT}, \mathrm{MA}, \mathrm{ME}^{*}, \mathrm{NH}, \mathrm{RI}$ & 100 \\
\hline WA & $11.9 /-/-/-$ & 11.9/-/-/- & $11.9 /-/-/-$ & ID, MT, OR, BC* & 43 \\
\hline WI & 9.9/-/-/- & 9.9/-/-/- & $10 /-/-/-$ & $\mathrm{IA}^{*}, \mathrm{MI}^{*}, \mathrm{MN}^{*}, \mathrm{ND}^{*}, \mathrm{SD}^{*}, \mathrm{MB}^{*}, \mathrm{SK}^{*}$ & 41 \\
\hline
\end{tabular}

"Interstate REC transactions that are required to be bundled with energy are marked with an asterisk.

${ }^{a}$ Based on historical observation, only $50 \%$ of the actual DG carve out for Colorado is assumed to be met using distributed solar technologies (DUPV and distributed PV).

${ }^{b}$ Based on historical observation, the solar carve out in these states are seen to be met only using distribution side solar technologies. Hence the solar carve out in these states are modeled as a DG carve out in ReEDS.

${ }^{c}$ Illinois allows for $50 \%$ of its RPS target to be met using alternative compliance payments, and hence ReEDS targets are adjusted to reflect this.

${ }^{d}$ Washington, D.C. RPS targets are rolled into Maryland (Washington D.C. load also rolled into Maryland). 


\subsection{Other Policy Capabilities}

In addition to the existing policies described above, ReEDS also includes a number of policy implementations that are useful for exploring alternative futures or the impact of existing policies. These additional policy frameworks include

- National Clean Energy Standard: This framework allows the user to specify which technologies count as "clean energy" and enforce a minimum limit for the penetration of these clean energy technologies.

- National Renewable Portfolio Standard: This standard enforces a national RPS, with the RPS trajectory defined by the user.

- Carbon Tax: This feature implements a user-specified carbon tax on burner-tip emissions from the power sector.

- National Emissions Limit: This framework limits the total national emissions according to user-specified values. The limit is often referred to as a carbon cap or $\mathrm{CO}_{2}$ cap.

- Alternative ITC and PTC Schedules: In addition to the ITC and PTC schedules described in Section 8.2, the ITC and PTC can be modified to apply for any number of years and to any technology.

- Alternative Financing Measures: Policy-related financing impacts such as MACRS or the under construction provisions for the ITC and PTC can be modified as specified by the user. 


\section{Capital Financing, System Cost, and Electricity Rates}

\subsection{Financing of Capital Stock}

Assumptions for the cost of financing vary considerably across the literature (Mai et al. 2015).

ReEDS uses generalized financial assumptions that are typically standardized across technologies. Using a standardized method allows technologies to be compared without projecting technology-specific risk profiles or specialized financing vehicles into the future. In other words, these simplified assumptions allow different projects and technologies to be compared and to compete across the long time horizon and spatial extent of ReEDS. The disadvantage of this approach is that many financing cost differences between technologies based on current practices are not well captured by ReEDS.

Using a utility-owned project perspective, ReEDS discounts future transactions, accounts for tax benefits, and weighs risk where possible. Table 20 lists the major financing parameters used in ReEDS. All costs, including new capital investments, O\&M costs, fuel costs, and transmission investments are considered on a 20 -year net present value basis. The discount rate used in the present value evaluation is the weighted average cost of capital based on the parameters shown by Table 20 and is $8.1 \%$ nominal $(5.4 \%$ real $) .{ }^{61}$

Table 20. Key Financial Assumptions

\begin{tabular}{ll}
\hline Evaluation Period & 20 Years \\
\hline Inflation rate & $2.5 \%$ \\
Interest rate—nominal & $8 \%$ \\
Rate of return on equity_nominal & $13 \%$ \\
Debt fraction & $60 \%$ \\
Combined state and federal tax & $40 \%$ \\
Weighted average cost of capital—nominal (real) & $8.1 \%(5.4 \%)$ \\
MACRS (non-hydropower renewables) & 5 years \\
MACRS (nuclear, combustion turbines) & 15 years \\
MACRS (other fossil, hydropower, storage) & 20 years \\
\hline
\end{tabular}

Key parameters for the weighted average cost of capital include the assumed rate of return on equity (RROE), the allowed debt fraction, and the debt interest rate. The nominal 13\% RROE assumption is intended to reflect long-term RROEs for a broad range of corporations and electric generation projects it generally falls within the ranges of RROEs reported elsewhere. For example, according to Edison Electric Institute, approved RROEs since 1990 for regulated investor-owned utilities have ranged from $10.0 \%$ to $12.9 \%$, with an average awarded RROE of $11.2 \%$ (EEI 2010a). The California Energy Commission, meanwhile, assumed an average rate of return on equity capital of $11.9 \%$ for investor-owned utility generation and $14.5 \%$ for merchant-

${ }^{61}$ ReEDS considers all costs in real dollar terms, but the parameters presented in Table 20 are primarily nominal. 
based generation (CEC 2009). The National Energy Technology Laboratory recommended a RROE of 20\% for independent power producer (IPP) development of fossil-based resources (NETL 2008).

The debt fraction of $60 \%$ is based on a literature survey by Mai et al. (2015) and summarized in Table 21 (next page). The debt interest rate assumption of $8 \%$ we use in ReEDS is roughly consistent with a long-term corporate bond interest rate forecast in EIA's AEO 2010. EIA forecasted a 7.6\% average interest rate for AA-rated utility bonds through 2035 (EIA 2010). The AA-rated utility bond would generally represent the borrowing cost for a project developed by an investment-grade investor-owned utility (IOU). The debt interest rate during construction is assumed to be consistent with the term debt (Harper, Karcher, and Bolinger 2007).

In addition to the general financial assumptions made, some technology-specific parameters are used within ReEDS. In particular, technology-specific construction periods yield different construction financing costs with greater amount of interest required for technologies that have longer construction periods. Tax credits and accelerated tax depreciation rules also yield different financing costs between technologies. Other modeled differences in financing terms between technologies are associated with the renewable tax credits (Section 8.2). We model lower debt fractions, resulting in higher WACCs when a tax credit (ITC or PTC) is available to reflect some of the higher costs associated with financing these projects. Bolinger (2015) summarizes these considerations and Mai et al. (2015) describe this implementation in detail. 
Table 21. Summary of Debt Fractions Found in the Literature

\begin{tabular}{|c|c|c|c|c|c|c|c|}
\hline \multirow[b]{2}{*}{ Source } & \multirow[b]{2}{*}{ Report Title } & \multirow{2}{*}{$\begin{array}{l}\text { Source } \\
\text { Year }\end{array}$} & \multicolumn{4}{|c|}{ Debt Fraction } & \multirow[b]{2}{*}{ Notes } \\
\hline & & & Default & IOU & IPP & With Solar ITC & \\
\hline $\begin{array}{l}\text { Bloomberg New } \\
\text { Energy Finance }\end{array}$ & H2 2014 LCOE & 2014 & $70 \%$ & - & - & - & \\
\hline $\begin{array}{l}\text { California Energy } \\
\text { Commission }\end{array}$ & $\begin{array}{l}\text { Estimated Cost of New Renewable and Fossil } \\
\text { Generation in California }\end{array}$ & 2014 & - & $45 \%$ & $60 \%$ & - & \\
\hline E3/WECC & $\begin{array}{l}\text { Capital Cost Review of Power Generation } \\
\text { Technologies }\end{array}$ & 2014 & - & $45 \%$ & - & $\begin{array}{l}44.9 \% \text { at } 30 \% \\
\text { ITC } \\
60.6 \% \text { at } 10 \% \\
\text { ITC }\end{array}$ & $\begin{array}{l}\text { PV Tracking } \\
>20 \mathrm{MW}\end{array}$ \\
\hline $\begin{array}{l}\text { Edison Electric } \\
\text { Institute }\end{array}$ & $\begin{array}{l}2014 \text { Financial Review: Annual Report of the } \\
\text { U.S. Investor-Owned Electric Utility Industry }\end{array}$ & 2014 & - & $56.7 \%$ & - & & For IOUs only \\
\hline $\begin{array}{l}\text { Electric Power } \\
\text { Research Institute }\end{array}$ & $\begin{array}{l}\text { Program on Technology Innovation: Integrated } \\
\text { Generation Technology Options } 2012\end{array}$ & 2013 & - & $50 \%$ & - & & \\
\hline EIA & $\begin{array}{l}\text { The Electricity Market Module of the National } \\
\text { Energy Modeling System: Model } \\
\text { Documentation } 2014\end{array}$ & 2014 & $45 \%$ & - & - & & \\
\hline EPA & (IPM Documentation) & unknown & $55 \%$ & - & - & & $\begin{array}{l}\text { Relies on } 75 / 25 \text { IOU/IPP } \\
\text { blend. }\end{array}$ \\
\hline Lazard & $\begin{array}{l}\text { Lazard's Levelized Cost of Energy Analysis- } \\
\text { Version } 8.0\end{array}$ & 2014 & $60 \%$ & - & - & $\begin{array}{l}30 \% \text { at } 30 \% \text { ITC } \\
60 \% \text { at } 10 \% \text { ITC }\end{array}$ & \\
\hline $\begin{array}{l}\text { Massachusetts } \\
\text { Institute of } \\
\text { Technology }\end{array}$ & Future of Solar & 2015 & $60 \%$ & & & & \\
\hline $\begin{array}{l}\text { National Energy } \\
\text { Technology } \\
\text { Laboratory }\end{array}$ & $\begin{array}{l}\text { Recommended Project Finance Structures for } \\
\text { the Economic Analysis of Fossil-Based Energy } \\
\text { Projects }\end{array}$ & 2011 & - & $50 \%$ & $70 \%$ & & \\
\hline $\begin{array}{l}\text { Lawrence Berkeley } \\
\text { National Laboratory }\end{array}$ & $\begin{array}{l}\text { An Analysis of the Costs, Benefits, and } \\
\text { Implications of Different Approaches to } \\
\text { Capturing the Value of Renewable Energy Tax } \\
\text { Incentives }\end{array}$ & 2014 & - & - & - & $\begin{array}{l}44.4 \% \text { at } 30 \% \\
\text { ITC } \\
58.1 \% \text { at } 10 \% \\
\text { ITC }\end{array}$ & \\
\hline
\end{tabular}

The table is reproduced from Mai et al. (2015). 


\subsection{Electric Sector Costs}

Two system-wide cost metrics are calculated from each ReEDS run: a present value of direct electric sector system costs and a national-average retail electricity price. These cost calculations are not part of the ReEDS optimization process; they are calculated after the ReEDS optimizations have been conducted. The cost metrics provided directly from ReEDS do not include any environmental or health externalities (e.g., social cost of carbon emissions).

\subsubsection{Present Value of Direct Electric Sector Cost}

The present value system cost metric accounts for capital and operating expenditures incurred over the entire study horizon for all technology types considered, including generation, transmission, and storage. The cost in each future year is discounted by a social discount. Not to be confused with the discount rate used in the optimization for investment decisions, the social discount rate is selected to represent private-sector investment decisions for electric system infrastructure and approximates the expected market rate of return of investors. All costs incurred prior to the start of the specified economic horizon are assumed to be sunk. The costs incurred from investments made near the end of the economic horizon are prorated to account for only the years in which the investment is used.

\subsubsection{Electricity Price}

In ReEDS, electricity prices are estimated assuming a restructured market ("cost-of-service") with a 30-year rate base or amortization of all investments to 30 equal annual payments. Investments include investments for new generation capacity, replaced generation capacity, and new transmission lines. The output electricity price — reported by BA—is a weighted average of the electricity prices for each time-slice, which are calculated differently depending on whether the region is a net importer or net exporter. The methodology uses a calibration step to match historical (2010) retail rates to consider distribution costs and/or the markup between wholesale and retail rates for regions with restructured markets. This additional cost is assumed to be uniform across all years. While this metric is not indicative of actual retail prices in all regions (e.g., price impacts for restructured markets are not evaluated with ReEDS), it provides an indication of the price impacts over time. Details about how the cost-of-service prices are calculated in ReEDS can be found in the appendix under the "Cost-of-Service Electricity Prices" section.

There is also another methodology within ReEDS to calculate the "competitive" 62 instead of the regulated electricity price (Murphy and Smeers 2005; Ventosa et al. 2005; EIA 2014b). This calculation takes advantage of the linear programming formulation of the model. Specifically, the marginal price on a model constraint represents how much the objective function would change given a change in the right-hand side of the constraint. Each constraint can be viewed as a market with a marginal price and quantity. At optimality, the total revenue (the product of price and quantity) across all constraints is equal to the objective function value.

\footnotetext{
${ }^{62}$ See Murphy and Smeers (2005), Ventosa et al. (2005) and EIA (2014b)
} 
The constraints within ReEDS are written such that the marginal values from the load constraints can be used as a proxy for the competitive electricity price. The load constraints are linked to the supply-demand balance constraints, capacity constraints, operating reserve constraints, and others ${ }^{63}$ through load variables. Taking the marginal value off the load constraint, we can find the marginal value of an additional unit of load (e.g., MWh) to the system, taking into account the additional energy, capacity, and operating reserves required. In other words, the reported competitive prices in ReEDS capture energy and capacity costs. It is assumed that this methodology mimics a competitive electricity market's behavior better than the regulated electricity price discussed above. The user has the choice to use the competitive price, the regulated price, or a blending of the two to calculate the national or regional electricity prices.

\footnotetext{
${ }^{63}$ Specifically, state RPS constraints
} 


\section{Extension of ReEDS Model to Canada}

As discussed in Section 6, ReEDS includes an exogenous representation of Canada. However, the ReEDS model also includes the capability to model Canada endogenously. This U.S.-Canada version of the ReEDS model, which is referred to as ReEDS-Canada, is described here. The ReEDS-Canada model includes 18 additional BAs and 45 new wind/CSP regions as shown in Figure 27. The new BAs only cover areas where the grid is directly connected and therefore do not include the Yukon, Northwest Territories, Nunavut, and parts of Newfoundland and Labrador. $^{64}$

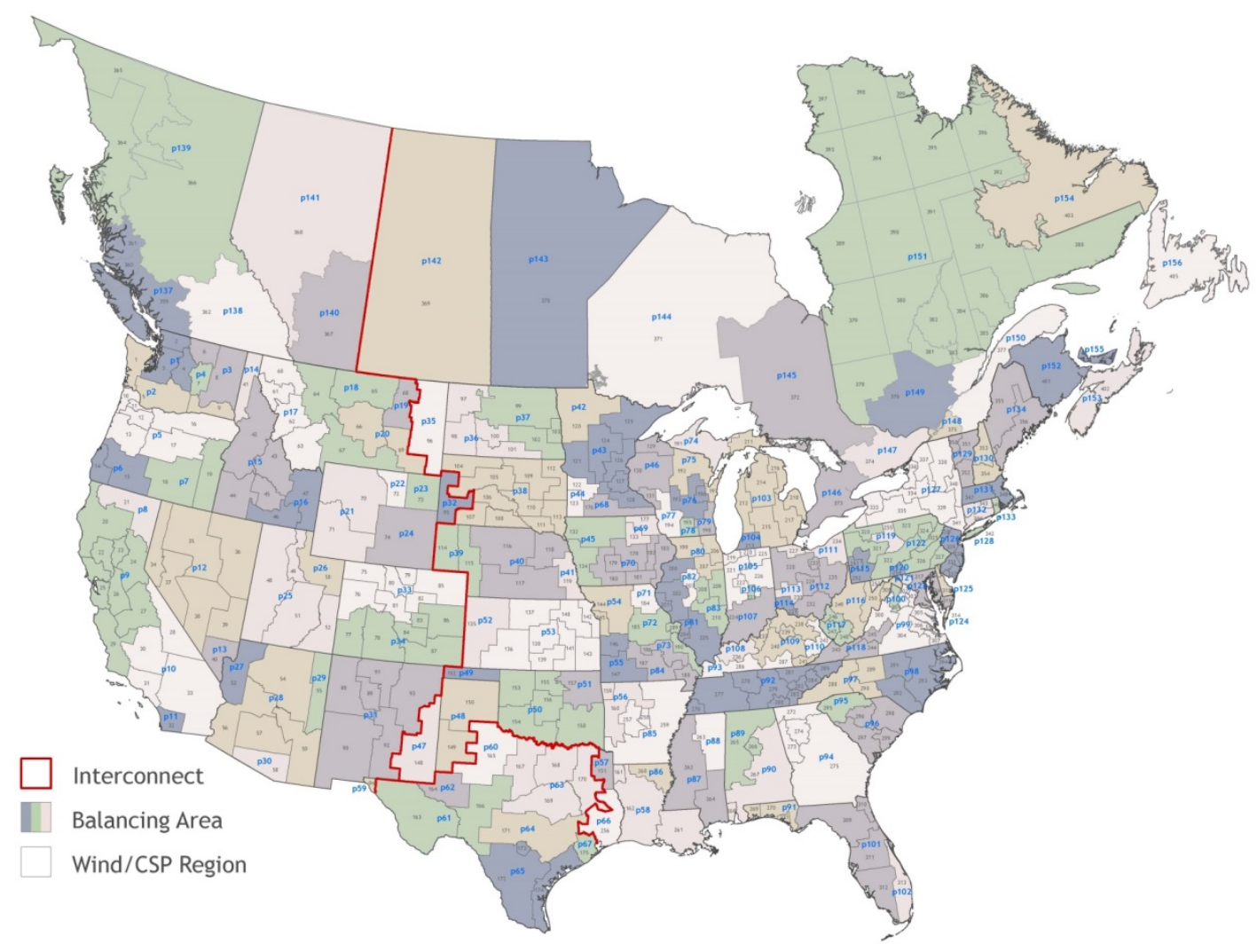

Figure 27. Regions defined in the ReEDS-Canada model

\subsection{Fuel Price and Availability}

Natural gas supply and demand dynamics are represented in ReEDS through regional supply curves along EIA Census Division boundaries (see the section titled, "Natural Gas Supply Curves" in the appendix). For Canadian provinces, the U.S.-only regional supply curves are modified based on consumption projections from the National Energy Board's Canada's Energy Future 2016 (NEB 2016). Natural gas supply curves are modified to capture the additional supply and demand for natural gas in Canadian regions; adjacent Canadian provinces are assigned to EIA census divisions. A map of this allocation is shown in Figure 28.

\footnotetext{
${ }^{64}$ The Labrador region that is adjacent to Quebec is represented in the model, while Newfoundland Island is not represented.
} 


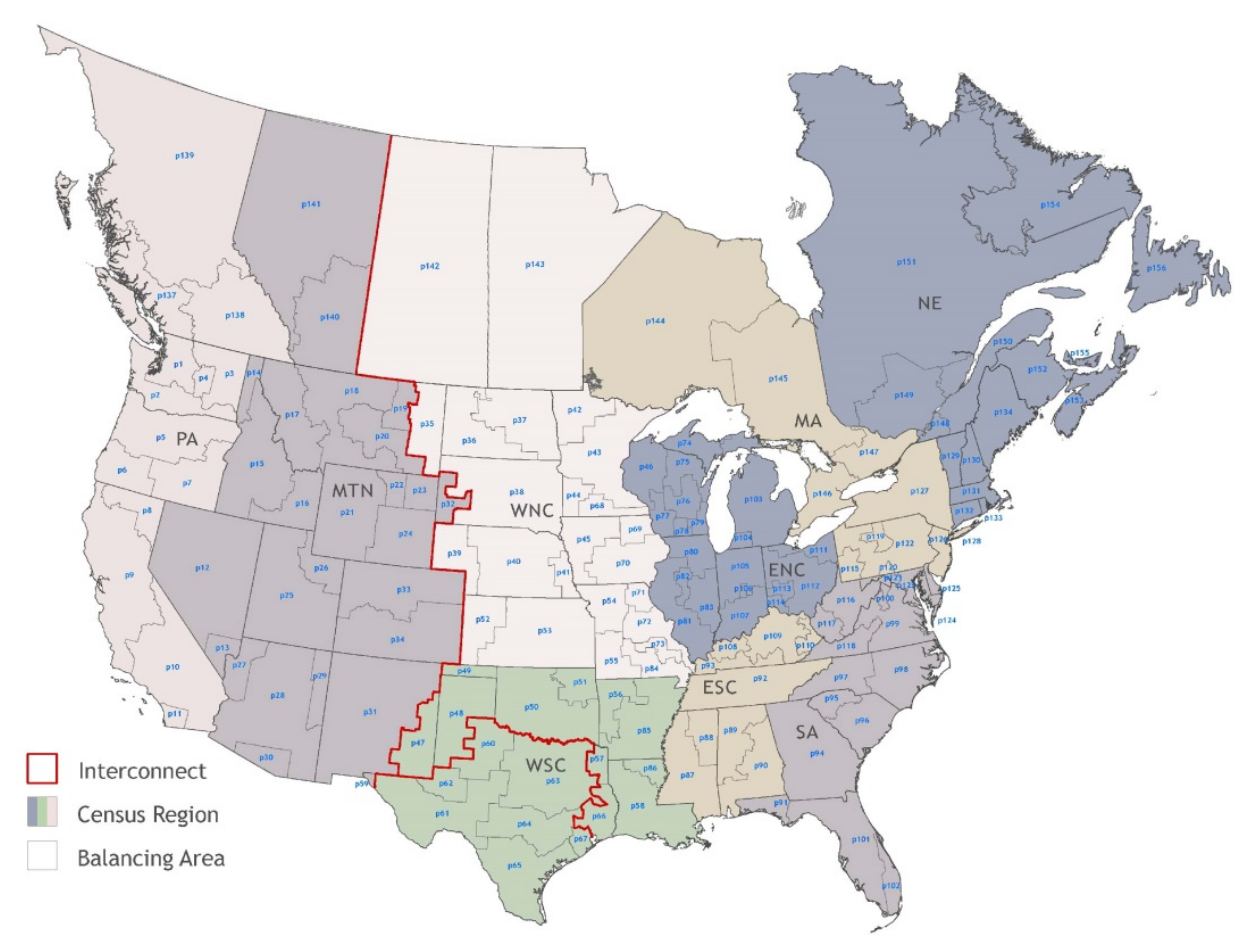

Figure 28. Map of EIA Census Division boundaries extended to Canadian provinces

Canadian coal prices are provincial and represented as inelastic to changes in consumption; they are consistent with Canadian provincial coal price projections from NEB (2016). The price of nuclear fuel for Canadian units is assumed to be same as those for nuclear units in the United States.

\subsection{Electricity Demand}

Annual electricity demand projections are based on the NEB (2016) reference scenario, and they reflect annual provincial load reduced by customer-sited electricity cogeneration. Provincial and zonal load shapes are described in Martinez et al. (2013). For provinces comprised of multiple ReEDS BAs (Alberta, British Columbia, Ontario, and Quebec), the spatial distribution of annual provincial electricity demand among BAs is also described in Martinez et al. (2013).

\subsection{Canadian Generation Fleet Representation}

Consistent with the representation of the generation fleet in the contiguous United States within ReEDS, the ABB Velocity Suite is used as a basis for Canadian generation units (ABB 2016). This data set is then cross-referenced with NEB (2016) and provincial energy plans to represent the Canadian fleet. The existing fleet, prescribed new builds, and prescribed retirements are all based on the ABB Velocity Suite database (ABB 2016).

Potential new transmission lines between the United States and Canada are from a list of pending applications as of January 2016 (DOE 2016a). Lines that are not yet under construction are allowed to be built in the ReEDS-Canada model, but they are not forced to be built. Transmission lines in Canada are assumed to have the same cost as their neighboring regions in the U.S. Table 22 summarizes pending cross-border transmission lines as of January 2016. 
Table 22. Pending Cross-Border Transmission Lines as of January 2016 (DOE 2016a)

\begin{tabular}{|c|c|c|c|c|c|c|c|}
\hline Name & Sponsor & State-Province & $\begin{array}{l}\text { Length } \\
\text { (miles) }\end{array}$ & $\begin{array}{l}\text { Voltage and } \\
\text { Capacity }\end{array}$ & Purpose & $\begin{array}{l}\text { In-service } \\
\text { Date }\end{array}$ & Permit Status \\
\hline $\begin{array}{l}\text { Champlain } \\
\text { Hudson Power } \\
\text { Express }\end{array}$ & $\begin{array}{l}\text { Transmission } \\
\text { Developers Inc. }\end{array}$ & $\begin{array}{l}\text { New York- } \\
\text { Québec }\end{array}$ & 333 & $\begin{array}{l}\text { 1,000 MW, } \\
\text { HVDC }^{\mathrm{a}} \\
\text { (underwater, } \\
\text { underground, } \\
\text { merchant) }\end{array}$ & $\begin{array}{l}\text { Deliver hydro and } \\
\text { wind energy from } \\
\text { QC to New York City } \\
\text { area }\end{array}$ & $\begin{array}{l}\text { Fall } 2017 \\
\text { (expected) }\end{array}$ & $\begin{array}{l}\text { Permit issued } \\
\text { October } 2014\end{array}$ \\
\hline $\begin{array}{l}\text { Great Northern } \\
\text { Transmission } \\
\text { Line }\end{array}$ & $\begin{array}{l}\text { Minnesota } \\
\text { Power (MP) }\end{array}$ & $\begin{array}{l}\text { Minnesota- } \\
\text { Manitoba }\end{array}$ & 220 & $\begin{array}{l}500 \mathrm{kV} \\
750 \mathrm{MW}, \mathrm{AC}\end{array}$ & $\begin{array}{l}\text { Part of MP-MB } \\
\text { Hydro PPA; supports } \\
\text { building wind in } \\
\text { North Dakota }\end{array}$ & $\begin{array}{l}\text { June } 2020 \\
\text { (expected) }\end{array}$ & $\begin{array}{l}\text { Application filed } \\
\text { April } 2014\end{array}$ \\
\hline $\begin{array}{l}\text { Lake Erie } \\
\text { Connector }\end{array}$ & ITC & $\begin{array}{l}\text { Pennsylvania- } \\
\text { Ontario }\end{array}$ & 72.4 & $\begin{array}{l}\text { 1,000 MW, } \\
\text { HVDC } \\
\text { (underwater, } \\
\text { merchant) }\end{array}$ & $\begin{array}{l}\text { Deliver surplus ON } \\
\text { renewable energy, } \\
\text { enhance service } \\
\text { reliability }\end{array}$ & Q4 2019 & $\begin{array}{l}\text { Application filed } \\
\text { May } 2015\end{array}$ \\
\hline $\begin{array}{l}\text { New England } \\
\text { Clean Power Link }\end{array}$ & $\begin{array}{l}\text { TDI-New } \\
\text { England }\end{array}$ & $\begin{array}{l}\text { Vermont- } \\
\text { Québec }\end{array}$ & 154 & $\begin{array}{l}\text { 1,000 MW, } \\
\text { HVDC } \\
\text { (underwater, } \\
\text { underground, } \\
\text { merchant) }\end{array}$ & $\begin{array}{l}\text { Deliver renewable } \\
\text { energy from QC into } \\
\text { VT and New } \\
\text { England }\end{array}$ & $\begin{array}{l}2019 \\
\text { (expected) }\end{array}$ & $\begin{array}{l}\text { Application filed } \\
\text { May } 2014\end{array}$ \\
\hline Northern Pass & $\begin{array}{l}\text { Northern Pass } \\
\text { Transmission } \\
\text { LLC }\end{array}$ & $\begin{array}{l}\text { New Hampshire- } \\
\text { Québec }\end{array}$ & 187 & $\begin{array}{l}\text { 1,200 MW, } \\
\text { HVDC line with } \\
345 \text { kV AC spur }\end{array}$ & $\begin{array}{l}\text { Deliver QC hydro } \\
\text { into } \mathrm{NH} \text { and New } \\
\text { England }\end{array}$ & $\begin{array}{l}2017 \\
\text { (expected) }\end{array}$ & $\begin{array}{l}\text { Application filed } \\
\text { October 2010; } \\
\text { re-filed with new } \\
\text { route July } 2013\end{array}$ \\
\hline $\begin{array}{l}\text { Soule River } \\
\text { Hydroelectric } \\
\text { Project }\end{array}$ & $\begin{array}{l}\text { Soule Hydro, } \\
\text { LLC }\end{array}$ & $\begin{array}{l}\text { Alaska-British } \\
\text { Columbia }\end{array}$ & 10 & $\begin{array}{l}138 \text { kV, HVAC } \\
\text { (submarine) }\end{array}$ & $\begin{array}{l}\text { Support } 77 \mathrm{MW} \\
\text { hydro project in AK } \\
\text { (sales to BC or } \\
\text { Pacific NW) }\end{array}$ & $\begin{array}{l}\text { To be } \\
\text { determined }\end{array}$ & $\begin{array}{l}\text { Application filed } \\
\text { March } 2013\end{array}$ \\
\hline
\end{tabular}

${ }^{a}$ high-voltage, direct current 


\subsection{Renewable Energy Representation}

\subsubsection{Hydropower Generation Capacity}

ReEDS is not allowed to endogenously build new hydropower capacity in Canada due to a lack of available hydropower supply curves that are compatible with those developed for the United States. So, we rely on a schedule of expected builds from NEB (2016) for new Canadian hydropower units. While annual hydropower output can fluctuate significantly from year to year based on precipitation and other weather patterns, we assume there is no inter-annual variation in available hydropower generation in ReEDS; rather, average capacity factors are assumed that reflect long-run historical averages. Seasonal hydropower capacity factors are specified for each Canadian province that are derived from NEB (2013).

\subsubsection{Wind Resource}

The classification of wind resource into TRGs requires processing typical wind speed profiles, which NREL licenses from AWS Truepower for the United States. The Canadian wind data set has geographical information of average wind speed (Environment Canada 2008). To convert average wind speed into TRGs, we performed an analysis of the U.S. wind resource data, which showed a high level of correlation between average wind speed and capacity factor. Ultimately, annual capacity factor determines the TRG classification. Linear regressions were performed for the western (Figure 29), central (Figure 30) and eastern (Figure 31) U.S. states adjacent to Canada to account for distinct regional wind climates; these regression curves were used to translate Canadian average wind speed into annual average capacity factor and thereafter assign each potential Canadian wind resource a TRG.

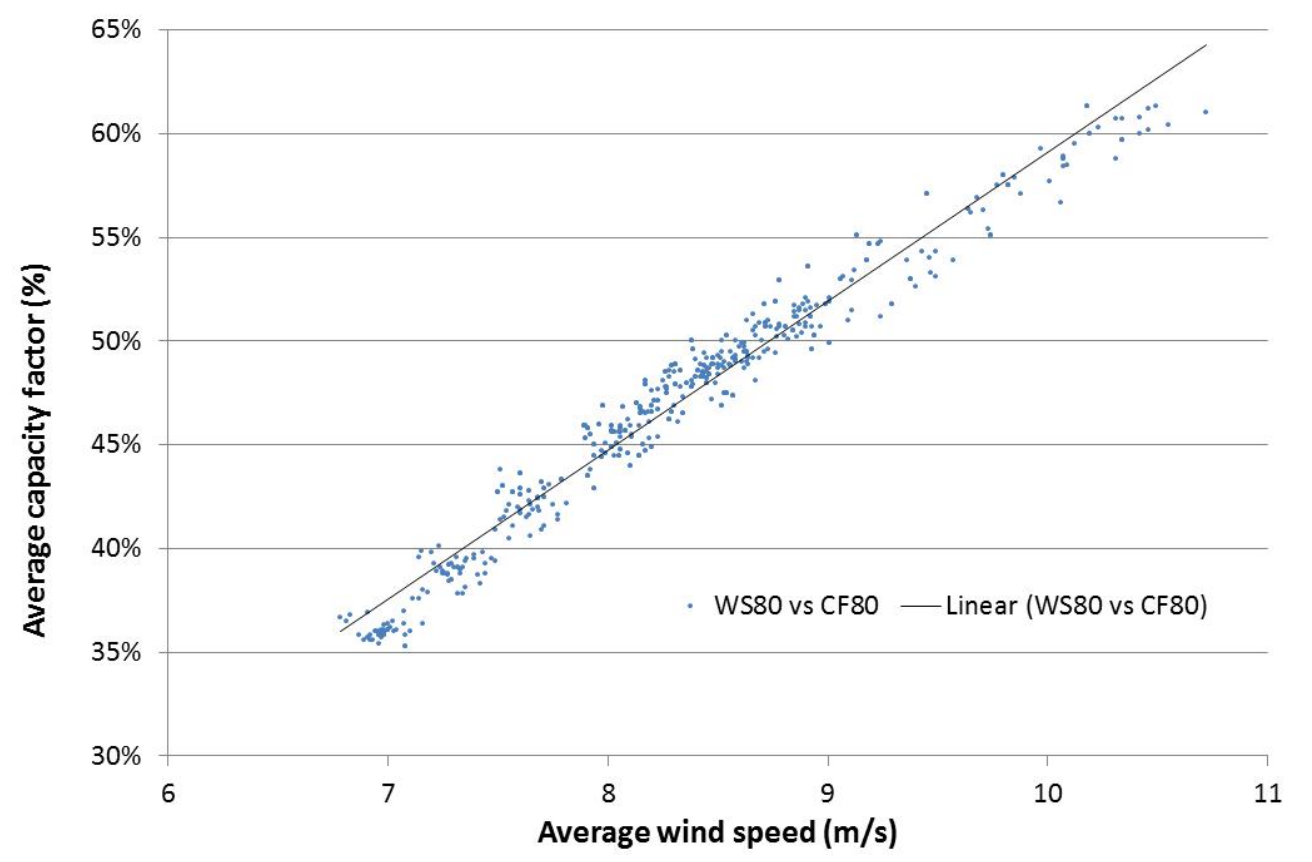

Figure 29. Capacity factor versus average wind speed in the western United States 


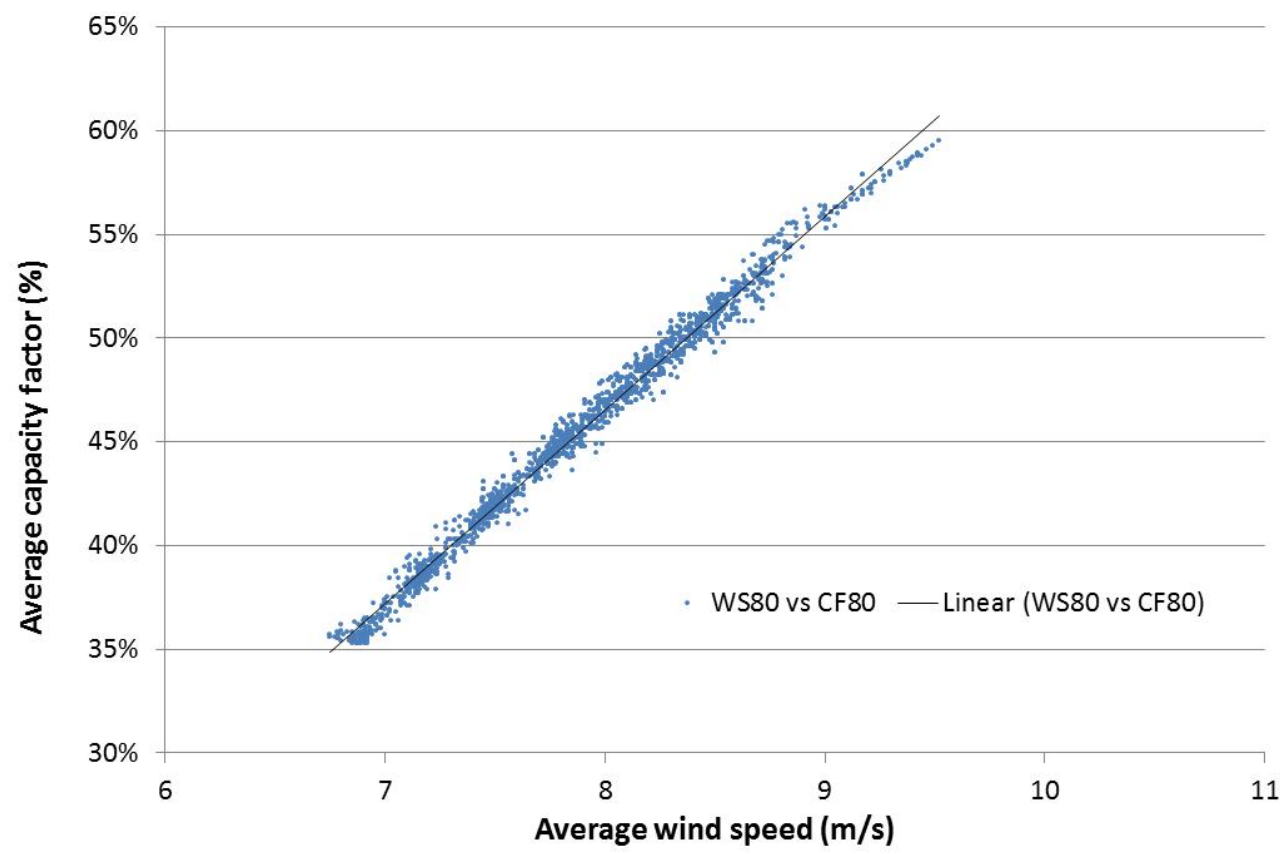

Figure 30. Capacity factor versus average wind speed in the U.S. Great Lakes

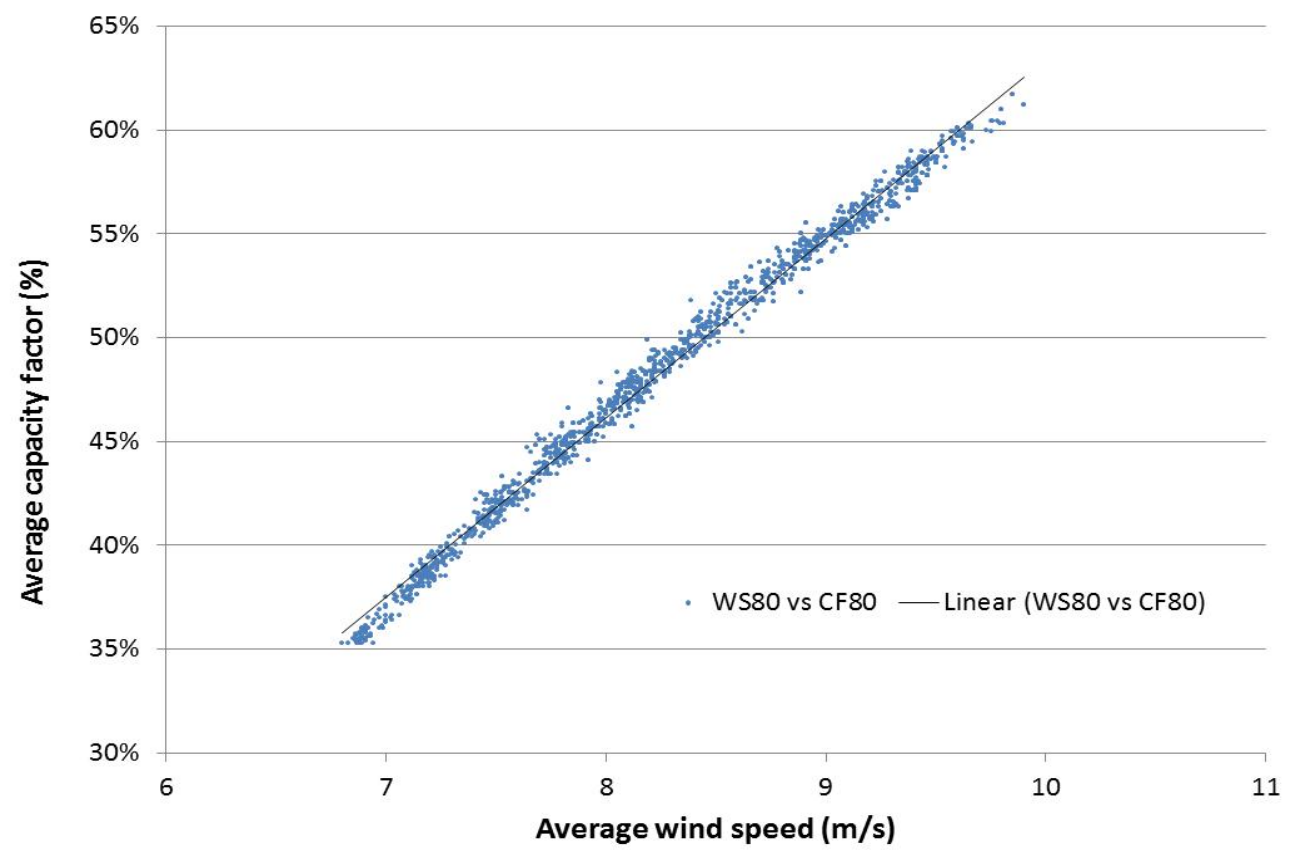

Figure 31. Capacity factor versus average wind speed in the northeast United States

We applied land exclusions to the Canadian wind resource data and implemented the same categories used in the U.S. analysis wherever adequate Canadian data were available. The exclusions include national parks and competing land use categories. Figure 32 illustrates the areas that were excluded from the analysis for potential wind development. Potential resources represented in Canada are 7,854 GW of land-based wind and 13,259 GW of offshore wind. 


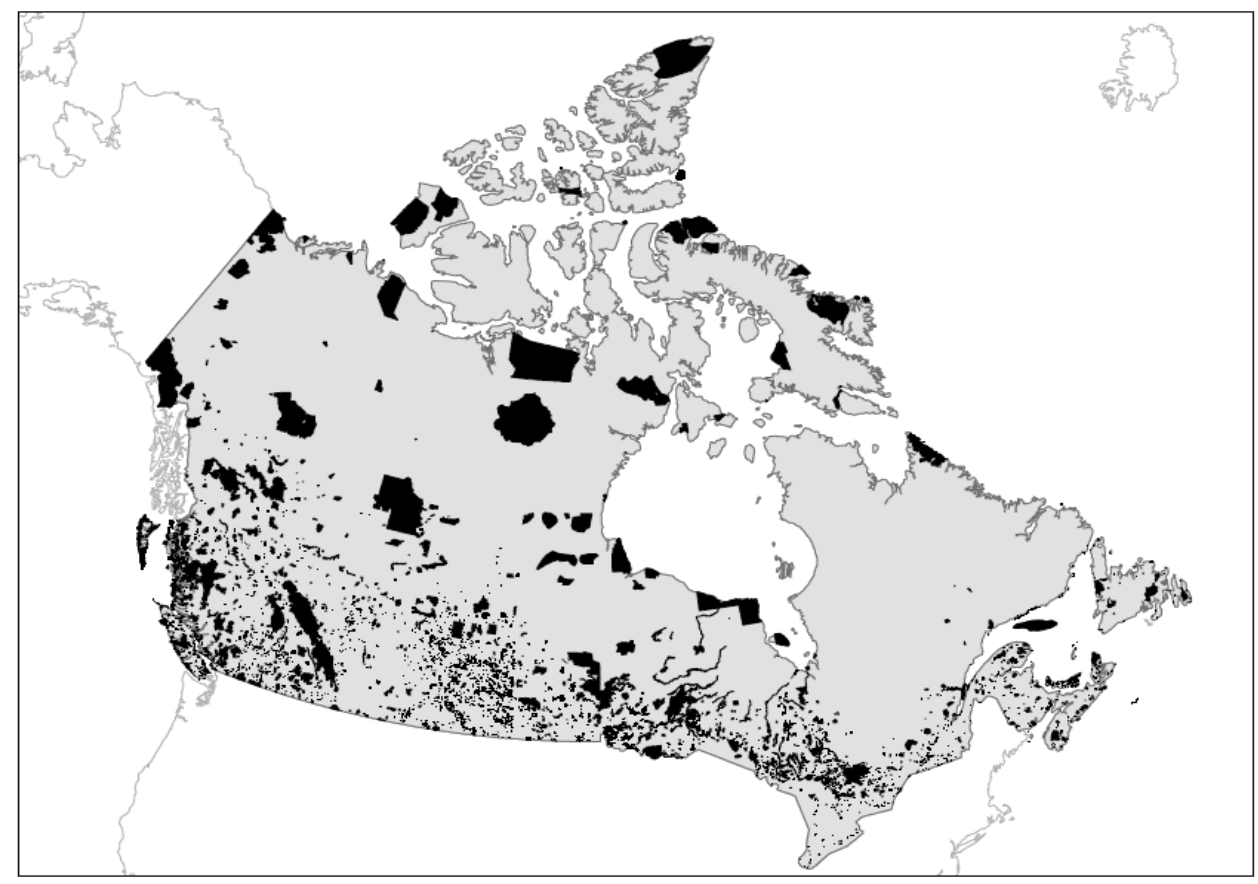

Figure 32. Land exclusions applied to Canadian wind resource

\subsubsection{Solar Resource}

Solar insolation data were obtained from the "Canadian Weather year for Energy Calculation," 65 a data set comprising 12 typical meteorological months (derived from almost 30 years of data) from 80 weather stations throughout Canada (Environment Canada 2014). Average insolation data were then aggregated to the ReEDS BA level and applied in SAM to create hourly output profiles for a representative utility-scale PV plant. ${ }^{66}$ Hourly plant output from SAM was then aggregated to ReEDS time-slice granularity and applied in the model.

The deployment of residential and commercial rooftop PV systems is exogenously defined in ReEDS using output from NREL's dGen model (see Section 2.1.3). Because this model is not currently designed to capture consumer behavioral dynamics in Canada, we assume no rooftop PV deployment in Canada. Direct normal irradiance throughout Canada is below the threshold necessary to produce economic CSP generation, and thus is not represented in Canada.

\subsubsection{Geothermal Resource}

Geothermal technologies are not represented in Canadian provinces due to a lack of sufficient information on the location and potential of geothermal resources.

\footnotetext{
${ }^{65}$ Canadian Weather year for Energy Calculation (CWEC)," https://datahub.io/dataset/canadian_weather_year_energy_calculation.

${ }^{66}$ For more information on the characteristics of this representative plant, see Short et al. (2011).
} 


\subsubsection{Biomass Resource}

The biomass feedstock supply curve for each Canadian BA is assumed to be the same as that of the contiguous BAs in the United States (scaling to account in differences in area). Future resource assessments for biomass feedstocks are needed to improve this representation.

\subsection{Policy and Regulation}

ReEDS represents existing RPS requirements for:

- New Brunswick: $40 \%$ by $2020^{67}$

- Nova Scotia: $5 \%$ by $2011,10 \%$ by $2013,25 \%$ by 2015 , and $40 \%$ by 2020 (Nova Scotia Department of Energy 2010)

- Prince Edward Island: 15\% by 2010 (Department of Environment, Energy and Forestry, n.d.).

Canadian contributions to U.S. state RPS (and vice versa) are permitted in alignment with existing laws, regulations, and practices as of October 2014. We list the rules for U.S.-Canada REC trading in Table 23, focusing on U.S. states that are physically or electrically adjacent to a Canadian province, or where international REC trading activity has been observed in practice.

\footnotetext{
67 "Provincial Government Strengthens its Commitment to Renewable Energy," news release dated August 7, 2014 http://www2.gnb.ca/content/gnb/en/news/news_release.2014.08.1007.html.
} 
Table 23. International REC Trading Rules Implemented in ReEDS

\begin{tabular}{lll}
\hline State/Province & $\begin{array}{l}\text { Canadian RECs } \\
\text { Accepted? }\end{array}$ & Notes \\
\hline California & Yes & Power must be delivered to state \\
Colorado & No & - \\
Massachusetts & Yes & Power must be delivered to ISO-New England \\
Maine & No & - \\
Michigan & No & - \\
Minnesota & Yes & Power must be delivered to state from Manitoba \\
Montana & No & - \\
Nevada & No & - \\
New Hampshire & No & - \\
New York & No & - \\
Nova Scotia & Yes & RECs accepted from New England Power Pool \\
Ohio & No & - \\
Oregon & Yes & Subject to same bundling rules as U.S. states \\
Pennsylvania & No & - \\
Rhode Island & Yes & Power must be delivered to ISO-New England \\
Washington & Yes & Power must be delivered to state \\
Wisconsin & Yes & Power must be delivered to state \\
\hline
\end{tabular}

British Columbia has a carbon tax that is applied to in-province electricity generation (British Columbia Ministry of Finance 2015). This tax is also applied to imported electricity; in this case, the average carbon intensity of delivered electricity is endogenously calculated ${ }^{68}$ and taxed appropriately. We also implement the British Columbia 2016 requirement for electricity selfsufficiency $^{69}$ (Clean Energy Act of 2010 2010).

New Canadian coal units that do not have carbon capture and storage are not in allowed in the model beginning in the 2016 solve year. The early retirement of existing coal units are reflected in the exogenous retirements of Canadian coal units. ${ }^{70}$

\footnotetext{
${ }^{68}$ This calculation uses a proportional sharing construct adapted from Bialek (1996).

${ }^{69}$ The requirement is structured such that plants within British Columbia must generate as much energy as is required to serve load within the province.

${ }^{70}$ For details about the electricity regulations for coal units in Canada, see "Coal-Fired Electricity Generation Regulations: Overview," Government of Canada, modified December 16, 2013, https://ec.gc.ca/cc/default.asp?lang=En\&n=C94FABDA-1.
} 


\section{References}

ABB. 2016. “ABB Velocity Suite.” http://new.abb.com/enterprise-software/energy-portfoliomanagement/market-intelligence-services/velocity-suite.

Akhil, Abbas A., Georgianne Huff, Aileen B. Currier, Benjamin C. Kaun, Dan M. Rastler, Stella Bingqing Chen, Andrew L. Cotter, Dale T. Bradshaw, and William D. Gauntlett. 2013. “DOE/EPRI 2013 Electricity Storage Handbook in Collaboration with NRECA." SAND20135131. Albuquerque, NM: Sandia National Laboratory.

Arora, Vipin. 2014. "Estimates of the Price Elasticities of Natural Gas Supply and Demand in the United States.” MPRA Paper No. 54232. U.S. Energy Information Administration.

http://mpra.ub.uni-muenchen.de/54232/.

Augustine, C. 2011. "Updated US Geothermal Supply Characterization and Representation for Market Penetration Model Input." NREL/TP-6A20-47459. Golden, CO: National Renewable Energy Laboratory.

Bernstein, Mark A., and James M. Griffin. 2006. "Regional Differences in the Price-Elasticity of Demand for Energy.” NREL/SR-620-39512. Golden, CO: National Renewable Energy Laboratory. http://www.nrel.gov/docs/fy06osti/39512.pdf.

Bird, Lori, Caroline Chapman, Jeff Logan, Jenny Sumner, and Walter Short. 2011. "Evaluating Renewable Portfolio Standards and Carbon Cap Scenarios in the U.S. Electric Sector." Energy Policy 39 (5): 2573-85. doi:10.1016/j.enpol.2011.02.025.

Black \& Veatch. 2012. “Cost and Performance Data for Power Generation Technologies.” Overland Park, KS: Black \& Veatch Corporation.

British Columbia Ministry of Finance. 2015. "Carbon Tax: Overview of the Revenue-Neutral Carbon Tax.” http://www.fin.gov.bc.ca/tbs/tp/climate/carbon_tax.htm.

Bureau of Reclamation. 2011. "Hydropower Resource Assessment at Existing Reclamation Facilities." Denver, CO: U.S. Department of the Interior, Bureau of Reclamation, Power Resources Office.

http://www.usbr.gov/power/AssessmentReport/USBRHydroAssessmentFinalReportMarch2011. pdf.

Canadian Electricity Association. 2015. "Canada's Electricity System." http://www.electricity.ca/media/Electricity101/Electricity101.pdf.

CEC. 2009. "Comparative Costs of California Central Station Electricity Generation Technologies, Draft Staff Report.” CEC-200-2009-017-SD. California Energy Commission (CEC). http://www.energy.ca.gov/2009publications/CEC-200-2009-017/CEC-200-2009-017SD.PDF.

Clean Energy Act of 2010. 2010. https://www.leg.bc.ca/pages/bclasslegacy.aspx\#/content/legacy/web/39th2nd/1st_read/gov17-1.htm. 
Clemmer, Steve, John Rogers, Sandra Sattler, Jordan Macknick, and Trieu Mai. 2013.

"Modeling Low-Carbon US Electricity Futures to Explore Impacts on National and Regional Water Use." Environmental Research Letters 8 (1): 15004. doi:10.1088/1748-9326/8/1/015004.

Cole, Wesley, Haley Lewis, Ben Sigrin, and Robert Margolis. 2016. "Interactions of Rooftop PV Deployment with the Capacity Expansion of the Bulk Power System." Applied Energy 168 (April): 473-81. doi:10.1016/j.apenergy.2016.02.004.

Cole, Wesley, Trieu Mai, Kelly Eurek, Daniel C. Steinberg, and Robert Margolis. 2015. "Considering the Role of Solar Generation under Rate-Based Targets in the EPA's Proposed Clean Power Plan.” The Electricity Journal 28 (8): 20-28. doi:10.1016/j.tej.2015.09.002.

Cole, Wesley, Trieu Mai, Jeffrey Logan, Daniel Steinberg, James McCall, James Richards, Benjamin Sigrin, and Gian Porro. 2016. "2016 Standard Scenarios Report: A U.S. Electricity Sector Outlook.” NREL/TP-6A20-66939. Golden, CO: National Renewable Energy Laboratory. http://www.nrel.gov/docs/fy17osti/66939.pdf.

Cole, Wesley, Cara Marcy, Venkat Krishnan, and Robert Margolis. 2016. "Utility-Scale Lithium-Ion Storage Cost Projections for Use in Capacity Expansion Models." In Proceedings of the 2016 North American Power Symposium. Denver, CO, United States.

Cole, Wesley, Kenneth B. Medlock III, and Aditya Jani. 2016. "A View to the Future of Natural Gas and Electricity: An Integrated Modeling Approach.” Energy Economics. Accessed April 1. doi:10.1016/j.eneco.2016.03.005.

Denholm, Paul, Erik Ela, Brendan Kirby, and Michael Milligan. 2010. "The Role of Energy Storage with Renewable Electricity Generation.” NREL/TP-6A2-47187. Golden, CO: National Renewable Energy Laboratory. http://www.nrel.gov/docs/fy10osti/47187.pdf.

Department of Environment, Energy and Forestry. n.d. "Energy Strategy Securing Our Future: Energy Efficiency and Conservation." Charlottetown, Prince Edward Island, Canada:

Department of Environment, Energy and Forestry. http://www.gov.pe.ca/photos/original/env_snergystr.pdf.

DOE. 2008. “20\% Wind Energy by 2030.” DOE/GO-102008-2567. Washington, D.C.: U. S. Department of Energy. http://www.nrel.gov/docs/fy08osti/41869.pdf.

—. 2011. "US Billion-Ton Update: Biomass Supply for a Bioenergy and Bioproducts Industry." ORNL/TM-2011/224. Agricultural and Biosystems Engineering Technical Reports and White Papers. Oak Ridge, TN: Oak Ridge National Laboratory. https://www1.eere.energy.gov/bioenergy/pdfs/billion_ton_update.pdf.

. 2012. "SunShot Vision Study." DOE/GO-102012-3037. Washington, D.C.: U.S. Department of Energy. http://www.nrel.gov/docs/fy12osti/47927.pdfDOE/GO-102012-3037.

2015. "Wind Vision: A New Era for Wind Power in the United States." DOE/GO102015-4557. Washington, D.C.: U.S. Department of Energy. http://www.energy.gov/sites/prod/files/WindVision_Report_final.pdf. 
_. 2016a. "Pending Applications | Department of Energy."

http:/energy.gov/oe/services/electricity-policy-coordination-and-implementation/internationalelectricity-regulation/pending-applications.

- 2016b. "Hydropower Vision: A New Chapter for America's 1st Renewable Electricity Source.” DOE/GO-102016-4869. Washington, D.C.: U. S. Department of Energy.

http://energy.gov/eere/water/articles/hydropower-vision-new-chapter-america-s-1st-renewableelectricity-source.

EEI. 2010a. "2010 Q1 Rate Case Data.” Edison Electric Institute (EEI).

http://www.eei.org/whatwedo/DataAnalysis/IndusFinanAnalysis/Documents/2010_Q1_Rate_Ca se_Data.xls.

- 2010b. “Transmission Project: At a Glance.” Edison Electric Institute with assistance from Navigant Consulting, Inc.

EIA. 1998. "Model Documentation: Renewable Fuels Module of the National Energy Modeling System.” DOE/EIA-M069(98). Washington, D.C.: U.S. Energy Information Administration.

—. 2009. "Annual Electric Power Industry Report (EIA-861 Data File)."

https://www.eia.gov/electricity/data/eia861/.

—. 2010. “Annual Energy Outlook 2010.” DOE/EIA-0383(2010). Washington, D.C.: U.S. DOE Energy Information Administration.

_. 2013a. "Updated Capital Cost Estimates for Utility Scale Electricity Generating Plants." Washington, D.C.: U.S. DOE Energy Information Administration.

http://www.eia.gov/forecasts/capitalcost/pdf/updated_capcost.pdf.

—. 2013b. “Annual Energy Outlook 2013.” Washington, D.C.: U.S. DOE Energy Information Administration.

—. 2014a. “Annual Energy Outlook 2014.” DOE/EIA-0383(2014). Washington, D.C.: U.S. DOE Energy Information Administration.

- 2014b. "The Electricity Market Module of the National Energy Modeling System: Model Documentation 2014." Washington, D.C.: U.S. DOE Energy Information Administration. http://www.eia.gov/forecasts/aeo/nems/documentation/electricity/pdf/m068\%282014\%29.pdf.

—. 2015a. "Electric Power Detailed State Data." http://www.eia.gov/electricity/data/state/.

- 2015b. "Assumptions to the Annual Energy Outlook 2015." Washington, D.C.: U.S.

DOE Energy Information Administration.

http://www.eia.gov/forecasts/aeo/assumptions/pdf/electricity.pdf.

—. 2016. “Annual Energy Outlook 2016.” DOE/EIA-0383(2016). Washington, D.C.: U.S. DOE Energy Information Administration. 
EIPC. 2012. "Phase 2 Report: DOE Draft - Parts 2-7 Interregional Transmission Development and Analysis for Three Stakeholder Selected Scenarios." Eastern Interconnect Planning Collaborative.

http://nebula.wsimg.com/2964d965b867c8786028b950057c7e52?AccessKeyId=E28DFA42F06 A3AC21303\&disposition=0\&alloworigin $=1$.

EnerNex. 2011. "Eastern Wind Integration and Transmission Study.” NREL/SR-5500-47078. Golden, CO: National Renewable Energy Laboratory.

EPA. 2016. "Resources for Implementation | Air Transport | US EPA." https://www3.epa.gov/crossstaterule/stateinfo.html\#states.

FERC. 2009. “A National Assessment of Demand Response Potential.” Washington, D.C.: Federal Energy Regulatory Commission. http://www.ferc.gov/legal/staff-reports/06-09-demandresponse.pdf.

Fischer, Carolyn. 2001. "Rebating Environmental Policy Revenues: Output-Based Allocations and Tradable Performance Standards." 01-22. RFF Discussion Paper. Washington, DC: Resources for the Future. http://www.rff.org/files/sharepoint/WorkImages/Download/RFF-DP01-22.pdf.

Fry, Joyce, George Xian, Suming Jin, Jon Dewitz, Collin Homer, Limin Yang, Christopher Barnes, Nathaniel Herold, and James Wickham. 2011. "Completion of the 2006 National Land Cover Database for the Conterminous United States." Photogrammetric Engineering \& Remote Sensing 77 (9): 858-64.

Fu, Ran, T.L. James, D. Chung, D. Gagne, A. Lopez, and A. Dobos. 2015. "Economic Competitiveness of U.S. Utility-Scale Photovoltaics Systems in 2015: Regional Cost Modeling of Installed Cost (\$/W) and LCOE (\$/kWh)." In Photovoltaic Specialist Conference (PVSC), 2015 IEEE 42nd, 1-11. doi:10.1109/PVSC.2015.7356261.

General Electric. 2010. "Western Wind and Solar Integration Study.” NREL/SR-550-47434. Golden, CO: National Renewable Energy Laboratory. http://www.nrel.gov/docs/fy10osti/47434.pdf.

Habte, A., A. Lopez, M. Sengupta, and S. Wilcox. 2014. "Temporal and Spatial Comparison of Gridded TMY, TDY, and TGY Data Sets." Golden, CO: National Renewable Energy Laboratory. http://www.osti.gov/scitech/biblio/1126297.

Hadjerioua, B., S.-C. Kao, R.A. McManamay, M.F.K. Pasha, D. Yeasmin, A.A. Oubeidillah, N.M. Samu, K.M. Stewart, M.S. Bevelhimer, S.L. Hetrick, Y. Wei, and B.T. Smith. 2013. “An Assessment of Energy Potential from New Stream-Reach Development in the United States: Initial Report on Methodology.” Oak Ridge, TN: Oak Ridge National Laboratory.

Hadjerioua, B., Yaxing Wei, and Shih-Chieh Kao. 2012. "An Assessment of Energy Potential at Non-Powered Dams in the United States." GPO DOE/EE-0711. Oak Ridge, TN: Oak Ridge National Laboratory. 
Harper, John, Matt Karcher, and Mark Bolinger. 2007. "Wind Project Financing Structures: A Review \& Comparative Analysis.” LBNL-63434. Berkeley, CA: Lawrence Berkeley National Laboratory. https://emp.lbl.gov/sites/all/files/report-lbnl-63434.pdf.

Heeter, Jenny. 2015. "Cross-State RPS Visualization." http://www.nrel.gov/analysis/docs/index.html.

Holt, Ed. 2016. "Potential RPS Markets for Renewable Energy Generators." Ed Holt \& Associates, Inc. http://www.cesa.org/assets/2016-Files/Potential-RPS-Markets-Report-Holt.pdf.

HSIP. 2012. "Homeland Security Infrastructure Project."

Huntington, Hillard. 2013. "EMF 26: Changing the Game? Emissions and Market Implications of New Natural Gas Supplies." Stanford, CA: Energy Modeling Forum, Stanford University. https://web.stanford.edu/group/emf-research/docs/emf26/Summary26.pdf.

Jordan, Dirk C., and Sarah R. Kurtz. 2013. "Photovoltaic Degradation Rates-an Analytical Review.” NREL/JA-5200-51664. Golden, CO: National Renewable Energy Laboratory. http://onlinelibrary.wiley.com/doi/10.1002/pip.1182/full.

Kao, Shih Chieh, Ryan A. McManamay, Kevin M. Stewart, Nicole M. Samu, Boualem Hadjerioua, Scott T. DeNeale, Dilruba Yeasmin, M. Fayzul, K. Pasha, Abdoul A. Oubeidillah, and Brennan T. Smith. 2014. "New Stream-Reach Development : A Comprehensive Assessment of Hydropower Energy Potential in the United States." GPO DOE/EE-1063. U.S. Department of Energy Wind \& Water Power Technologies Office, prepared by Oak Ridge National Laboratory. http://nhaap.ornl.gov/sites/default/files/ORNL_NSD_FY14_Final_Report.pdf.

Lantz, Eric, Daniel Steinberg, Michael Mendelsohn, Owen Zinaman, Ted James, Gian Porro, Maureen Hand, Trieu Mai, Jeffrey Logan, Jenny Heeter, and Lori Bird. 2014. "Implications of a PTC Extension on U.S. Wind Deployment." NREL/TP-6A20-61663. Golden, CO: National Renewable Energy Laboratory. http://www.nrel.gov/docs/fy14osti/61663.pdf.

Logan, Jeffrey, Anthony Lopez, Trieu Mai, Carolyn Davidson, Morgan Bazilian, and Douglas Arent. 2013. "Natural Gas Scenarios in the US Power Sector." Energy Economics 40: 183-95.

Lopez, Anthony, Billy Roberts, Donna Heimiller, Nate Blair, and Gian Porro. 2012. "US Renewable Energy Technical Potentials: A GIS-Based Analysis." NREL/TP-6A20-51946. Golden, CO: National Renewable Energy Laboratory. http://cdn.decarboni.se/sites/default/files/publications/138258/US-renewable-energy-technicalpotentials-GIS-based-analysis.pdf.

Macknick, Jordan, Stuart Cohen, Robin Newmark, Andrew Martinez, Patrick Sullivan, and Vince Tidwell. 2015. "Water Constraints in an Electric Sector Capacity Expansion Model." NREL/TP-6A20-64270. Golden, CO: National Renewable Energy Laboratory. http://www.nrel.gov/docs/fy15osti/64270.pdf. 
Macknick, Jordan, Robin Newmark, Garvin Heath, and Kathleen C. Hallett. 2012. “Operational Water Consumption and Withdrawal Factors for Electricity Generating Technologies: A Review of Existing Literature." Environmental Research Letters 7 (4): 45802. doi:10.1088/17489326/7/4/045802.

Mai, Trieu, Wesley Cole, Venkat Krishnana, and Mark Bolinger. 2015. "Impact of Federal Tax Policy on Utility-Scale Solar Deployment Given Financing Interactions." NREL/PR-6A2065014. Golden, CO: National Renewable Energy Laboratory.

Mai, Trieu, David Mulcahy, M. Maureen Hand, and Samuel F. Baldwin. 2014. "Envisioning a Renewable Electricity Future for the United States." Energy 65 (February): 374-86. doi:10.1016/j.energy.2013.11.029.

Mai, Trieu, R. Wiser, D. Sandor, G. Brinkman, G. Heath, P. Denholm, D. J. Hostick, N. Darghouth, A. Schlosser, and K. Strzepek. 2012. "Exploration of High-Penetration Renewable Electricity Futures. Vol. 1 of Renewable Electricity Futures Study.” NREL/TP-6A20-52409-1. Golden, CO: National Renewable Energy Laboratory.

Martinez, Andrew, Kelly Eurek, Trieu Mai, and Andrew Perry. 2013. "Integrated Canada-US Power Sector Modeling with the Regional Energy Deployment System (ReEDS)." NREL/TP6A20-56724. Golden, CO: National Renewable Energy Laboratory.

Mignone, Bryan K., Thomas Alfstad, Aaron Bergman, Kenneth Dubin, Richard Duke, Paul Friley, Andrew Martinez, Matthew Mowers, Karen Palmer, Anthony Paul, Sharon Showalter, Daniel Steinberg, Matt Woerman, and Frances Wood. 2012. "Cost-Effectiveness and Economic Incidence of a Clean Energy Standard.” Economics of Energy \& Environmental Policy 1 (3). doi:10.5547/2160-5890.1.3.5.

Montgomery, Watson, and Harza. 2009. "Hydropower Modernization Initiative, Phase I, Needs and Opportunities Evaluation and Ranking. Report Prepared for the U.S. Army Corps of Engineers Northwest Division Hydroelectric Design Center." Contract No. W9127N-08-D-0003, Task Order 0013.

Murphy, Frederic H., and Yves Smeers. 2005. "Generation Capacity Expansion in Imperfectly Competitive Restructured Electricity Markets.” Operations Research 53 (4): 646-661.

NEB. 2013. "Canada's Energy Futures 2013: Energy Supply and Demand Projections through 2035.” NE2-12/2013E-PDF. National Energy Board. http://www.nebone.gc.ca/nrg/ntgrtd/ftr/2016/2016nrgftr-eng.pdf.

- 2016. "Canada's Energy Futures 2016: Energy Supply and Demand Projections through 2040.” NE2-12/2015E-PDF. National Energy Board. http://www.nebone.gc.ca/nrg/ntgrtd/ftr/2016/2016nrgftr-eng.pdf.

NERC. 2010. “2010 Long-Term Reliability Assessment.” North American Electric Reliability Corporation (NERC). http://www.nerc.com/files/2010\%20LTRA.pdf. 
_. 2016. "Glossary of Terms Used in NERC Reliability Standards." North American Electric Reliability Corporation. http://www.nerc.com/files/glossary_of_terms.pdf.

NETL. 2008. "Recommended Project Finance Structures for the Economic Analysis of FossilBased Energy Projects." DOE/NETL-401/090808. National Energy Technology Laboratory. http://www.netl.doe.gov/energy-analyses/pubs/Project $\% 20$ Finance $\% 20$ Parameters $\% 20$ \%20Final\%20Report\%20-\%20Sept\%202008_1.pdf.

Nova Scotia Department of Energy. 2010. "Renewable Electricity Plan: A Path to Good Jobs, Stable Prices, and a Cleaner Environment." Halifax, Nova Scotia, Canada: Province of Nova Scotia. http://energy.novascotia.ca/sites/default/files/renewable-electricity-plan.pdf.

NREL. 2012. "Renewable Electricity Futures Study.” NREL/TP-6A20-52409. Golden, CO: National Renewable Energy Laboratory.

—. 2016. "2016 Annual Technology Baseline.” Golden, CO: National Renewable Energy Laboratory. http://www.nrel.gov/analysis/data_tech_baseline.html.

O’Connor, Patrick, Qin Fen Zhang, Scott T. Deneale, Dol Raj Chalise, and Emma Centurion. 2015. "Hydropower Baseline Cost Modeling." ORNL/TM-2015/14. Oak Ridge, TN: Oak Ridge National Laboratory.

http://hydropower.ornl.gov/docs/pubs/Hydropower_Baseline_Cost_Modeling.pdf.

Previsic, Mirko, Jeff Epler, Maureen Hand, Donna Heimiller, Walter Short, and Kelly Eurek. 2012. "The Future Potential of Wave Power in the United States." RE Vision Consulting. http://www.re-vision.net/documents/The\%20Future\%20of\%20Wave\%20Power\%20MP\%20920-12\%20V2.pdf.

Short, Walter, Nate Blair, Donna Heimiller, and Vikram Singh. 2003. "Modeling the Long-Term Market Penetration of Wind in the United States." NREL/CP-620-34469. Golden, CO: National Renewable Energy Laboratory. http://www.nrel.gov/docs/fy03osti/34469.pdf.

Short, Walter, Nate Blair, Patrick Sullivan, and Trieu Mai. 2009. "ReEDS Model Documentation: Base Case Data and Model Description.” Golden, CO: National Renewable Energy Laboratory.

Short, Walter, Patrick Sullivan, Trieu Mai, Matthew Mowers, Caroline Uriarte, Nate Blair, Donna Heimiller, and Andrew Martinez. 2011. "Regional Energy Deployment System (ReEDS).” NREL/TP-6A20-46534. Golden, CO: National Renewable Energy Laboratory.

Sigrin, Benjamin, Michael Gleason, Robert Preus, Ian Baring-Gould, and Robert Margolis,. 2016. "The Distributed Generation Market Demand Model (dGen): Documentation." NREL/TP6A20-65231. Golden, CO: National Renewable Energy Laboratory. http://www.nrel.gov/docs/fy16osti/65231.pdf.

Smith, S. 2014. "EPA: Clean Power Plan Could Increase Power Sector Gas Use by 1.2 Tcf in 2020.” SNL Financial, June 2. 
Stott, Brian, Jorge Jardim, and Ongun Alsaç. 2009. "DC Power Flow Revisited." Power Systems, IEEE Transactions on 24 (3): 1290-1300.

Sullivan, Patrick, Wesley Cole, Nate Blair, Eric Lantz, Venkat Krishnan, Trieu Mai, David Mulcahy, and Gian Porro. 2015. "2015 Standard Scenarios Annual Report: U.S. Electric Sector Scenario Exploration.” NREL/TP-6A20-64072. Golden, CO: National Renewable Energy Laboratory.

Tegen, S., M. Hand, B. Maples, E. Lantz, P. Schwabe, and A. Smith. 2012. "2010 Cost of Wind Energy.” NREL/TP-5000-52920. Golden, CO: National Renewable Energy Laboratory. http://www.idmarch.org/document_cache/bf7e00e30c994eed0e244043d5f29acd.pdf.

Tester, Jefferson W., Brian J. Anderson, Anthony S. Batchelor, David D. Blackwell, Ronald DiPippo, Elisabeth M. Drake, John Garnish, Bill Livesay, Michal C. Moore, Kenneth Nichols, Susan Petty, M. Nafi Toksoz, and Ralph W. Veatch,. 2006. "The Future of Geothermal Energy." INL/EXT-06-11746. Idaho Falls, ID: Idaho National Laboratory. https://energy.mit.edu/wpcontent/uploads/2006/11/MITEI-The-Future-of-Geothermal-Energy.pdf.

Tidball, Rick, Joel Bluestein, Nick Rodriguez, and Stu Knoke. 2010. “Cost and Performance Assumptions for Modeling Electricity Generation Technologies.” NREL/SR-6A20-48595. Golden, CO: National Renewable Energy Laboratory. http://www.nrel.gov/docs/fy11 osti/48595.pdf.

Tidwell, Vince C., Katie Zemlick, and Geoff Klise. 2013. "Nationwide Water Availability Data for Energy-Water Modeling.” SAND2013-9968. Albuquerque, NM: Sandia National Laboratories.

Union of Concerned Scientists. 2012. "UCS EW3 Energy-Water Database V.1.3." www.ucsusa.org/ew3database.

Uria-Martinez, Rocio, Patrick W. O’Connor, and Megan M. Johnson. 2015. "2014 Hydropower Market Report.” DOE/EE-1195. Washington, D.C.: U.S. Department of Energy Wind \& Water Power Technologies Office, prepared by Oak Ridge National Laboratory.

http://www.energy.gov/sites/prod/files/2015/04/f22/2014\%20Hydropower\%20Market\%20Repor t_20150424.pdf.

U.S. Environmental Protection Agency. 2015. "Data File: Goal Computation Appendix 1-5." https:/www.epa.gov/cleanpowerplan/clean-power-plan-final-rule-technical-documents.

2016. “Federal Plan Requirements.” Federal Register 80 (205): 64965-116.

Ventosa, Mariano, Álvaro Baíllo, Andrés Ramos, and Michel Rivier. 2005. "Electricity Market Modeling Trends.” Energy Policy 33 (7): 897-913. doi:10.1016/j.enpol.2003.10.013.

Ventyx. 2014. "Ventyx Velocity Suite.” http://www.ventyx.com/en/solutions/businessoperations/business-products/velocity-suite. 
WECC. 2013. “2013 Interconnection-Wide Plan Tools and Models.” Western Electricity Coordinating Council. https://www.wecc.biz/Reliability/2013Plan_ToolsandModels.docx.

—. 2015. “TEPPC Study Report - 2024 PC1 Common Case.” Western Electricity Coordinating Council.

https://www.wecc.biz/Administrative/150805_2024\%20CCV1.5_StudyReport_draft.pdf.

Williams, Colin F., Marshall J. Reed, and Robert H. Mariner. 2008. "A Review of Methods Applied by the US Geological Survey in the Assessment of Identified Geothermal Resources." 1296.

Woldeyesus, Tibebe, Jordan Macknick, and Jesse Colman. forthcoming. "A Review of Cost and Performance Characteristics of Cooling System Options at Thermoelectric Power Plants." NREL Technical Report. Golden, CO.

Zavadil, Robert M, J. King, L. Xiadong, B. Lee, D. Moon, C. Finley, L. Alnes, L. Jones, F. Hudry, M. Monstream, S. Lai, and J. Smith. 2004. "Xcel Energy and the Minnesota Department of Commerce, Wind Integration Study-Final Report." EnerNex Corporation and Wind Logics, Inc. 


\section{Appendix}

\section{Natural Gas Supply Curves}

The ReEDS model by itself does not explicitly model the U.S. natural gas (NG) system, which touches all sectors of the economy and includes complex infrastructure and markets. Rather, a supply curve representation is a used to approximate the NG system. For more information on the impact of natural gas representation in ReEDS, see Cole et al. (2016).

The premise of using regional supply curves is that the price in each region will be a function of both the regional and national NG demand. The supply curves are parameterized from AEO 2014 (EIA 2014a) scenarios for each of the nine EIA census divisions (see Figure 33). We extract the regional and national NG consumption and price for the electricity sector for the 31 AEO 2014 scenarios.

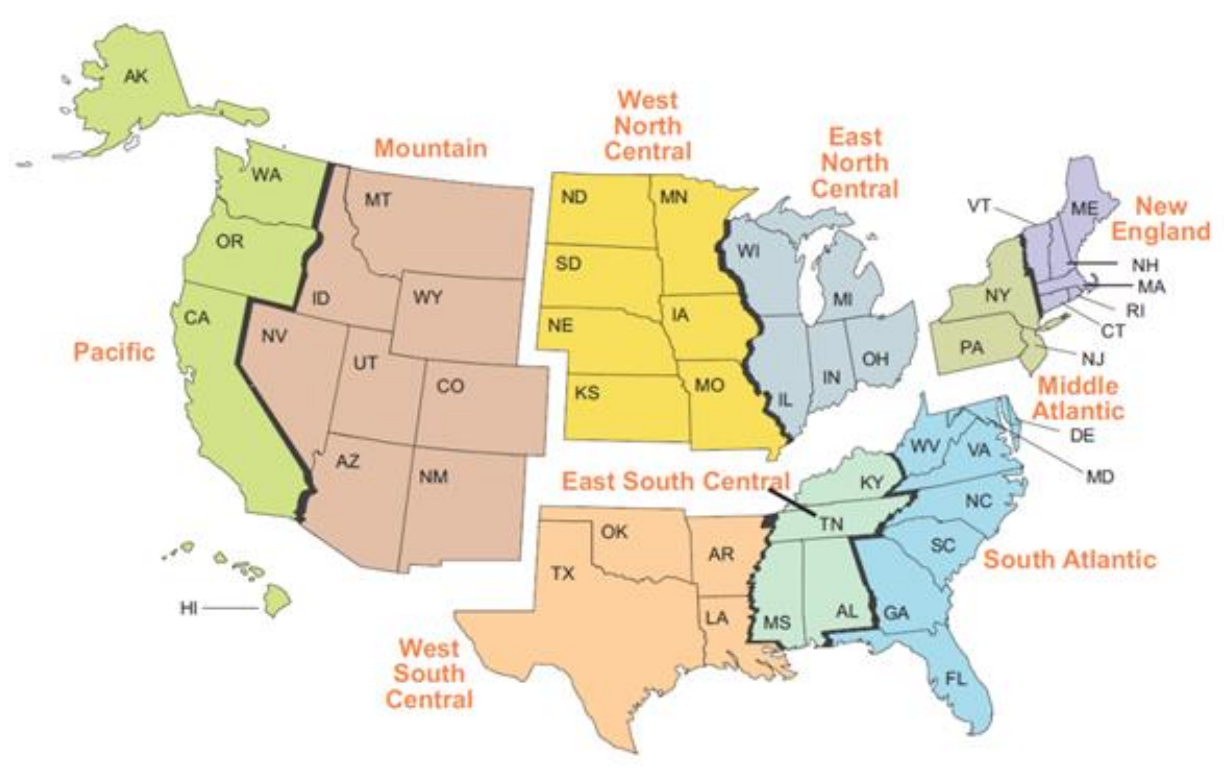

Figure 33. The nine census divisions defined by EIA (EIA 2014a)

A regional supply curve was created in ReEDS for each of these census divisions.

The AEO 2014 scenarios were used to estimate parameters for the following NG priceconsumption model:

$$
P_{i, j}=\alpha+\alpha_{i}+\alpha_{j}+\alpha_{i, j}+\beta_{n a t} Q_{n a t_{j}}+\beta_{i} Q_{i, j}
$$

where $P_{i, j}$ is the price of natural gas (in $\$ / \mathrm{MMBtu}$ ) in region $i$ and year $j$, the $\alpha$ parameters are the intercept terms of the supply curves with adjustments made based on region $\left(\alpha_{i}\right)$, year $\left(\alpha_{j}\right)$, and the region-year interaction $\left(\alpha_{i, j}\right), \beta_{\text {nat }}$ is the coefficient for the national NG demand $\left(Q_{\text {nat }}\right.$, in quads), $\beta_{i}$ is the coefficient for the regional NG demand $\left(Q_{i, j}\right)$ in region $i$. Note that the $\alpha$ parameters in [1] can be represented using only $\alpha_{i, j}$. Nine of the 31 AEO 2014 scenarios were removed as outlier scenarios. These outlier scenarios typically included cases of very low or very high natural gas resource availability, which are useful for estimating NG price as a function of supply but not for estimating NG price as a function of demand - for given supply scenarios. 
The national and regional $\beta$ terms are reported in Figure 34. We made a specific post-hoc adjustment to the regression model's outputs for one region; the $\beta_{i}$ term for the West North Central division was originally an order of magnitude higher than the other $\beta_{i}$ values because the West North Central usage in the electricity sector is so low ( 0.05 quad $^{71}$ in 2013 , compared to $\sim 0.5$ quad or more in most regions). The overall natural gas usage (i.e., not just electricity sector usage) in West North Central is similar to the usage in East North Central, so intuitively it makes sense to have a $\beta_{i}$ for West North Central relatively close to that of East North Central. We therefore manually adjusted the West North Central $\beta_{i}$ term to be 0.6 (in 2004\$/MMBtu/quad), and recalculated the alpha terms with the new beta to achieve the AEO 2014 target prices. The situation in West North Central whereby such a small fraction of NG demand goes to electricity is unique; we do not believe that the other regions warrant similar treatment.

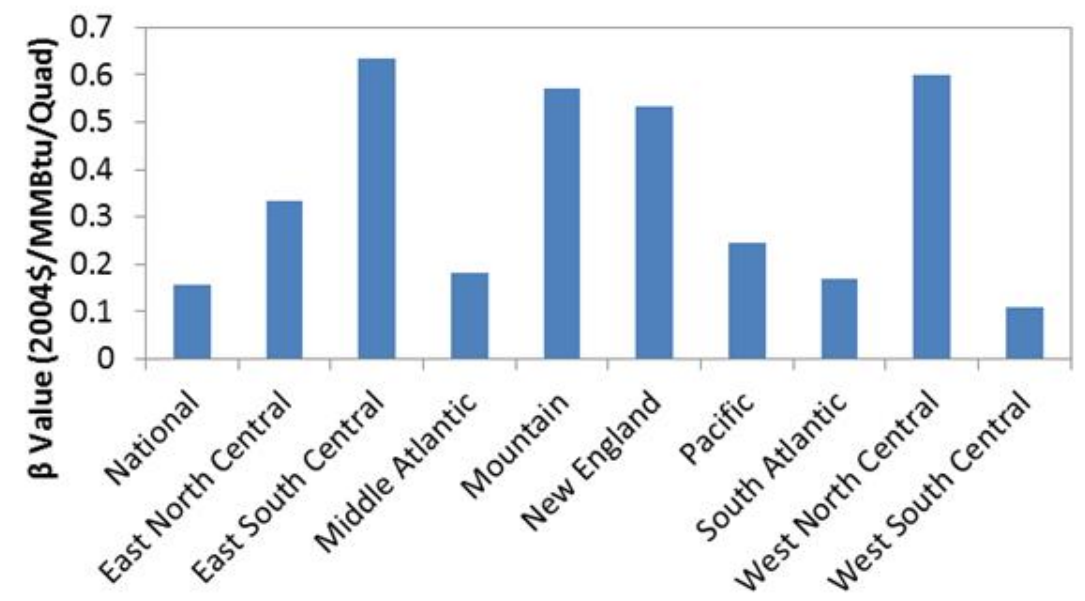

Figure 34. $\beta$ values for the nine census divisions

The "National" value at the far left is $\beta_{\text {nat }}$. A $\beta$ of 0.2 means that if demand increases by one quad, the price will increase by $\$ 0.20 / \mathrm{MMBtu}$ (see Equation [1]).

\section{Comparison to Literature Values}

Technical literature tends to report the price elasticity of supply and the price elasticity of demand, which are estimates of the supply and demand, respectively, of a good given a change in price. In the formulation given by Equation [1], we attempt to estimate a value that is similar to the price elasticity of demand - we estimate a change in price given a change in demand. Therefore we present here a comparison against the price elasticity of demand as the closest available proxy, noting however that it is not necessarily identical to estimates of $\beta$. Price elasticity of demand is typically negative but will be reported here as a positive number for convenience.

External sources are varied and often vague in their estimates of price sensitivity of natural gas. Using the reported domestic NG market demand given for 2012 in AEO 2014, the $\beta$ values reported here yield an overall NG sector elasticity value of $0.36-0.92$ (higher values of $\beta$ correspond to lower elasticity values). Arora (2014) estimated the price elasticity of demand for

\footnotetext{
${ }^{71}$ A quad is a quadrillion Btu, or $10^{15} \mathrm{Btu}$.
} 
NG to be $0.11-0.70$, depending on the granularity and time horizon of the NG price data considered. Bernstein and Griffin (2006) examined the price elasticity of demand for residential NG usage, and they estimated the long-run elasticity to be $0.12-0.63$ depending on the region. The Energy Modeling Forum at Stanford University reports NG price elasticity of demand for 13 different energy models (Huntington 2013). The reported elasticity ranges from 0 to 2.20 depending on the year, model, and scenario considered. For the NEMS, which is used for the Annual Energy Outlooks, the elasticity ranges from 0.22 to 0.81 depending on the year and scenario (Huntington 2013).

The EPA's proposed Clean Power Plan includes a projection that natural gas usage will increase by 1.2 quads in 2020 , resulting in an $8 \%-12 \%$ increase in NG prices for the electric sector (Smith 2014). This corresponds to a $\beta_{\text {nat }}$ of $0.38-0.51$ in $2004 \$ / M M B t u / q u a d$.

\section{Seasonal Natural Gas Price Adjustments}

We use natural gas futures prices to estimate the ratio of winter to non-winter natural gas prices. We chose futures prices for two reasons: (1) ReEDS represents a system with no unforeseen disturbances, which is similar to futures prices and (2) historical natural gas prices have fluctuated greatly since the deregulation of natural gas prices.

Figure 35 shows the cyclical nature of the natural gas futures prices. Figure 36 breaks the same prices out into seasons, showing that the non-winter seasons have nearly the same price while wintertime prices are consistently higher. Wintertime prices are on average 1.054 times higher than non-winter prices. The standard deviation of this price ratio is 0.004 , indicating that the ratio shows very little year-to-year variation.

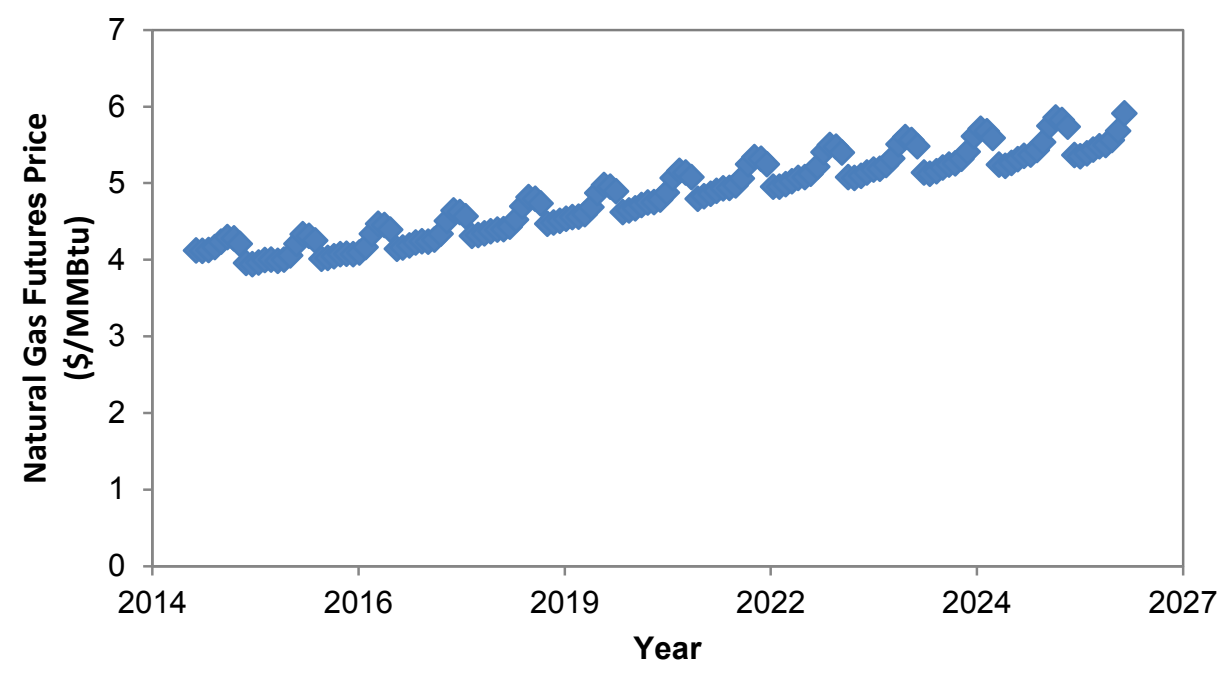

Figure 35. Natural gas futures prices from the New York Mercantile Exchange for July 10, 2014

The prices show the higher wintertime prices and the cyclical nature of the prices. 


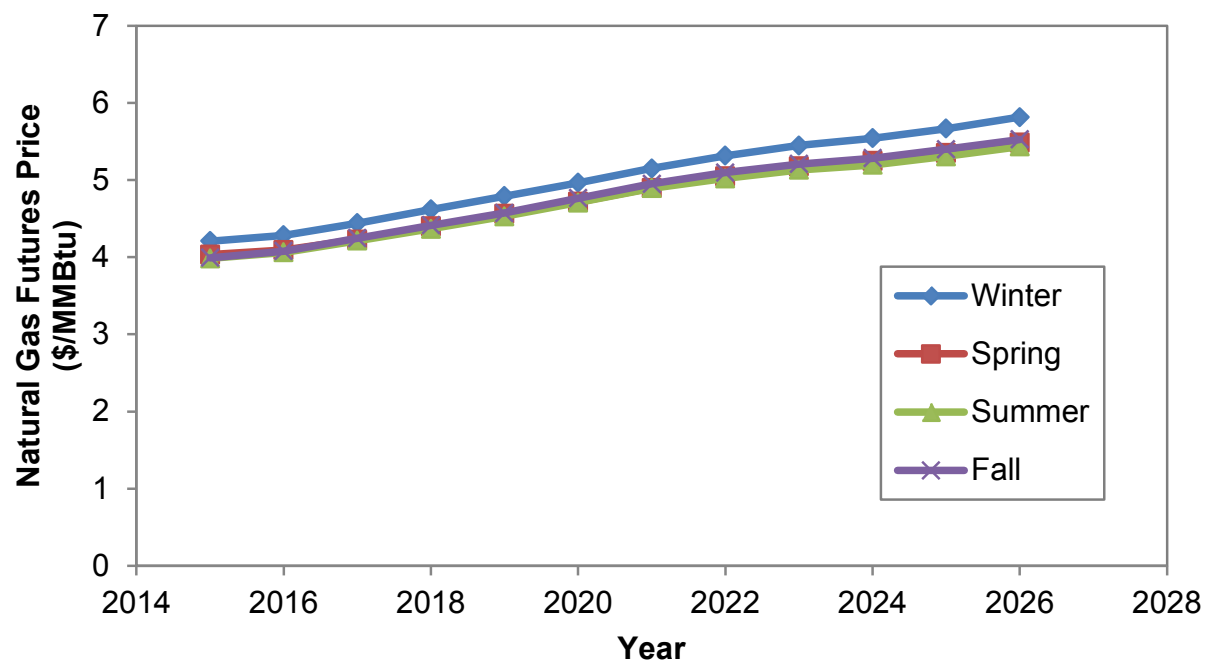

Figure 36. Natural gas futures prices from Figure 35 separated by season

Non-winter prices are nearly the same while wintertime prices are consistently higher.

A seasonal natural gas price multiplier is calculated in ReEDS based on the natural gas price ratio such that wintertime prices are 1.054 times higher than non-winter prices without changing the year-round average price. Mathematically, this can be expressed as

$$
\begin{aligned}
& P_{\text {year-round }}=W_{\text {winter }} P_{\text {winter }}+\left(1-W_{\text {winter }}\right) P_{\text {non-winter }} \\
& P_{\text {winter }}=1.054 P_{n o n-w i n t e r} \\
& P_{\text {winter }}=\alpha P_{\text {year-round }} \\
& P_{n o n-\text { winter }}=\beta P_{\text {year-round }}
\end{aligned}
$$

where $P$ is the natural gas price for the period indicated by the subscript, $W_{\text {winter }}$ is the fraction of natural gas consumption that occurs in the winter months, and $\alpha$ and $\beta$ are the seasonal multipliers for winter and non-winter, respectively. The multipliers $\alpha$ and $\beta$ are determined by solving Equations [2] through [5]. 


\section{Present Value of Direct Electric Sector Cost}

The following equations are used to calculate the present value cost of building and operating the system for some defined economic analysis period. The cost in each future year is discounted to the initial year of the economic analysis period, $t_{o}$, by a social discount rate, $d .{ }^{72}$ In the equations, $P V_{o p}$ represents the present value cost to operate the system for the analysis period, including fixed and variable operating and maintenance costs, and fuel costs. ${ }^{73}$ The second term, $P V_{c 1}$, represents the cost of new capital investments made a least 20 years prior to the end of the analysis period, $t_{f}$. The third term, $P V_{c 2}$, represents the cost of new capital investments from the last 18 years of the analysis period. For investments that will clearly last beyond the end of the model horizon, the cost is reduced by the weighting factor.

"New capacity" in $P V_{c 1}$ and $P V_{c 2}$ includes the capital cost ${ }^{74}$ for new generation and storage capacity installed in each year. Grid interconnection costs for new generators are also included. New generation capacity includes "rebuilding" costs of renewable generation after the physical lifetime of the plants. ReEDS does not consider the replacement of existing or new transmission infrastructure.

\section{Parameters}

- $t_{o}$ - initial year of economic analysis

- $t_{f}$ - final year of economic analysis

- $d$ - social discount rate $=0.03$

- $n$ - economic lifetime $=20$ years

- $C R F$ - capital recovery factor

- $C_{o p, t}$-operational costs in year $\boldsymbol{t}$

- $C_{c a p, t}$ - capital costs in year $\boldsymbol{t}$

- $P V_{o p}$ - present value of operational costs

- $P V_{c 1}-$ present value of capital investments made at least 20 years prior to $\boldsymbol{t}_{\boldsymbol{f}}$

- $P V_{c 2}$ - present value of capital investments made within 18 years of $\boldsymbol{t}_{\boldsymbol{f}}$

\section{Sets}

- $T$ - set of optimization years: $\{2010,2012, \ldots, 2050\}$

- $T_{o p} \subseteq T:\left\{t \mid t \geq t_{o} \cap t \leq t_{f}\right\}$ - set of years $\boldsymbol{t}$ between $\boldsymbol{t}_{\boldsymbol{o}}$ and $\boldsymbol{t}_{\boldsymbol{f}}$

- $T_{c 1} \subseteq T:\left\{t \mid t \geq t_{o} \cap t \leq t_{f}-20\right\}$ - set of years $\boldsymbol{t}$ that are at least 20 years prior to $\boldsymbol{t}_{\boldsymbol{f}}$

- $T_{c 2} \subseteq T:\left\{t \mid t \leq t_{f}-18 \cap t \leq t_{f}\right\}$ - set of years $t$ that are within 18 of $\boldsymbol{t}_{\boldsymbol{f}}$

\footnotetext{
${ }^{72}$ The real discount rate used here represents the social discount rate and is not the same as the discount rate used in the investment decisions within the optimization.

${ }_{74}$ Operation costs assume the marginal price of fuel.

74 The capital costs are not overnight capital costs; the costs account for capital financing (e.g., construction financing, interest on debt, and return to equity), but they do not include investment tax credits.
} 
We discount operational costs from model year $t$ by $\frac{1}{(1+d)^{t-t_{o}}}$ for the all model years in $T_{o p}$ and we multiply by two in order to accounts for the operational costs of non-modeled years:

$$
P V_{o p}=2 \cdot \sum_{t \in T_{o p}}^{t_{f}} C_{o p, t} \cdot \frac{1}{(1+d)^{t-t_{o}}}
$$

We discount investments made at least 20 years prior to the $t_{f}$ by $\frac{1}{(1+d)^{t-t_{o}}}$ :

$$
P V_{c 1}=\sum_{t \in T_{c 1}} C_{c a p, t} \cdot \frac{1}{(1+d)^{t-t_{o}}}
$$

We scale investments made within 18 years of $t_{f}$ to only account for years that the investment is utilized. We then discount these scaled investments by $\frac{1}{(1+d)^{t-t_{o}}}$ :

$$
P V_{c 2}=\sum_{t \in T_{c 2}} C_{c a p, t} \cdot \text { scaling factor } \cdot \frac{1}{(1+d)^{t-t_{o}}}
$$

We define the scaling factor as the ratio of the capital recovery factor for the full economic lifetime $n$ to the capital recovery factor for the number of years that the investment is used (i.e., $\left.t_{f}+1-t\right)$. Note that we add 1 to $t_{f}$ to correctly calculate the number of years that the capacity is used. For example, assuming a 20-year economic lifetime and an analysis period out to 2050, investments made in 2031 will be paid off by 2050, which is represented by the 2050 solve year. So, $t_{f}+1-t=2050+1-2031=20$, gives the correct number of years the investments made in 2031 are utilized in the analysis horizon:

$$
\begin{aligned}
\text { scaling factor } & =\frac{\operatorname{CRF}(d, n)}{\operatorname{CRF}\left(d, t_{f}+1-t\right)} \\
\operatorname{CRF}(d, n) & =\frac{d}{1-\frac{1}{(1+d)^{n}}}
\end{aligned}
$$

\section{Cost-of-Service Electricity Prices}

The retail cost-of-service price for a net exporter region-where generation exceeds load - is the average cost of local generation, which is adjusted for non-generation transaction costs, a markup from wholesale to retail: ${ }^{75}$

$$
P_{e x, n}=\bar{c}_{g e n, n}+n g t c_{n} \quad \forall n \in N
$$

\footnotetext{
75 The non-generation transaction cost defined as the difference between the 2010 historical retail price and the estimated wholesale cost-of-service price in the 2010 model year.
} 
Alternatively, the retail cost-of-service price for a net importer region-where load exceeds generation - is a weighted average of costs from local and imported generation, which is adjusted for non-generation transaction costs:

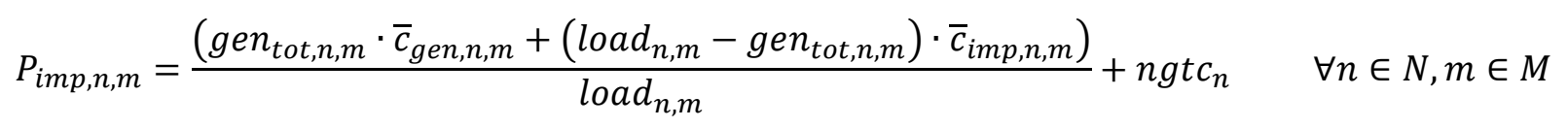

The average cost of local generation is the total cost of local generation averaged over the total electricity generated. Total costs includes the rate base cost (additional cost to consumers to cover a utility's regulated rate of return), fixed and variable OM (including PTC), fuel (including $\mathrm{CO}_{2}$ tax), RPS shortfall compliance cost, water cost, Clean Power Plan compliance costs (allowances, ERCs), Canadian imports, and rooftop PV cost:

$$
\begin{aligned}
\bar{c}_{g e n, n, m}=\frac{\left(c_{r b, n}+c_{o m, n}+c_{f u e l, n}+c_{r p s, n}+c_{\text {water }, n}+c_{c p p, n}\right)}{g e n_{t o t, n, a n n}} & \\
+\frac{\left(n t x_{c a n, n, m} \cdot c_{t x, c a n, n}+g e n_{d p v, n, m} \cdot c_{d p v, n}\right)}{g e n_{n, m}} & \forall n \in N, m \in M
\end{aligned}
$$

The costs associated with the rate base include the annual payments owed and the "interest" on the remaining rate base, which is based on the discount rate, $d$, corresponding to the investment discount rate:

$$
c_{r b, n, t}=r b_{\text {owed }, n, t}+r b_{\text {remain }, n, t} \cdot d \quad \forall n \in N, t \in T
$$

The annual rate base payment owed includes the payment from initial rate base and payments from new investments since the initial year. We assume the investments for the initial rate base are spread equally from 2080 to 2009 . Therefore, by 2010, the investment in 2080 is fully depreciated by 2010; by 2030, the entire initial rate base is depreciated. The initial rate base is scale by $\left(1-\frac{t-t_{o}}{30}\right)$ to account for implicit payments made prior to 2010 :

$$
\begin{gathered}
r b_{\text {owed }, n, t}=\frac{1}{30} \cdot r b_{\text {init }, t_{o}} \cdot\left(1-\frac{t-t_{o}}{30}\right)+\frac{1}{30} \cdot \sum_{t^{\prime}=\max \left(t_{o}, t-29\right)}^{t} \text { invest }_{t^{\prime}} \quad \forall t \leq t_{o}+30 \\
r b_{\text {owed }, n, t}=\frac{1}{30} * \sum_{t^{\prime}=\max \left(t_{o}, t-29\right)}^{t} \text { invest }_{t^{\prime}} \quad \forall t>t_{o}+30
\end{gathered}
$$

The remaining rate base is calculated from the remaining rate base in the prior year, adding in new investments, and deducting payment owed from initial rate base:

$$
r b_{\text {remain }, n, t}=r b_{\text {remain }, n, t-1}+\text { invest }_{t}-r b_{\text {owed }, n, t} \quad \forall n \in N, t \in T
$$


The average cost of imports to region is the blending of the cost of Canadian power imports and the wheeling cost of all other imported generation, including the levelized cost of new transmission. ${ }^{76}$ These costs are weighted by net transmission flows:

$$
\bar{c}_{i m p, n, m}=\frac{n t x_{c a n, n, m} \cdot c_{t x, c a n, j}+\sum_{n^{\prime}} n t x_{n^{\prime}, n, m} \cdot\left(\bar{c}_{\text {wheel }, n, m}+c_{t x, n^{\prime}, n}\right)}{n t x_{c a n, n, m}+n t x_{n^{\prime}, n, m}}+n g t c_{n} \quad \forall n \in N, m \in M
$$

The weighted average wheeling cost of imported generation is the blending of local generation costs from all regions where the imports originate. The local generation costs are weighted by the fraction of the total imports that was generated at the upstream origin (i.e., upstream power fraction:

$$
\bar{c}_{w h e e l, n, m}=\sum_{n^{\prime}} \bar{c}_{g e n, n^{\prime}, m} \cdot u_{p} f_{n, n^{\prime}, m} \quad \forall n \in N, m \in M
$$

\section{Marginal Electricity Prices}

In standard form, the primal formulation of a linear program is:

$$
\begin{array}{rr}
\text { (P) } \quad & \min c^{T} x \\
\text { s.t. } & A x=b \\
& x \geq 0
\end{array}
$$

The associated dual formulation of the primal is:

$$
\begin{gathered}
\text { (D) } \quad \max y^{T} b \\
\text { s.t. } \quad y^{T} A \leq c^{T}
\end{gathered}
$$

Consider a simplified formulation of the ReEDS model with a subset of constraints: (1) resource limits, (2) capacity limits, (3) supply/demand balance, (4) planning reserve margin requirement, and (5) operating reserve requirement. The primal formulation is:

\section{Parameters}

- capcost $_{i}$ - capital cost of model plant $i(\$ / \mathrm{MW})$

- vomcost $_{i}$ - variable OM cost of model plant $i(\$ / M W h)$

- $\quad s_{i}$ - available supply of model plant $i$ (MW)

- load - electric load (MW)

- $\quad c v_{i}$ - capacity value of model plant $i$ (MW)

- $f^{\text {prm }}$ - planning reserve margin (unitless)

- $f^{o r}$ - operating reserve requirement (unitless)

\section{Variables}

- $\quad C_{i}$ - capacity of model plant $i(\mathrm{MW})$

- $G_{i}$ - generation of model plant $i(\mathrm{MWh})$

\footnotetext{
${ }^{76}$ The levelized cost of new transmission connect two regions is the annualized cost of transmission (line + substation) connecting the regions averaged over the net energy flow across the line.
} 
- $O R_{i}$ - operating reserve allocation of plant $i(\mathrm{MWh})$

minimize $\sum_{i} \operatorname{capcost}_{i} \cdot C_{i}+$ vomcost $_{i} \cdot G_{i}$

Subject to:

$$
\begin{gathered}
\frac{G_{i}}{8760}+\frac{O R_{i}}{8760}-C_{i} \leq 0 \quad \forall i \quad \forall i \\
\sum_{i} G_{i}=\text { load } \\
\sum_{i} c v_{i} \cdot C_{i} \geq \frac{\left(1+f^{\text {prm }}\right)}{8760} \cdot \text { load } \\
\sum_{i} O R_{i} \geq f^{\text {or }} \cdot \text { load } \\
C_{i}, G_{i}, O R_{i} \geq 0 \quad \forall i
\end{gathered}
$$

Constraints [1] define the resource limits for each model plant. Constraints [2] limit how capacity is allocated for each model plant (i.e., for energy or reserves). Constraint [3] requires the total generation supplied to equal the load. Constraint [4] ensures the total firm capacity meets the planning reserve margin requirement. Constraint [5] ensures the total operating reserves meet the operating reserve requirement.

From the dual formulation of the primal, the objective function is:

$$
y^{T} b=y_{1} \cdot s+y_{2} \cdot 0+y_{3} \cdot \text { load }+y_{4} \cdot \frac{(1+\text { prm })}{8760} \cdot d+y_{5} \cdot f^{\text {or }} \cdot \text { load }
$$

Reformulating the primal with Constraints [3], [4], and [5] "linked" with a "load" variable, $L$, an alternative, but equivalent, primal formulation is the following:

$$
\begin{aligned}
& \text { minimize } \sum_{i} \operatorname{capcost}_{i} \cdot C_{i}+\text { vomcost }_{i} \cdot G_{i} \\
& \begin{array}{r}
G_{i} \\
8760+\frac{O R_{i} \leq s_{i}}{8760}-C_{i} \leq 0 \quad \forall i \\
\sum_{i} G_{i}-L \geq 0
\end{array} \\
& \sum_{i} c v_{i} \cdot C_{i}-\frac{\left(1+f^{p r m}\right)}{8760} \cdot L \geq 0 \\
& \sum_{i} O R_{i}-f^{o r} \cdot L \geq 0 \\
& C_{i}, G_{i}, O R_{i} \geq 0 \\
& L=\text { load }
\end{aligned}
$$


From the dual formulation of the alternative primal, the objective function is:

$$
y^{T} b=y_{1} \cdot s+y_{2} \cdot 0+y_{3^{\prime}} \cdot 0+y_{4^{\prime}} \cdot 0+y_{5^{\prime}} \cdot 0+y_{7^{\prime}} \cdot \text { load }
$$

Equating the dual objective functions from the two equivalent primal formulations, we find that the marginal off the linking constraint [7'] is a blending of all constraints containing the "load" variable, including, constraints [3], [4], and [5]:

$$
\begin{gathered}
y_{7^{\prime}} \cdot \text { load }=y_{3} \cdot \text { load }+y_{4} \cdot \frac{\left(1+f^{\text {prm }}\right)}{8760} \cdot \text { load }+y_{5} \cdot f^{\text {or }} \cdot \text { load } \\
y_{7^{\prime}}=y_{3}+y_{4} \cdot \frac{\left(1+f^{\text {prm }}\right)}{8760}+y_{5} \cdot f^{\text {or }}
\end{gathered}
$$

Therefore, we define the marginal off the linking constraint $\left[\mathrm{y}_{7^{\prime}}\right]$ as the "all-in" marginal price of electricity (i.e., change in total cost [objective function] given a small change in load). This marginal electricity price includes the energy price, capacity price and ancillary service price. 